\title{
Huellas de dinosaurios en la costa oeste del embalse Ezequiel Ramos Mexía y alrededores (Cretácico Superior, Provincia de Neuquén, República Argentina)
}

\author{
Jorge Orlando Calvo, Cynthia Rivera
}

\begin{abstract}
Jorge Orlando Calvo
jocalvomac@gmail.com

Grupo de Transferencia Proyecto Dino, Ruta 51, km 65, Universidad Nacional del Comahue, Facultad de Ingeniería, Departamento de Geología, Bs. As. 1400, (8300). Neuquén, Argentina.

Universidad Nacional de la Pampa, Facultad de Ciencias Exactas y Naturales, Santa Rosa, Av. Uruguay 151 (6300). La Pampa, Argentina.
\end{abstract}

\section{Cynthia Rivera}

Grupo de Transferencia Proyecto Dino, Ruta 51, km 65, Universidad Nacional del Comahue, Facultad de Ingeniería, Bs. As. 1400, (8300). Neuquén, Argentina.
BOL. SOC. GEOL. MEX. 2018

VOL. 70 NO. 2

P. $449-497$

http://dx.doi.org/10.18268/BSGM2018v70n2a1 1

\section{RESUMEN}

Una de las áreas más importantes de huellas de dinosaurios de Argentina se encuentra en la costa oeste del embalse Ezequiel Ramos Mexía, en la provincia de Neuquén. Con más de $100 \mathrm{~km}$ de línea de costa, centenares de huellas han sido reconocidas en casi 30 años. Las huellas se encuentran en la Formación Candeleros, Grupo Neuquén, con una antigüedad Albiano?-Cenomaniano Inferior. Un estudio de detalle y revisión de las huellas descritas hace casi 30 años, es reevaluado y mejorado. Se describe un nuevo icnogénero: Candeleroichnus canalei icnogen. nov. icnosp. nov. Se seleccionó un neotipo para Deferrariïschnium mapuchensis Calvo, 1991 y se enmienda su diagnosis. Se amplía la diagnosis de Picunichnus benedettoi Calvo, 1991 con el hallazgo de pistas que permiten establecer distancia y ángulo de paso. Se analizan todos los sitios descubiertos en la costa oeste del embalse y se identifican todas las icnoformas reconocidas, incluidas Sousaichnium monettae, Limayichnus major, Abelichnus astigarrae y Sauropodichnus giganteus en los distintos yacimientos. Se incluyen nuevas figuras, fotos y tablas sobre los icnotipos.

Palabras clave: Huellas, Dinosauria, Theropoda, Sauropoda, Patagonia, Gretácico.

\section{ABSTRACT}

In Argentina, some of the most important dinosaur tracksites are found on the west coast of the Ezequiel Ramos Mexía reservoir, in the Neuquén province. In the last 30 years, more than $100 \mathrm{~km}$ of coastline have yielded hundreds of dinosaur tracks. The tracks are part of the Albian?-lower Cenomanian Candeleros Formation, Neuquén Group. An extensive study and review of the dinosaur tracks described in the past 30 years is reinterpreted and revised. Candeleroichnus canalei ichnogen. nov. ichnosp. nov. is described. A neotype is chosen for Deferrariischnium mapuchensis Calvo, 1991 and an emended diagnosis improves the ichnospecies. In addition, new information of the trackway diagnosis of Picunichnus benedettoi Calvo, 1991, such as length of pace and pace angle is given. We analyze all the dinosaur sites discovered until now and we identify all described ichnoforms such as Sousaichnium monettae, Limavichnus major, Abelichnus astigarrae and Sauropodichnus giganteus. We include unpublished figures, photos and tables of the ichnotypes.

Keywords: Tracks, Dinosauria, Theropoda, Sauropoda, Patagonia, Cretaceous. 


\section{Introducción}

El embalse Ezequiel Ramos Mexía, Provincia de Neuquén, Patagonia, Argentina, ha dado en los últimos 30 años una riquísima fauna de vertebrados mesozoicos continentales (Figura 1). Si bien se conoce la existencia de huellas desde 1979 en los alrededores, el primer informe inédito fue realizado a finales de la década del 70 (Gasparini y Musacchio, 1979). Los primeros datos publicados sobre huellas de dinosaurios en la región son mencionados por Leonardi (1981) sin realizar ningún tipo de diagnosis ni descripciones detalladas. Los primeros estudios de icnitas se restringieron al área suroccidental del embalse, en la Península Nueva e Isla Cerrito del Bote en la localidad de Picún Leufú (Calvo, 1989, 1991). Posteriormente, se descubrieron nuevas huellas en distintos sectores de la costa oeste del embalse cuyos sitios fueron dados a conocer como Cañadón Carrizo, Cañadón de las Campanas, Punta de Pescadores, Cañadón de Coria y Balneario Villa El Chocón en la Provincia de Neuquén (Calvo et al., 1989) y en la costa este del embalse, en la Provincia de Río Negro en el sitio denominado El Gigante (Calvo et al., 2000). A pesar de estos hallazgos, no se realizó ningún estudio sistemático de las huellas descubiertas, excepto el de Península Nueva (Calvo, 1991, 1999). En años recientes, nuevos trabajos de icnitas de dinosaurios en la costa occidental del embalse, con redescripciones de las icnoespecies, se llevaron a cabo por diversos investigadores (Leonardi, 1994; Calvo y Coria, 1995; Calvo y Salgado, 1995; Calvo, 1999, 2007; Mazzetta y Blanco, 2001; Calvo y Vejsbergj, 2003; Calvo y Mazzetta, 2004; Krapovickas, 2010; Rivera y Calvo, 2016). En este trabajo presentamos una actualización de todos los sitios y trabajos publicados sobre huellas de dinosaurios en la costa oeste del embalse Ezequiel Ramos Mexía, se asignaron las huellas a las icnoespecies ya conocidas y se aportó nueva información sobre las mismas. Se presentan fotos y tablas con medidas nunca antes publicadas de los icnotipos y otros sitios para mayor referencia. Se mencionan las icnoespecies
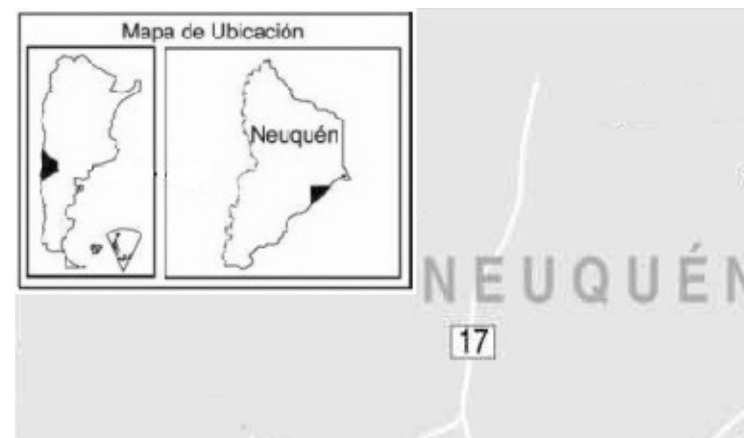

- $69^{\circ} 15^{\prime}$

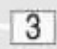

D

20

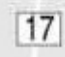

3

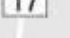

illa El Chocón

F
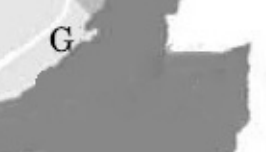
válidas y se define una nueva icnoforma para el Cerro Mesa y la Isla Cerrito del Bote. Se establece un nuevo neotipo con diagnosis mejorada para Deferrariischnium mapuchensis.

\section{Geología y edad}

La Cuenca Neuquina es una enorme depresión con depósitos marinos y continentales superpuestos de más de $7000 \mathrm{~m}$ de potencia y depositados durante el Jurásico y Cretácico (Zavala, 2005). En los términos superiores de la misma se desarrolla el Grupo Neuquén, una secuencia de rocas sedimentarias clásticas de origen continental (Cazau y Uliana, 1973; Ramos, 1981; Uliana y Dellapé, 1981). El Grupo Neuquén incluye tres subgrupos: de abajo hacia arriba, Río Limay, Río Neuquén y Río Colorado (Figura 2). En la base del Subgrupo Río Limay se encuentra la Formación Candeleros, que es la portadora de las huellas de dinosaurios del presente estudio. La antiguedad de la Formación Candeleros es Albiano-Cenomaniano tal como fue propuesta por Calvo (1989; 1991) basada en huellas de dinosaurios. Fue confirmada utilizando, en la base del Grupo Neuquén, datos de antigüedad $\mathrm{U} / \mathrm{Pb}$ de los detritus de zircón (100 Ma; Fennell et al., 2017). También con base en las discontinuidades estratigráficas (Asurmendi et al., 2017). La Formación Candeleros es muy extensa en la Cuenca Neuquina, por lo que ha sido objeto tanto de estudios generales como de detalle; es por ello que ha dado lugar a interpretaciones variadas de su geología y ambiente de depositación (Roll, 1939; Herrero-Ducloux, 1946; Di Paola y Marchese, 1970; Marchese, 1971; Digregorio, 1972; Cazau y Uliana, 1973; Di Paola, 1973; Ramos, 1981; Uliana y Dellapé, 1981; Spalletti y Gazzera, 1989; Gazzera y Spalletti, 1990; Leanza y Hugo, 1995, 1997, 2001; Ardolino et al., 1996; Leanza, 1999; Hugo y Leanza, 2001; Leanza et al., 2001; Sánchez et al., 2004; Garrido, 2010).

La Formación Candeleros es una potente secuencia sedimentaria que se asienta discordantemente sobre la Formación Lohan Cura o Rayoso (Leanza,
2003). Tiene un espesor que puede alcanzar entre 200 (Garrido, 2010) y 300 m (Cazau y Uliana, 1973). A pesar de su extensión areal y espesor, se trata de una secuencia clástica de color violeta, púrpura, rojo oscuro y marrón depositadas en un ambiente fluvial bajo un régimen meandroso y anastomosado, así como también eólico (Spalletti y Gazzera, 1989). Paleosuelos son frecuentes en algunos horizontes, mientras que arcilitas y limolitas de colores marrones y pardas están presentes en capas delgadas, algunas representando condiciones pantanosas (Cazau y Uliana, 1973; Leanza y Hugo, 1997). Las areniscas van de tamaños gruesos a finos y son de composición cuarzolítica con granos subangulosos a subredondeados, y moderada a buena selección y pelitas rojizas (Garrido, 2010).

Si bien el ambiente de depositación es variado dependiendo del sector de la cuenca donde se le estudie, en la zona próxima a la costa del embalse

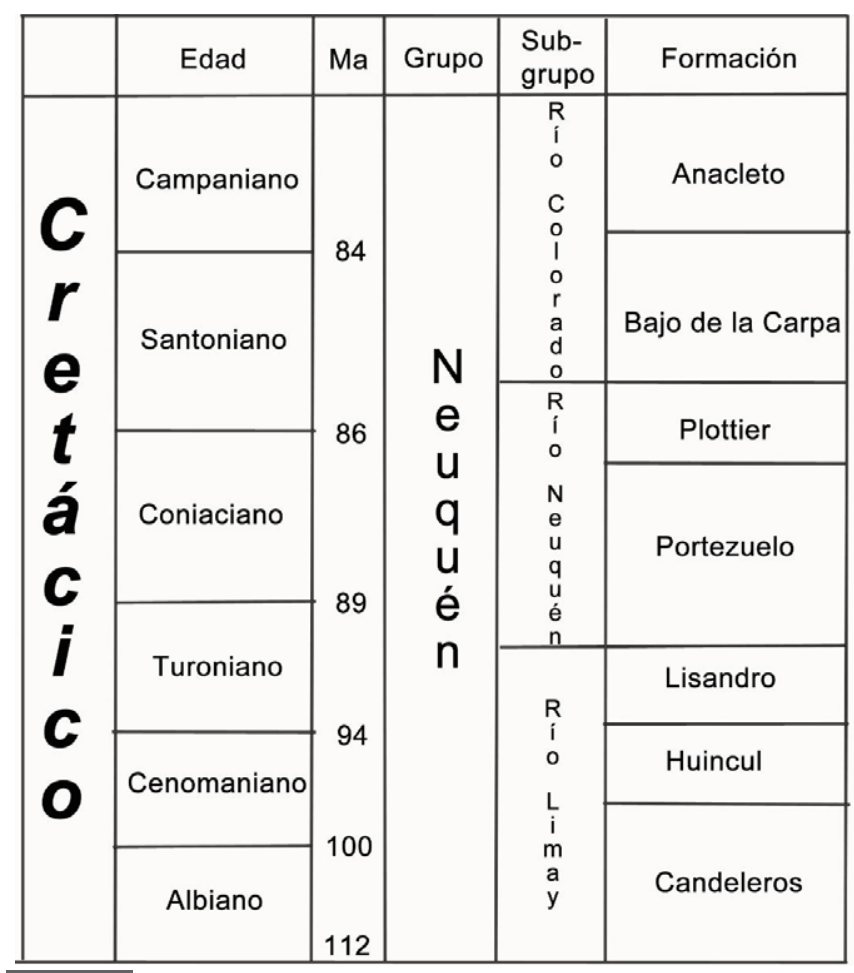

Figura 2 Cuadro de unidades litoestratigráficas del Grupo Neuquén con la ubicación de la Formación Candeleros, portadora de las icnitas de dinosaurios (modificado de Garrido, 2010; Fenell et al., 2017; Asurmendi et al., 2017). 
Ezequiel Ramos Mexía, los estudios sedimentológicos nos indican que se trata de una llanura aluvial asociada a depósitos de barreales y cauces efímeros de poco desarrollo (Calvo y Gazzera, 1989). Este esquema se habría modificado hacia los términos superiores de la secuencia donde el ambiente de depositación correspondería a dunas eólicas y de playa-lake (Spalletti y Gazzera, 1989) o depósitos de abanicos terminales (Sánchez et al., 2004). Estos modelos habrían coexistido espacial y temporalmente; donde los sistemas de canales efímeros de abanicos terminales aportarían periódicamente sedimentos fango-arenosos hacia los sectores deprimidos o bajos. Lo anterior genera barreales ligeramente salinos y sobre los que se habrían desarrollado, de forma asociada, pequeños campos de dunas eólicas (Garrido, 2010). En general, es probable que los depósitos de fangos asociados a cauces meandrosos se desarrollaran bajo un clima cálido a templado húmedo con alternancia de períodos secos y lluviosos (Calvo y Gazzera, 1989) cambiando hacia climas más áridos a semiáridos, pero con marcado régimen de estacionalidad reconocido por la presencia de grandes depósitos eólicos, junto al desarrollo de barreales salinos y paleosuelos ricos en carbonato (caliche) (Garrido, 2010).

Abreviaturas: MUCPv- Museo de Geología y Paleontología, Universidad Nacional del Comahue.

\section{Sitios icnológicos en la costa oeste del embalse Ezequiel Ramos Mexía}

La costa oeste del embalse Ezequiel Ramos Mexía se caracteriza por ser muy irregular con cañadones secos que desembocan en él. En toda su extensión aflora la Formación Candeleros por lo que la probabilidad de hallar huellas de dinosaurios es muy alta. Hasta ahora se han reconocido ocho sitios que se describen a continuación. El principal yacimiento icnológico se encuentra en el extremo sur del embalse, en la Península Nueva. En el extremo norte de esta península se encuentra el yacimiento denominado Punta de Pescadores, lugar donde se describieron las primeras icnitas. En el sector sur de la península, también llamado Balneario Picún Leufú, se han registrado más hallazgos hasta ahora sin describir. Finalmente, el tercer sitio de hallazgos se ubica en la isla frente a la Península Nueva llamada Isla Cerrito del Bote.

Desde el sur hacia el norte, los hallazgos han sido esporádicos habiéndose detectado icnitas en los Cañadones El Carrizo, de las Campanas, de Coria y finalmente el extremo norte del embalse en lo que se llama el Balneario Villa El Chocón. Es en este último donde se han descubierto decenas de icnitas de distintos grupos de dinosaurios. De esta manera, a continuación se describirán los yacimientos icnológicos presentes en la costa oeste del embalse Ezequiel Ramos Mexia.
a) Punta de Pescadores
b) Balneario Picún Leufú
c) Isla Cerrito del Bote
d) Cerro Mesa
e) Cañadón El Carrizo
f) Cañadón de las Campanas
g) Cañadón de Coria
h) Balneario Villa El Chocón

\section{Icnología sistemática}

Si bien el registro de huellas de dinosaurios es abundante en la costa oeste del embalse Ezequiel Ramos Mexía; poco se ha trabajado ya que se le ha dado más importancia a la abundancia de restos de vertebrados fósiles. El presente estudio actualiza el registro icnológico del área nominando algunas huellas, mientras que otras se han reasignado a icnotaxones conocidos. Los estudios realizados por Calvo (1991) son la base de las clasificaciones sistemáticas de las icnitas que se registran en la base de la Formación Candeleros. Con el objeto de ordenar los hallazgos y los sitios paleontológicos, se describirán las especies conocidas y 
posteriormente se analizarán los principales sitios con huellas indicando, si es necesario, los nuevos registros paleontológicos.

Saurischia Seeley, 1888

Theropoda Marsh, 1881

Abelichnus Calvo, 1991

Abelichnus astigarrae Calvo, 1991

Figura 3; Tabla 1)

Diagnosis. Huellas de un gigantesco terópodo con impresiones digitales largas y anchas. El dígito III más desarrollado que los dígitos II y IV. Sus impresiones digitales son muy prominentes. La garra del dígito III está desplazada hacia el interior. El dígito IV es más largo que el dígito II y sus garras están desplazadas hacia el exterior. El talón es subredondeado y pequeño. El ángulo de paso promedio es de $150^{\circ}$ (Calvo, 1991).

Horizonte y localidad. Nivel inferior de la Formación Candeleros

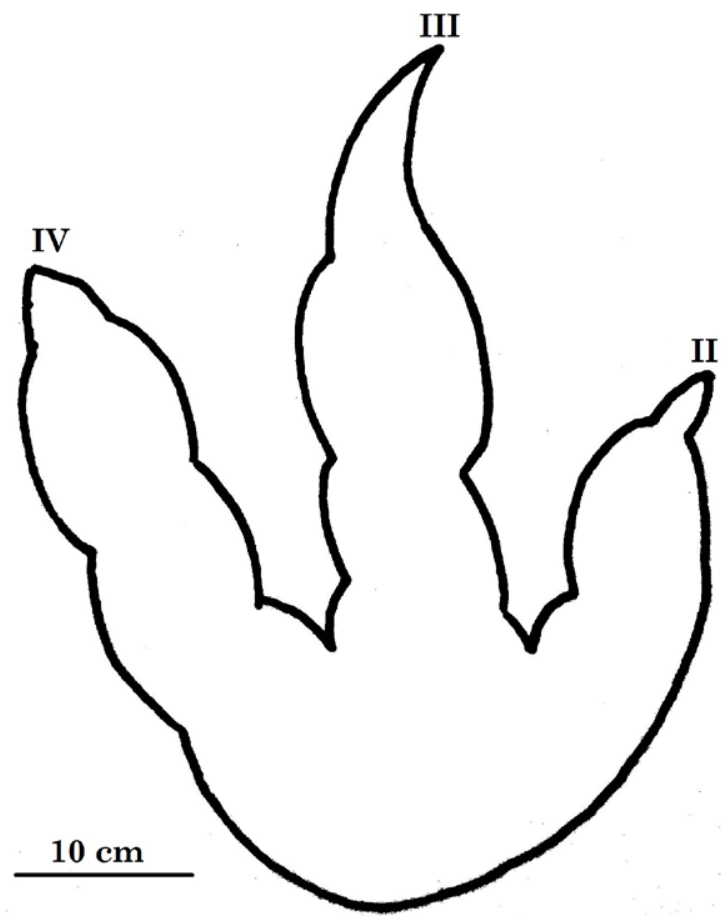

Figura 3 Dibujo del Holotipo de la huella de Abelichnus astigarrae Calvo, 1991. II, III, IV indican nombre de los dígitos.

Tabla 1. Datos de las huellas y pista del holotipo Abelichnus astigarrae MUCPv-74 (Pista A) e hipodigma (Pista B). Medidas en cm.

\begin{tabular}{|c|c|c|c|}
\hline \multicolumn{4}{|c|}{ Datos de pista y huellas de $A b e$} \\
\hline Pista "A" & Paso doble & Paso oblicuo & Ángulo paso \\
\hline $1 / 2$ & \multirow{3}{*}{$\begin{array}{l}245 \\
265\end{array}$} & 112 & \multirow{3}{*}{$145^{\circ} \quad 148^{\circ}$} \\
\hline $2 / 3$ & & 140 & \\
\hline $3 / 4$ & & 140 & \\
\hline $\mathrm{X}$ & 255 & 130 & $146.5^{\circ}$ \\
\hline $\mathrm{T}$ & 14.1 & 16.2 & $2.1^{\circ}$ \\
\hline $\mathrm{n}$ & 2 & 3 & 2 \\
\hline
\end{tabular}

lichnus astigarrae MUCPv- 74 
(Albiano?- Cenomaniano)- Punta de Pescadores, Península Nueva, Picún Leufú, Neuquén.

Bressanichnus Calvo, 1991

Bressanichnus patagonicus Calvo, 1991

(figuras 4 y 5 ; tablas 2a y 2b)

Diagnosis. Huellas de tamaño mediano, con el dígito III más desarrollado que los laterales y todos presentan impresiones de garras. Cada huella tiene una longitud que oscila entre los 20 y $25 \mathrm{~cm}$ y la relación entre largo y ancho es de 1.5. La impresión del dígito III está curvada internamente y el talón es subredondeado y pequeño. Las huellas son levemente asimétricas. El hypex entre los dígitos II y III está posteriormente ubicado con respecto al hypex entre los dígitos III y IV. El ángulo de paso es aproximadamente $175^{\circ}$ (Calvo, 1991).

Horizonte y localidad. Nivel inferior de la Formación Candeleros

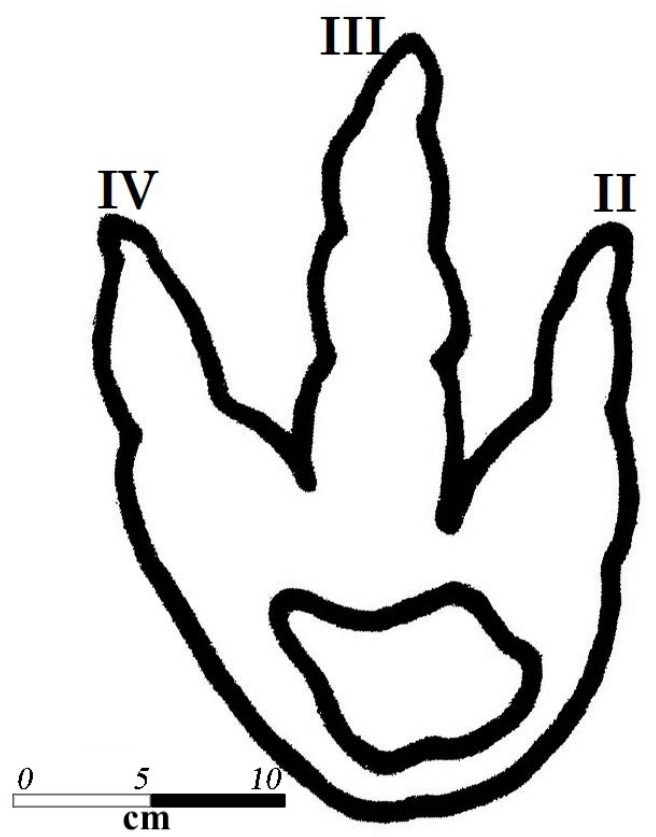

Figura 4 MUCPv-60, dibujo del holotipo de la huella de Bressanichnus patagonicus Calvo, 1991. II, III, IV indican nombre de los dígitos.

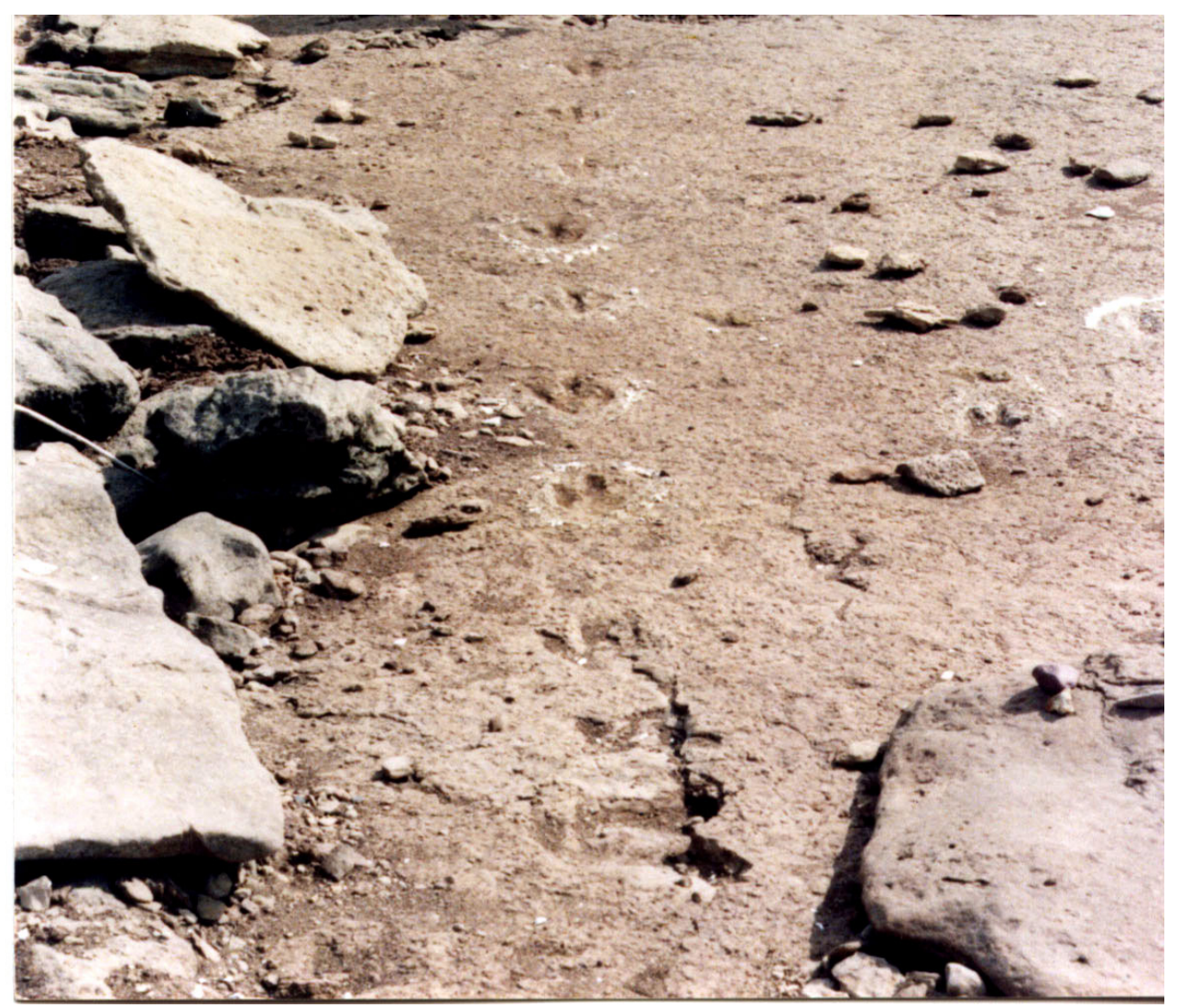

Figura 5 MUCPv-60, vista de la pista del holotipo de Bressanichnus patagonicus (Calvo, 1991). Como referencia, las huellas tienen 22 $\mathrm{cm}$ de largo y el paso de $80 \mathrm{~cm}$. 
Tabla 2a. Datos de las pista y huellas del holotipo Bressanichnus patagonicus - MUCPv-68. Medidas en cm.

\begin{tabular}{|c|c|c|c|c|c|c|}
\hline \multicolumn{7}{|c|}{ Pista del terópodos Bressanichnus patagonicus - MUCPv- 68 } \\
\hline & Paso doble & Paso oblicuo & Ángulo paso & $\begin{array}{c}\text { Ancho } \\
\text { externo }\end{array}$ & $\begin{array}{c}\text { Ancho } \\
\text { interno }\end{array}$ & Ancho paso \\
\hline $1 / 2$ & 157 & 73 & $174^{\circ}$ & 17 & -14 & 3 \\
\hline $2 / 3$ & 165 & 84 & $168^{\circ}$ & 16 & -11 & 3 \\
\hline $3 / 4$ & & 82 & & 10 & -17 & 7 \\
\hline $\mathrm{X}$ & 161 & 79.6 & $172^{\circ}$ & 14.3 & -14 & 4.3 \\
\hline $\mathrm{T}$ & 5.65 & 5.9 & $4.2^{\circ}$ & 3.8 & 3 & 2.3 \\
\hline $\mathrm{n}$ & 2 & 3 & 2 & 3 & 3 & 3 \\
\hline
\end{tabular}

\begin{tabular}{|c|c|c|c|c|c|c|c|c|c|c|c|c|c|c|c|}
\hline \multicolumn{16}{|c|}{ Huellas del terópodo Bressanichnus patagonicus - MUCPv- 68} \\
\hline & \multirow{2}{*}{$\begin{array}{l}\text { Ancho } \\
\text { pisada }\end{array}$} & \multirow{2}{*}{$\begin{array}{l}\text { Largo } \\
\text { pisada }\end{array}$} & \multirow{2}{*}{$\begin{array}{c}\text { Paso } \\
\text { doble/ } \\
\text { Largo } \\
\text { pisada }\end{array}$} & \multirow{2}{*}{$\begin{array}{c}\text { Ancho } \\
\text { externo/ } \\
\text { Largo } \\
\text { pisada }\end{array}$} & \multirow{2}{*}{$\begin{array}{l}\text { Largo } \\
\text { pisada/ } \\
\text { Ancho } \\
\text { pisada }\end{array}$} & \multirow{2}{*}{$\begin{array}{c}\text { Campo } \\
\text { variación }\end{array}$} & \multicolumn{3}{|c|}{ Largo dedo } & \multicolumn{3}{|c|}{ Ancho dedo } & \multicolumn{3}{|c|}{ Divergencia } \\
\hline & & & & & & & II & III & IV & II & III & IV & II & III & IV \\
\hline 1 & - & - & - & - & - & - & - & - & - & - & - & - & - & - & - \\
\hline 2 & 35 & 42 & 5.7 & 1.1 & 1.6 & 8 & 7 & 9 & 7 & 7 & 2.5 & - & $23^{\circ}$ & $13^{\circ}$ & $36^{\circ}$ \\
\hline 3 & 35 & 42 & 5.6 & 1.1 & 1.75 & 6 & - & - & - & - & - & - & $23^{\circ}$ & $22^{\circ}$ & $45^{\circ}$ \\
\hline 4 & - & - & - & - & 1.6 & - & - & - & - & - & - & - & - & - & - \\
\hline o & 14.5 & 23 & - & - & 1.6 & - & - & 9 & - & - & - & - & $24^{\circ}$ & $15^{\circ}$ & $40^{\circ}$ \\
\hline$X$ & 13.6 & 22.5 & 7.3 & 1.1 & 1.65 & - & 7 & 9 & 7 & - & 2.5 & - & $23.3^{\circ}$ & $16.6^{\circ}$ & $40^{\circ}$ \\
\hline $\mathrm{T}$ & 1.4 & 1.3 & 0.8 & 0.03 & 0.1 & - & & 0 & & & & & 0.6 & 4.7 & 4.5 \\
\hline $\mathrm{n}$ & 3 & 3 & 2 & 2 & 3 & - & & 2 & & & & & 3 & 3 & 3 \\
\hline
\end{tabular}

Tabla 2b. Datos de las pista y huellas del holotipo Bressanichnus patagonicus - MUCPv-69. Medidas en cm.

\begin{tabular}{|c|c|c|c|c|c|c|}
\hline \multicolumn{7}{|c|}{ Pista del terópodo Bressanichnus patagonicus - MUCPv-69 } \\
\hline & Paso doble & Paso oblicuo & Ángulo paso & $\begin{array}{c}\text { Ancho } \\
\text { externo }\end{array}$ & $\begin{array}{l}\text { Ancho } \\
\text { interno }\end{array}$ & Ancho paso \\
\hline $1 / 2$ & \multirow{3}{*}{$\begin{array}{l}150 \\
157\end{array}$} & 74 & \multirow{3}{*}{$\begin{array}{l}168^{\circ} \\
173^{\circ}\end{array}$} & - & - & - \\
\hline $2 / 3$ & & 79 & & 21 & -10 & 6 \\
\hline $3 / 4$ & & 77 & & 20 & -8 & 6 \\
\hline$X$ & 153.5 & 76.6 & $170.5^{\circ}$ & 20.5 & -9 & 6 \\
\hline $\mathrm{T}$ & 4.9 & 2.5 & $3.5^{\circ}$ & 0.7 & 1.4 & 0 \\
\hline $\mathrm{n}$ & 2 & 3 & 2 & 2 & 2 & 2 \\
\hline
\end{tabular}

\begin{tabular}{|c|c|c|c|c|c|c|c|c|c|c|c|c|c|c|c|}
\hline \multicolumn{16}{|c|}{ Huellas del terópodo Bressanichnus patagonicus - MUCPv-69 } \\
\hline & \multirow{2}{*}{$\begin{array}{l}\text { Ancho } \\
\text { pisada }\end{array}$} & \multirow{2}{*}{$\begin{array}{l}\text { Largo } \\
\text { pisada }\end{array}$} & \multirow{2}{*}{$\begin{array}{c}\text { Paso } \\
\text { doble/ } \\
\text { Largo } \\
\text { pisada }\end{array}$} & \multirow{2}{*}{$\begin{array}{c}\text { Ancho } \\
\text { externo/ } \\
\text { Largo } \\
\text { pisada }\end{array}$} & \multirow{2}{*}{$\begin{array}{c}\text { Largo } \\
\text { pisada/ } \\
\text { Ancho } \\
\text { pisada }\end{array}$} & \multirow{2}{*}{$\begin{array}{c}\text { Campo } \\
\text { variación }\end{array}$} & \multicolumn{3}{|c|}{ Largo dedo } & \multicolumn{3}{|c|}{ Ancho dedo } & \multicolumn{3}{|c|}{ Divergencia } \\
\hline & & & & & & & II & III & IV & II & III & IV & II & III & IV \\
\hline 1 & - & - & - & - & - & - & - & - & - & - & - & - & - & - & - \\
\hline 2 & 15 & 23 & 6.5 & 1.4 & 1.5 & $-8^{\circ}$ & - & 9 & - & - & - & - & $25^{\circ}$ & $30^{\circ}$ & $50^{\circ}$ \\
\hline 3 & 13 & - & - & 1.6 & - & $5^{\circ}$ & - & - & - & - & - & - & - & - & - \\
\hline 4 & - & - & - & - & 1.6 & - & - & - & - & - & - & - & - & - & - \\
\hline X & 14 & 23 & 6.5 & 1.5 & - & - & - & 9 & - & - & - & - & $25^{\circ}$ & $30^{\circ}$ & $50^{\circ}$ \\
\hline $\mathrm{T}$ & 1.4 & - & - & 0.1 & - & - & & 0 & & & & & & & \\
\hline $\mathrm{n}$ & 2 & - & - & 2 & - & - & & 2 & & & & & & & \\
\hline
\end{tabular}


(Albiano?-Cenomaniano)- Punta de Pescadores, Península Nueva, Picún Leufú, Neuquén.

\section{Deferrariischnium Calvo, 1991}

Deferrariischnium mapuchensis Calvo, 1991

(figuras 6, 7 y 9 ; tablas $3 a$, 3b y 11 )

Diagnosis enmendada. Son huellas tridáctilas casi simétricas con la impresión de un largo dígito III, casi la mitad del largo de la huella, desplazado internamente y con una impresión de garra muy marcada y aguzada. El dígito II es un poco más corto que el IV, mostrando indicios de pequeñas garras. Los dígitos II y IV divergen en no más de $25^{\circ}$ con respecto al dígito III. Las falanges basales son gruesas, por lo que se fusionan dando un aspecto masivo. El talón es pequeño y agudo y se conecta lateralmente con los dígitos.

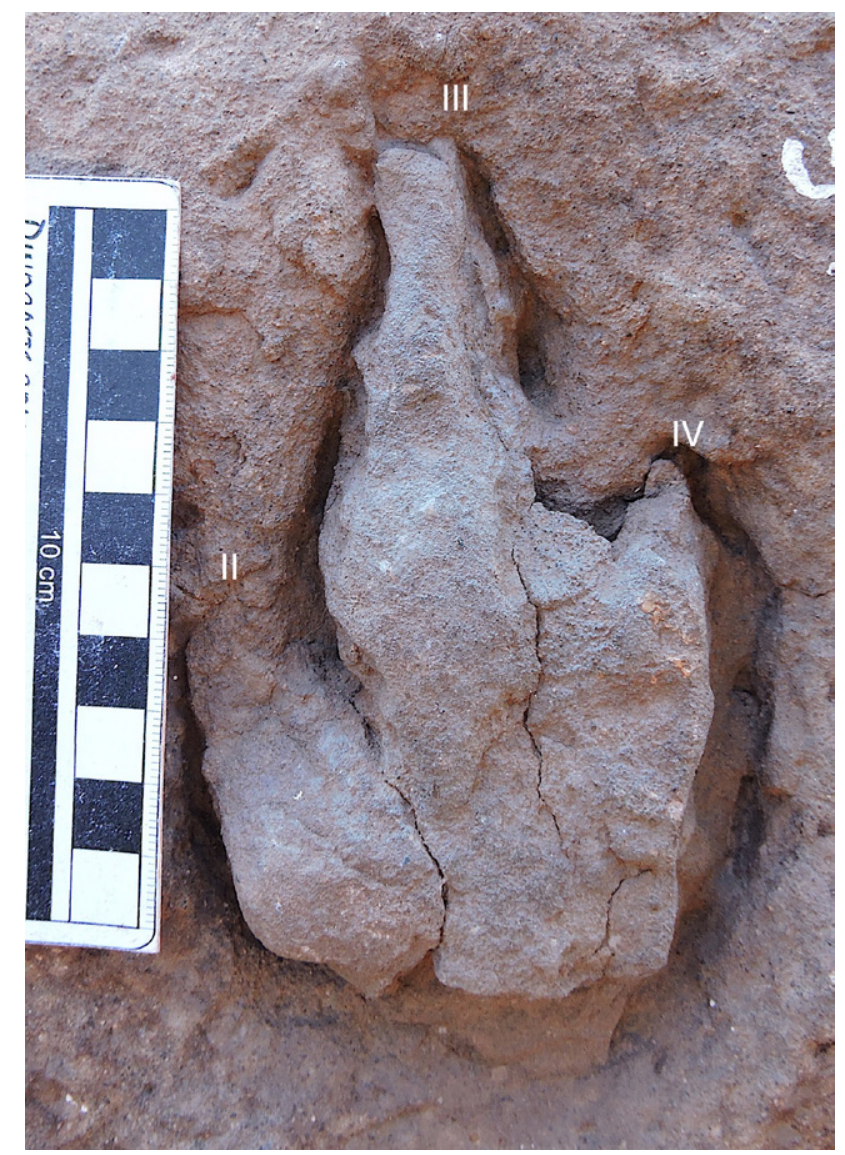

Figura 6 MUCPv-97, neotipo de Deferrariischnium mapuchensis colectada en el sitio Punta de Pescadores. II, III, IV indican nombre de los dígitos.
Comentarios. Estas huellas pertenecen a pequeños terópodos y su diagnosis fue realizada por Calvo (1991) con base en huellas in situ que lamentablemente no se pudieron extraer por problemas de logística. Se dispone ahora de nuevos materiales entre los cuales se encuentra una huella en muy buen estado de preservación y que ha permitido mejorar la diagnosis realizada y se elije como neotipo (Figura 6, MUCPv-97).

Horizonte y localidad. Nivel inferior de la Formación Candeleros (Albiano?-Cenomaniano)Punta de Pescadores, Península Nueva, Picún Leufú, Neuquén.

Neotipo. MUCPv-97. Se ha detectado en las colecciones del Museo de Geología y Paleontología de la Universidad Nacional del Comahue una huella original proveniente del sitio Punta de Pescadores que corresponde a la icnoespecie

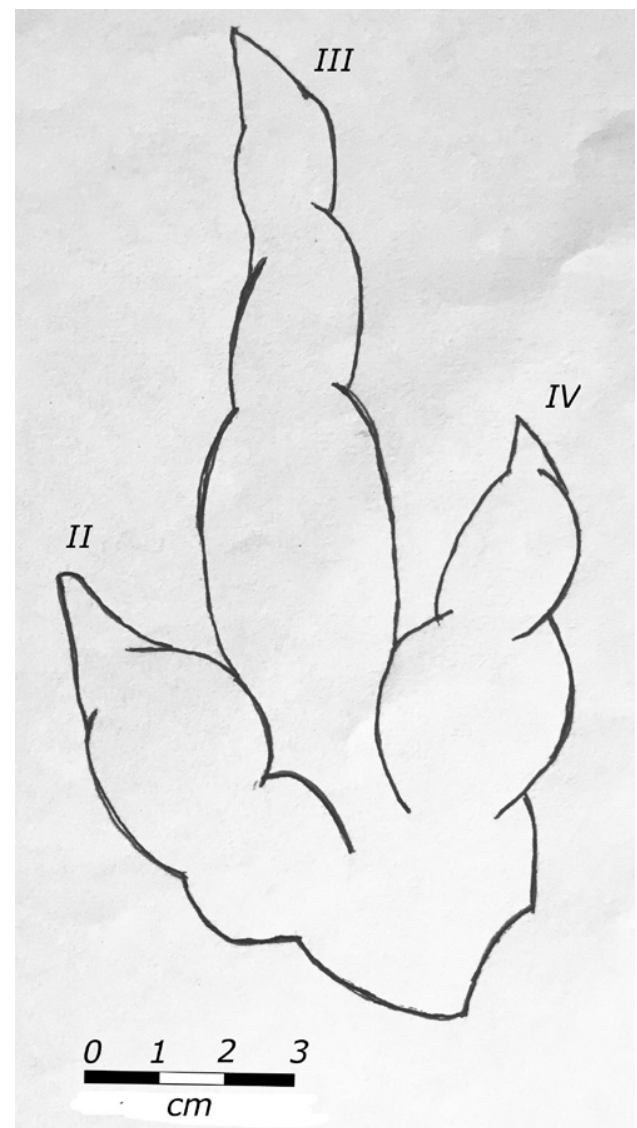

Figura 7 MUCPv-97, dibujo del neotipo de Deferrariischnium mapuchensis colectada en el sitio Punta de Pescadores. II, III, IV indican nombre de los dígitos. 
Tabla 3a. Datos de las pista y huellas del holotipo Deferrariischnium mapuchensis MUCPv-66. Medidas en cm.

\begin{tabular}{|c|c|c|c|c|c|c|}
\hline \multicolumn{7}{|c|}{ Pista de Deferrariischnium mapuchensis MUCPv-66 } \\
\hline & Paso doble & Paso oblicuo & Ángulo paso & $\begin{array}{c}\text { Ancho } \\
\text { externo }\end{array}$ & $\begin{array}{c}\text { Ancho } \\
\text { interno }\end{array}$ & Ancho paso \\
\hline $1 / 2$ & 138 & 68 & $178^{\circ}$ & 10 & -8 & 1 \\
\hline $2 / 3$ & 68 & & 9 & -9 & 1 \\
\hline $\mathrm{X}$ & 138 & 68 & $178^{\circ}$ & 9.5 & 8.5 & 1 \\
\hline $\mathrm{T}$ & 0 & 0 & 0 & 0.7 & 0.7 & 0 \\
\hline $\mathrm{n}$ & 1 & 2 & 1 & 2 & 2 & 2 \\
\hline
\end{tabular}

\begin{tabular}{|c|c|c|c|c|c|c|c|c|c|c|c|c|c|c|c|}
\hline \multicolumn{16}{|c|}{ Huellas de Deferrariischnium mapuchensis MUCPv-66 } \\
\hline & \multirow{2}{*}{$\begin{array}{l}\text { Ancho } \\
\text { pisada }\end{array}$} & \multirow{2}{*}{$\begin{array}{l}\text { Largo } \\
\text { pisada }\end{array}$} & \multirow{2}{*}{$\begin{array}{l}\text { Paso } \\
\text { doble/ } \\
\text { Largo } \\
\text { pisada }\end{array}$} & \multirow{2}{*}{$\begin{array}{c}\text { Ancho } \\
\text { externo/ } \\
\text { Largo } \\
\text { pisada }\end{array}$} & \multirow{2}{*}{$\begin{array}{l}\text { Largo } \\
\text { pisada/ } \\
\text { Ancho } \\
\text { pisada }\end{array}$} & \multirow{2}{*}{$\begin{array}{c}\text { Campo } \\
\text { variación }\end{array}$} & \multicolumn{3}{|c|}{ Largo dedo } & \multicolumn{3}{|c|}{ Ancho dedo } & \multicolumn{3}{|c|}{ Divergencia } \\
\hline & & & & & & & II & III & IV & II & III & IV & II & III & IV \\
\hline 1 & - & 17 & 8.7 & 1.2 & 1.7 & - & - & - & - & - & - & - & - & - & - \\
\hline 2 & 10 & 17 & 8.7 & 1.4 & 2 & - & - & 10 & - & - & 2 & - & $21^{\circ}$ & $13^{\circ}$ & $35^{\circ}$ \\
\hline 3 & - & - & - & - & - & - & - & - & - & - & - & - & - & - & - \\
\hline
\end{tabular}

Tabla 3b. Datos de las pista y huellas del holotipo Deferrariischnium mapuchensis MUCPv-63. Medidas en cm.

\begin{tabular}{|c|c|c|c|c|c|c|}
\hline \multicolumn{7}{|c|}{ Pista de Deferrariischnium mapuchensis MUCPv-63 } \\
\hline & Paso doble & Paso oblicuo & Ángulo paso & $\begin{array}{c}\text { Ancho } \\
\text { externo }\end{array}$ & $\begin{array}{c}\text { Ancho } \\
\text { interno }\end{array}$ & Ancho paso \\
\hline $1 / 2$ & 148 & 74 & $174^{\circ}$ & 12 & -10 & 1.5 \\
\hline $2 / 3$ & 73 & & 12 & -10 & 2 \\
\hline $\mathrm{X}$ & 148 & 73.5 & $174^{\circ}$ & 12 & 10 & 1.75 \\
\hline $\mathrm{T}$ & 0 & 0.7 & 0 & 0 & 0 & 0.35 \\
\hline $\mathrm{n}$ & 1 & 2 & 1 & 2 & 2 & 2 \\
\hline
\end{tabular}

\begin{tabular}{|c|c|c|c|c|c|c|c|c|c|c|c|c|c|c|c|}
\hline \multicolumn{16}{|c|}{ Huellas de Deferrarïschnium mapuchensis MUCPv-63 } \\
\hline & \multirow{2}{*}{$\begin{array}{l}\text { Ancho } \\
\text { pisada }\end{array}$} & \multirow{2}{*}{$\begin{array}{l}\text { Largo } \\
\text { pisada }\end{array}$} & \multirow{2}{*}{$\begin{array}{l}\text { Paso } \\
\text { doble/ } \\
\text { Largo } \\
\text { pisada }\end{array}$} & \multirow{2}{*}{$\begin{array}{c}\text { Ancho } \\
\text { externo/ } \\
\text { Largo } \\
\text { pisada }\end{array}$} & \multirow{2}{*}{$\begin{array}{l}\text { Largo } \\
\text { pisada/ } \\
\text { Ancho } \\
\text { pisada }\end{array}$} & \multirow{2}{*}{$\begin{array}{c}\text { Campo } \\
\text { variación }\end{array}$} & \multicolumn{3}{|c|}{ Largo dedo } & \multicolumn{3}{|c|}{ Ancho dedo } & \multicolumn{3}{|c|}{ Divergencia } \\
\hline & & & & & & & II & III & IV & II & III & IV & II & III & IV \\
\hline 1 & 10 & 17 & 8.7 & 1.2 & 1.7 & 4 & - & - & - & - & - & - & - & - & - \\
\hline 2 & 8.5 & 17 & 8.7 & 1.4 & 2 & 3 & 4 & 10 & 5.5 & - & 2.5 & - & $17^{\circ}$ & $25^{\circ}$ & $42^{\circ}$ \\
\hline 3 & 8.5 & 16.5 & 8.9 & 1.4 & 1.9 & 11 & - & - & - & - & 2.5 & - & $17^{\circ}$ & $22^{\circ}$ & $39^{\circ}$ \\
\hline X & 9 & 16.8 & 8.8 & 1.3 & 1.9 & & 4 & 10 & 5.5 & - & 2.5 & - & $17^{\circ}$ & $23.5^{\circ}$ & $40.5^{\circ}$ \\
\hline $\mathrm{T}$ & 0.9 & 0.3 & 0.1 & 0.1 & 0.2 & & 0 & 0 & 0 & - & 0 & - & 0 & 2.1 & 2.1 \\
\hline $\mathrm{n}$ & 3 & 3 & 3 & 3 & 3 & & 1 & 1 & 1 & - & 2 & - & 2 & 2 & 2 \\
\hline
\end{tabular}


Deferrariischnium mapuchensis Calvo, 1991 lo que nos permitió enmendar la diagnosis original de la especie (figuras 6 y 7; Tabla 11). Si bien se había descripto la pista como holoplastotipo (Calvo, 1991), el hallazgo de material original (MUCPv97) y más detalles morfológicos permiten definir a este material como nuevo holotipo de esta icnoespecie.

Descripción. MUCPv-97 tiene $15 \mathrm{~cm}$ de largo y $7.5 \mathrm{~cm}$ de ancho (Tabla 11). El talón está prácticamente completo pero la parte faltante se puede inferir a partir del material original. El dígito III con $125 \mathrm{~mm}$ es el más largo, el dedo II tiene $60 \mathrm{~mm}$ y el dedo IV posee $75 \mathrm{~mm}$. La segunda falange del dedo III es gruesa y larga como también la primera falange del dedo II. El dedo IV no se encuentra con buen detalle de falanges. El talón es agudo, está desplazado hacia el exterior y es muy pequeño.

Picunichnus Calvo, 1991

Picunichnus benedettoi Calvo, 1991 (figuras 8 y 9; Tabla 4)

Diagnosis ampliada. MUCPv-72. Esta icnoespecie está definida a partir de una sola huella tetradáctila de $22 \mathrm{~cm}$ de largo y $13 \mathrm{~cm}$ de ancho que presenta muy buenas impresiones de sus garras (Figura 8). El dígito I, dirigido medialmente, es muy pequeño y está conectado a la mitad posterior del talón. El dígito III es el más largo y los dígitos II y IV divergen muy poco con respecto al dígito III. Las impresiones de las falanges están muy bien marcadas y en general son más largas que anchas.
El talón es muy pequeño (Calvo, 1991). Se ha descubierto una plataforma con varias pistas, una de las cuales corresponde a Picunichnus benedettoi. La misma tiene $10.1 \mathrm{~m}$ de largo con huellas de $20 \mathrm{~cm}$

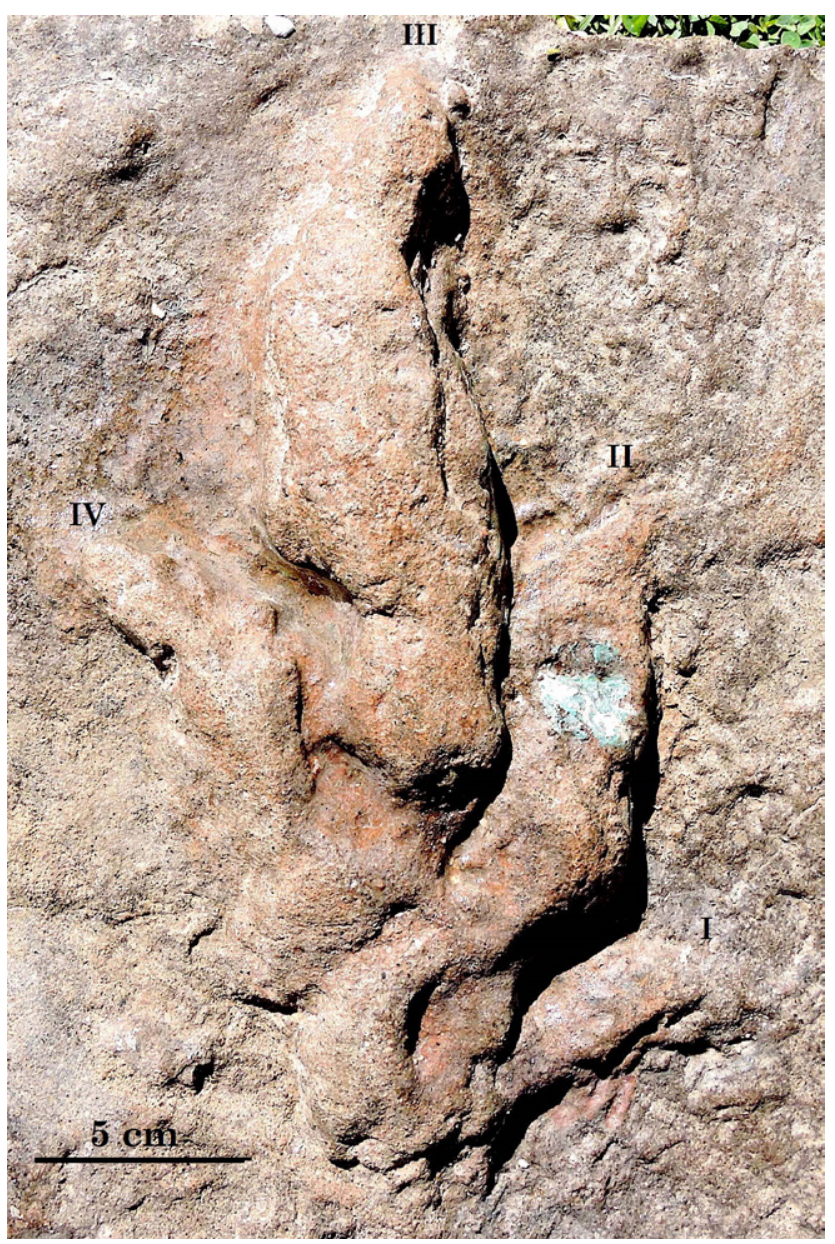

Figura 8 MUCPv-72, holotipo de Picunichnus benedettoi (Calvo, 1991), molde en roca (epirelieve). II, III, IV indican nombre de los dígitos.

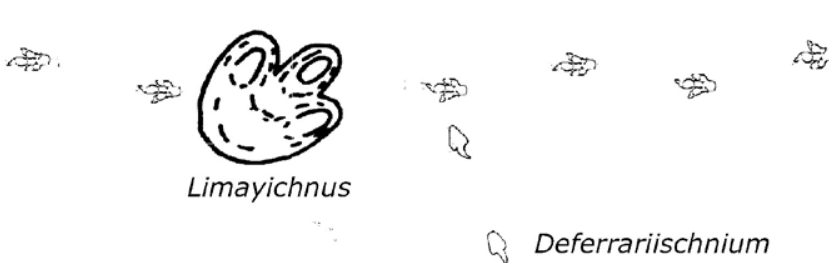

Figura 9

Sitio icnológico del balneario Picún Leufú. 
Tabla 4. Datos de los holotipos de Limayichnus major, MUCPv-70; Sousaichnium monettae, MUCPv-71; Picunichnus benedettoi, MUCPv72. Medidas en cm.

\begin{tabular}{|c|c|c|c|c|c|c|c|c|c|c|c|c|c|c|c|}
\hline \multirow{2}{*}{ MUCPv } & \multirow{2}{*}{$\begin{array}{l}\text { Ancho } \\
\text { pisada }\end{array}$} & \multirow{2}{*}{$\begin{array}{l}\text { Largo } \\
\text { pisada }\end{array}$} & \multicolumn{4}{|c|}{ Largo dedo } & \multicolumn{4}{|c|}{ Ancho dedo } & \multicolumn{5}{|c|}{ Divergencia } \\
\hline & & & I & II & III & IV & I & II & III & IV & II-III & III-IV & II -IV & I-II & I- IV \\
\hline 70 & 52 & 62 & - & - & 31 & - & $\mathrm{u}$ & 14 & 17 & 14 & $20^{\circ}$ & $30^{\circ}$ & $51^{\circ}$ & - & - \\
\hline 71 & 53 & 64 & - & - & - & - & - & 18 & 15 & 10 & $25^{\circ}$ & $20^{\circ}$ & $50^{\circ}$ & - & - \\
\hline 72 & 13 & 22 & 4.5 & 8 & 16 & 10 & 2 & 2.5 & 3 & 3 & $14^{\circ}$ & $20^{\circ}$ & $33^{\circ}$ & $66^{\circ}$ & $100^{\circ}$ \\
\hline
\end{tabular}

de largo y una separación entre ellas de $74 \mathrm{~cm}$. El ángulo de paso es de $170^{\circ}$ (Figura 9).

Horizonte y localidad. Nivel inferior de la Formación Candeleros (Albiano?-Cenomaniano)Punta de Pescadores, Península Nueva, Picún Leufú, Neuquén.

Candeleroichnus icnogen. nov. (figuras 10, 11, 12 y 13; Tabla 5)

Etimología. En referencia a la Formación geológica Candeleros, la cual hace referencia a cerros testigos parecidos a los candelabros usados en la antigüedad. Esta formación ha dado una riquísima y abundante icnofauna en toda su extensión. Diagnosis. Huellas tridáctilas de pequeño tamaño. Dedo III bien desarrollado y desplazado hacia el interior. Dedos II y IV más delgados que el central y elongados. Dedo II con impresión de garra desplazada levemente hacia el interior. La divergencia interdigital en general no supera los $10^{\circ}$. El hypex entre dedos II y III está desplazado posteriormente. El ángulo de paso oscila entre 175 y $180^{\circ}$. El talón es pequeño y está desplazado hacia afuera. Las pisadas son de tipo digitígrado.

Candeleroichnus canalei icnosp. nov. (figuras 10, 11, 12 y 13; Tabla 5)

Etimología. En homenaje al Dr. Juan Ignacio Canale, especializado en el estudio de dinosaurios terópodos. Trabajó en la zona del embalse Ezequiel Ramos Mexía.
Diagnosis de la especie. La misma del género. Horizonte y Localidades. Estratos inferiores de la Formación Candeleros, Albiano? o Cenomaniano Inferior. Cerro Mesa en el paraje El Sauce e Isla Cerrito del Bote en los alrededores de la ciudad de Picún Leufú, Provincia del Neuquén. Holotipo. Roca original con cuatro huellas MUCPv-76 (Figura 13).

Paratipo. Se han preservado tres plastotipos MUCPv-133, 134 y 135 y dibujo de las pistas (figuras 12 y 14).

Material. Del sitio Cerro Mesa, $5 \mathrm{~km}$ al oeste de la ciudad de Picún Leufú, proceden cuatro calcos en roca, en dos bloques, MUCPv-76 (Figura 11) y un molde en roca mal conservada, MUCPv-201. Tres plastotipos MUCPv-133, 134 y 135 y dibujos de cinco icnitas proceden de la Isla Cerrito del Bote al norte de la Península Nueva (figuras 10 y 12), $15 \mathrm{~km}$ al este de la ciudad de Picún Leufú.

Descripción. Estas huellas y pistas procedentes de la Isla Cerrito del Bote fueron descritas en gran detalle pero no fueron reconocidas como nuevos icnotaxones (Galvo y Mazzetta, 2004). En este trabajo utilizamos la descripción dada por estos autores e incorporamos nueva información ya que describimos en detalle el holotipo MUCPv-76 y transcribimos la descripción realizada por Calvo y Mazzetta (2004) que incorpora más datos a partir de éste. El trabajo original incluye cinco pistas $(\mathrm{CB}$ 2 a 6) producidas por dinosaurios bípedos de talla pequeña. Algunas están bien preservadas y representadas por huellas largas y medianamente gráciles (sensu Lockley, 1998; Figura 9), mesaxónicas y 


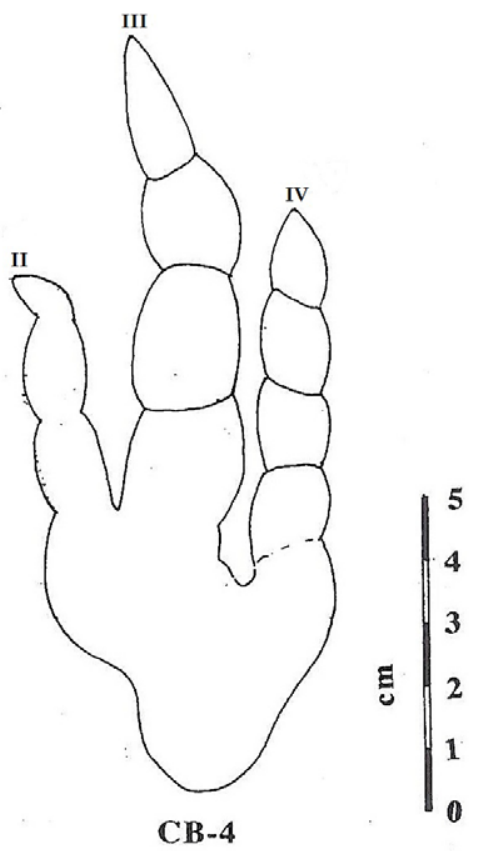

Figura 10 Candeleroichnus canalei nov. gen. nov. sp. de la Isla Cerrito del Bote (tomado de Calvo y Mazzetta, 2004). II, III, IV indican nombre de los dígitos.

tridáctilas, con postura digitígrada y sin rotación apreciable. Tanto en las huellas de Isla Cerrito del Bote como en el holotipo de Cerro Mesa sus dimensiones alcanzan los $11 \mathrm{~cm}$ de longitud y $6 \mathrm{~cm}$ de ancho en promedio. El dedo III es más largo y más robusto que los laterales. El 90\% de su longitud es ocupado por la impronta de los dedos. El hypex del dedo II y IV está desplazado posteriormente con respecto al del II y III. Las garras de los dedos son prominentes y bien desarrolladas, las impresiones falangeales del dedo III son más anchas que las de los dígitos II y IV. Las huellas son asimétricas, con la impronta del talón casi no preservada o muy pequeña y desplazada hacia el exterior. El dedo III imprime tres falanges y su garra. La impronta está distalmente desplazada hacia el interior. El dedo II, más pequeño que el IV en las huellas mejor preservadas, imprime dos falanges y su garra, y la impronta de su extremo distal se desplaza hacia el interior o adelante. El dedo IV, prácticamente recto, imprime tres falanges y su garra con indicio de la falange ungueal desplazada hacia el interior. La divergencia interdigital de la

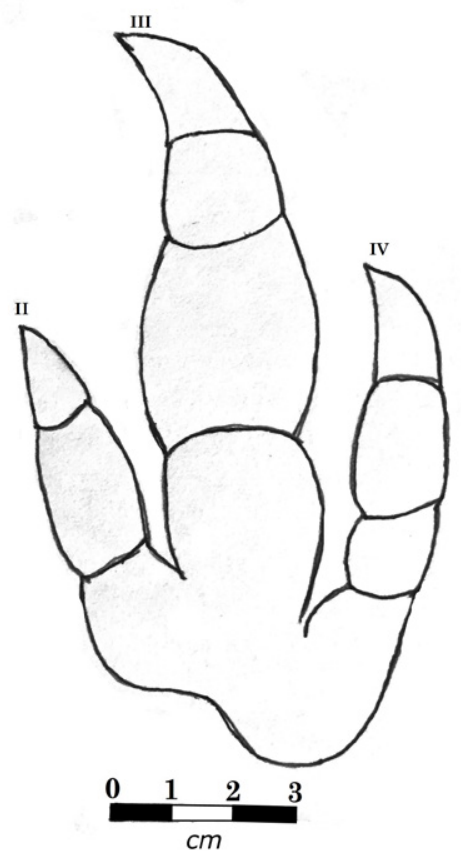

Figura 11 MUCPv-76, holotipo de Candeleroichnus canalei nov. gen. nov. sp. del sitio Cerro Mesa. II, III, IV indican nombre de los dígitos.

mayoría de las huellas no supera los $10^{\circ}$. Las pistas son extremadamente estrechas y rectilíneas, con un ángulo de paso que oscila entre 175 y $180^{\circ}$. En el Cerrito del Bote las huellas se dirigen al este o este-sudeste, con los siguientes rumbos y detalles: CB-2 (107 ; cinco huellas mal preservadas; plastotipo de huella MUCPv-133), CB-3 (115º; siete huellas; plastotipo de huella MUCPv-135), CB-4 (105'; seis huellas), CB-5 (108; nueve huellas; plastotipo de huella MUCPv-134), y CB-6 (90% ocho huellas) (Calvo y Mazzetta, 2004). Excepto en el caso de la pista CB-6, las pistas de estos pequeños dinosaurios bípedos se disponen muy cercanas (la distancia entre las mismas no supera los $0.8 \mathrm{~m})$ y se encuentran aproximadamente paralelas entre sí, indicando una misma dirección y sentido de desplazamiento.

Comparaciones. Si bien se realizaron comparaciones de estas huellas con otras conocidas (Calvo y Mazzetta, 2004), las mismas no se pudieron diagnosticar en su momento ya que son huellas muy conservadoras y presentes en muchos grupos de vertebrados. Por ejemplo, hay grandes similitudes 
$y^{5}$

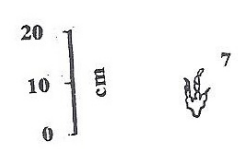

$8^{9}$

읭

8

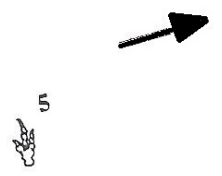

${ }^{7}$

$$
{ }^{6}
$$

4

$s^{6}$

ज्ञ

$8^{4}$

$3^{4} m^{4}$

sing

${ }^{2}$

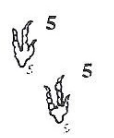

离

$4^{5}$

留

6

过

$a^{4}$

题:

$\mathrm{H}^{3} \mathrm{~d}^{3}$

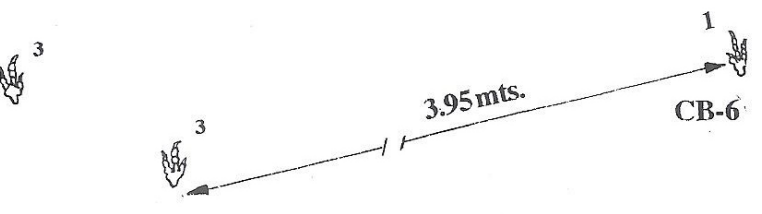

$\mathrm{CB}=2$

$y^{2} y^{2}$

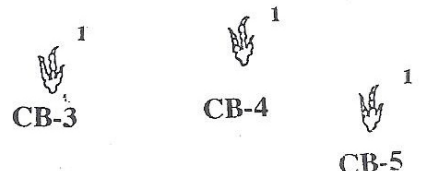

Figura 12 Dibujo de las pistas de Candeleroichnus canalei nov. gen. nov. sp. de la Isla Cerrito del Bote (CB) (tomado de Calvo y Mazzetta, 2004). La flecha indica el Norte geográfico. 


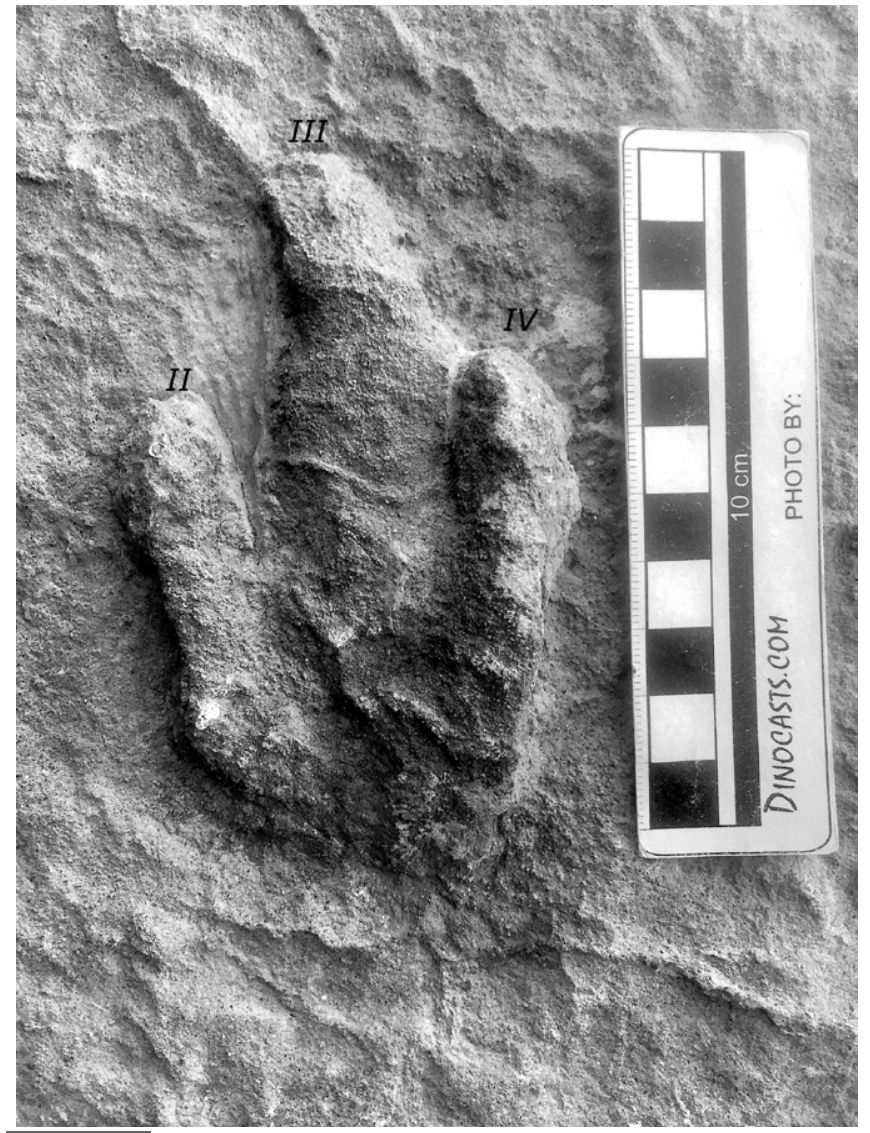

Figura 13 MUCPv-76, holotipo de Candeleroichnus canalei nov. gen. nov. sp. del sitio Cerro Mesa. II, III, IV indican nombre de los dígitos.

con Grallator (Hitchcock, 1858) del Triásico MedioJurásico Inferior y Triásico Superior (Conrad et al., 1987) en tamaño, forma, relación entre paso doble y largo de pisada y posición de los dedos; sin embargo, hay diferencias en la impresión de la palma. Con Anchisauripus hitchcocki Lull (1904) tiene algunas similitudes en el aspecto general, pero se diferencia de esta especie por tener impresión de la garra del dedo I y un ángulo de paso mayor, no presente en el icnogénero neuquino. Con las formas neuquinas se las comparó con Deferrariischnium mapuchensis indicando similitudes pero también diferencias. Por ejemplo, en este icnogénero varía la simetría y el tamaño de esas huellas, mientras que los dedos laterales no muestran impresión de garras y divergen del central con un ángulo mucho mayor que el material aquí comunicado, por lo que no fue asignado a esta icnoespecie (Calvo y Mazzetta, 2004). Se observa además cierto parecido con Coelurosaurichnus (Conrad et al., 1987), pero hay diferencias en el ángulo de paso, impresión del talón, ángulo interdigital mayor, relación paso doble/largo de pisada menor, etc., por lo que no se asignó a ese icnogénero. No se correspondería tampoco con icnotaxones de la Icnofamilia Dromaeopodidae los cuales presentan impresiones de dos o tres dígitos y marcas de garras $(\mathrm{Li}$ et al., 2008) o como las asignadas a dromaeosáuridos de Toro Toro en Bolivia (Apesteguía et al., 2011). Desde su primera publicación hasta el presente, este sitio ha sido el más abundante en calidad y cantidad de huellas de dinosaurios (Calvo, 1989, 1999; Calvo y Mazzetta, 2004; Rivera y Calvo, 2016). Han pasado 28 años y huellas similares han sido detectadas en forma aislada en distintas partes de la costa del embalse. Por otro lado, las decenas de restos de vertebrados fósiles que han sido estudiados nos hablan de una icnofauna muy particular para la base de la Formación Candeleros (Cretácico Inferior alto-Cretácico Superior bajo). Si bien hay formas similares a este patrón de icnitas, la nueva icnoforma que se describe muestra una morfología particular, lo que valida su designación con un nombre genérico. Estas huellas completan la fauna de terópodos de pequeño tamaño registrados en la Formación Candeleros, lo cual indica que la fauna estaba compuesta por numerosas especies de dinosaurios carnívoros de variadas formas y tamaños asociadas a dinosaurios ornitópodos y saurópodos.

\section{Sauropoda Marsh, 1878 \\ Sauropodichnus Calvo, 1991 \\ Sauropodichnus giganteus Calvo, 1991}

(figuras 14 y 15)

Diagnosis. Las huellas de Sauropodichnus indican un gran animal de cadera ancha que caminaba con un ángulo de paso menor a $160^{\circ}$. El borde interno de las huellas izquierda y derecha está bien separado de la línea media. Las huellas delanteras 
Tabla 5. Datos de las pistas del material referido de Candeleroichnus canalei nov. gen. nov. sp. Las pistas de esta icnoespecie están graficadas en la Figura 12. Medidas en $\mathrm{cm}$.

\begin{tabular}{|c|c|c|c|c|c|c|c|c|}
\hline \multicolumn{9}{|c|}{ Candeleroichnus canalei nov. gen. nov.sp. } \\
\hline Pista CB-2 & $\begin{array}{c}\text { Paso } \\
\text { oblicuo }\end{array}$ & Paso doble & $\begin{array}{l}\text { Ángulo de } \\
\text { paso }\end{array}$ & Huella & Ancho pista & $\begin{array}{l}\text { Largo } \\
\text { pisada }\end{array}$ & $\begin{array}{l}\text { Paso doble/ } \\
\text { Largo pisada }\end{array}$ & $\begin{array}{c}\text { Largo } \\
\text { pisada/ } \\
\text { Ancho } \\
\text { Pisada }\end{array}$ \\
\hline \multirow[t]{2}{*}{$1 / 2$} & 41 & & & 1 & 3.9 & 9.5 & 8.6 & 2.4 \\
\hline & & 82 & $177^{\circ}$ & & & & & \\
\hline \multirow[t]{2}{*}{$2 / 3$} & 41 & & & 2 & 4.6 & 9.8 & 8.4 & 2.1 \\
\hline & & 84 & $178^{\circ}$ & & & & & \\
\hline \multirow[t]{2}{*}{$3 / 4$} & 43 & & & 3 & 3.2 & 8.7 & 9.6 & 2.7 \\
\hline & & 84.5 & $175^{\circ}$ & & & & & \\
\hline \multirow[t]{3}{*}{$4 / 5$} & 41.5 & & & 4 & 4.3 & 8.5 & 9.9 & 1.9 \\
\hline & & & & 5 & 4.2 & 8.5 & 9.9 & 2 \\
\hline & & & & & & & \multicolumn{2}{|l|}{ Promedio: 9.3} \\
\hline \multicolumn{9}{|l|}{ Pista CB-3 } \\
\hline \multirow[t]{2}{*}{$1 / 2$} & 50 & & & 1 & 5.2 & 11.4 & 8.9 & 2.1 \\
\hline & & 102 & $178^{\circ}$ & & & & & \\
\hline \multirow[t]{2}{*}{$2 / 3$} & 52 & & & 2 & 5 & 11.4 & 8.9 & 2.2 \\
\hline & & 102 & $175^{\circ}$ & & & & & \\
\hline \multirow[t]{2}{*}{$3 / 4$} & 50 & & & 3 & 4.6 & 9.8 & 10.4 & 2.1 \\
\hline & & 103 & $177^{\circ}$ & & & & & \\
\hline \multirow[t]{2}{*}{$4 / 5$} & 53 & & & 4 & 5.5 & 10.2 & 10.3 & 1.8 \\
\hline & & 102 & $186^{\circ}$ & & & & & \\
\hline \multirow[t]{2}{*}{$5 / 6$} & 49 & & & 5 & 4.5 & 10.5 & 9.8 & 2.3 \\
\hline & & 100 & $177^{\circ}$ & & & & & \\
\hline \multirow[t]{3}{*}{$6 / 7$} & 51 & & & 6 & 5.2 & 10.7 & 9.6 & 2 \\
\hline & & & & 7 & 5.2 & 11.5 & 8.7 & 2.2 \\
\hline & & & & & & & Promedio: 9.5 & \\
\hline \multicolumn{9}{|l|}{ Pista CB-4 } \\
\hline \multirow[t]{2}{*}{$1 / 2$} & - & & & 1 & 4.4 & 9.4 & 10.1 & 2.1 \\
\hline & & 95 & & & & & & \\
\hline $2 / 3$ & - & & & 2 & - & - & - & - \\
\hline \multirow[t]{2}{*}{$3 / 4$} & 43 & & & 3 & 5.5 & 10.4 & 9.1 & 1.9 \\
\hline & & 91 & $175^{\circ}$ & & & & & \\
\hline \multirow[t]{2}{*}{$4 / 5$} & 48 & & & 4 & 4.5 & 10 & 9.1 & 2.2 \\
\hline & & 92.5 & $176^{\circ}$ & & & & & \\
\hline \multirow[t]{3}{*}{$5 / 6$} & 44.5 & & & 5 & 5 & 10.8 & 8.6 & 2.1 \\
\hline & & & & 6 & 4.5 & 10 & 9.2 & 2.2 \\
\hline & & & & & & & Promedio: 9.2 & \\
\hline
\end{tabular}


Tabla 5. Datos de las pistas del material referido de Candeleroichnus canalei nov. gen. nov. sp. Las pistas de esta icnoespecie están graficadas en la Figura 12 (continuación). Medidas en cm.

\begin{tabular}{|c|c|c|c|c|c|c|c|c|}
\hline \multicolumn{7}{|c|}{ Candeleroichnus canalei nov. gen. nov.sp. } \\
\hline Pista CB-5 & $\begin{array}{c}\text { Paso } \\
\text { oblicuo }\end{array}$ & Paso doble & $\begin{array}{c}\text { Ángulo de } \\
\text { paso }\end{array}$ & Huella & Ancho pista & $\begin{array}{c}\text { Largo } \\
\text { pisada }\end{array}$ & $\begin{array}{c}\text { Paso doble/ } \\
\text { Largo pisada }\end{array}$ & $\begin{array}{c}\text { Largo } \\
\text { pisada/ } \\
\text { Ancho } \\
\text { Pisada }\end{array}$ \\
\hline $1 / 2$ & 43.5 & & & & & & & \\
\hline
\end{tabular}

Promedio: 9.0

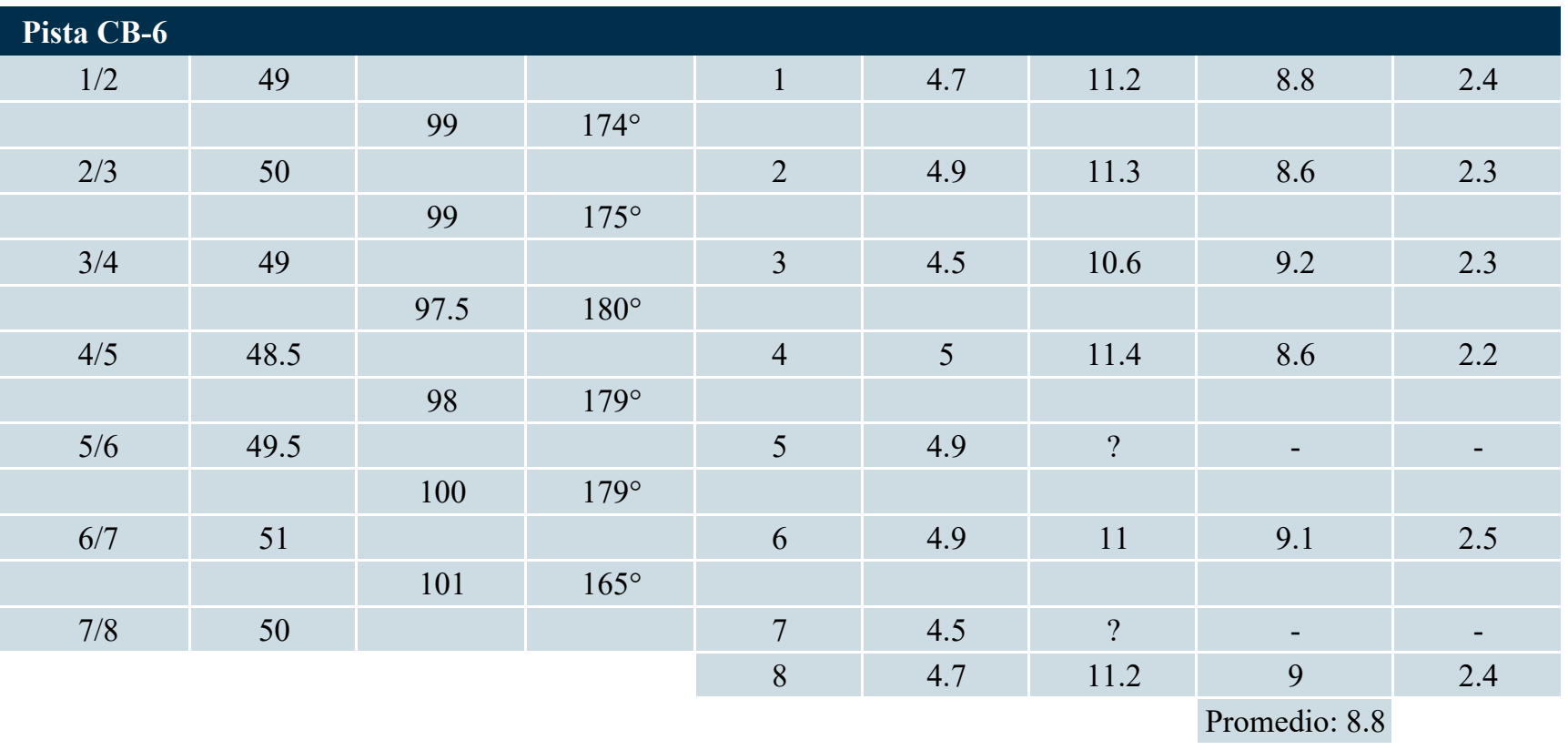




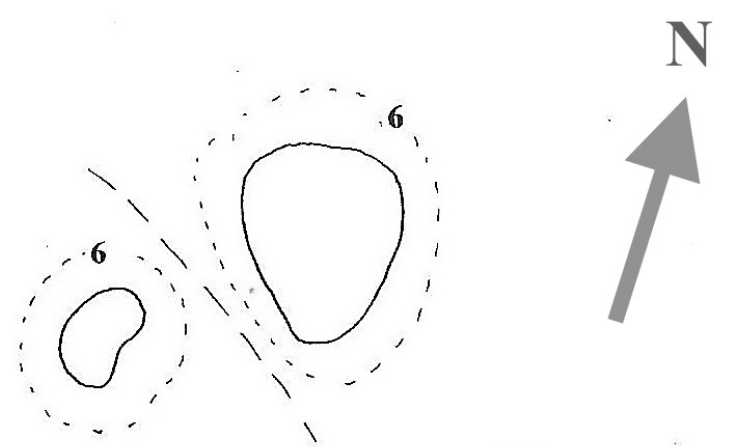

poseen una longitud entre 60 y $100 \mathrm{~cm}$ y son de forma subtriangular cuando están bien preservadas, a circulares, cuando están deterioradas. Las huellas de las manos, de forma arriñonada, convexas hacia adelante, son más anchas $(40 \mathrm{~cm})$ que largas $(25 \mathrm{~cm})$, pero siempre más pequeñas que las de las patas delanteras. Calvo (1999) interpretó que estas huellas fueron dejadas por el saurópodo Andesaurus delgadoi Calvo y Bonaparte, 1991.

Horizonte y localidad. Nivel inferior de la Formación Candeleros (Albiano?- Cenomaniano)Punta de Pescadores, Península Nueva, Picún Leufú, Neuquén.

Ornithopoda Marsh, 1881

Iguanodontidae Cope, 1869

Limayichnus Calvo, 1991

Limayichnus major Calvo, 1991

(figuras 16 y 18; tablas 4, 6, 7 y 8)

Sinonimia. "Bonaparteichnium tali" (Calvo 1991, 1999)

(Figura 17; Tabla 9)

Diagnosis. Huellas de dinosaurios ornitisquios de andar bípedo y con huellas tridáctilas. El ángulo de paso es superior a $150^{\circ}$ y menor a $70^{\circ}$. Las huellas son cortas, simétricas, sin impresión de garras o talón agudo. La separación entre huellas es de $170 \mathrm{~cm}$ para un largo de las mismas de 60 $\mathrm{cm}$. Las impresiones de los dígitos y del talón son redondeadas. Dedos II y IV divergen levemente del dedo III con un ángulo de $25^{\circ}$ o menos. La impresión plantar del dígito III tiene forma oval y está separada de la impresión del talón. Los dígitos II y IV presentan impresiones con forma de U.

Horizonte y localidad. Nivel inferior de la Formación Candeleros (Albiano?-Cenomaniano)Punta de Pescadores, Península Nueva, Picún Leufú, Neuquén.

Sousaichnium Leonardi, 1979 Sousaichnium monettae Calvo, 1991 (Figura 19; Tabla 4) 


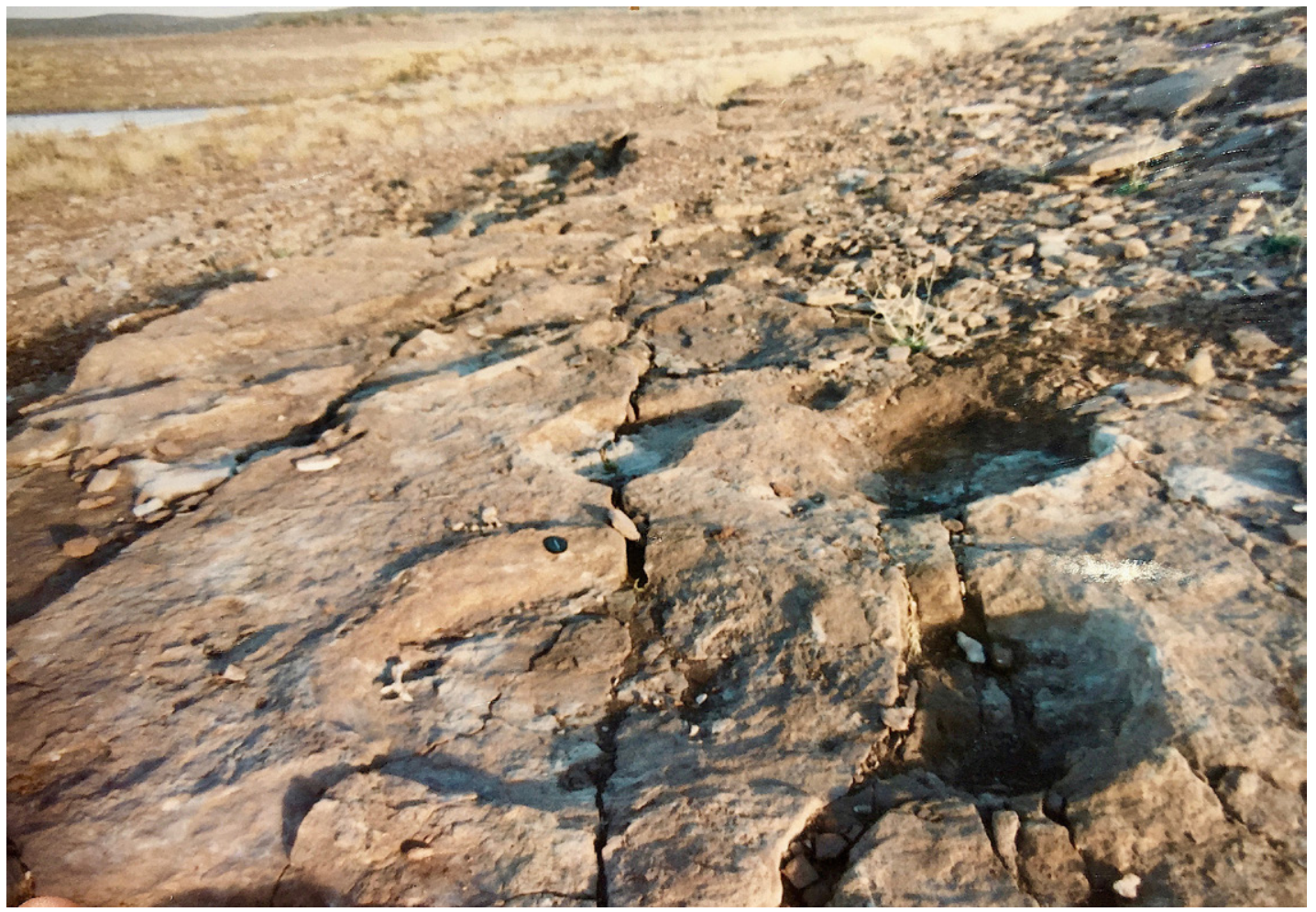

Figura 15 Pista de Sauropodichnus giganteus en sitio Balneario El Chocón. Las huellas tienen 85 cm de diámetro en promedio. Se observan las rebabas del desplazamiento del barro.

Tabla 6. Datos del holotipo de Limayichnus major MUCPv-65. Medidas en cm.

\begin{tabular}{|c|c|c|c|c|c|c|}
\hline \multicolumn{7}{|c|}{ Pista de Limayichnus major -MUCPv-65 } \\
\hline & Paso doble & Paso oblicuo & Ángulo paso & $\begin{array}{c}\text { Ancho } \\
\text { externo }\end{array}$ & $\begin{array}{c}\text { Ancho } \\
\text { interno }\end{array}$ & Ancho paso \\
\hline $1 / 2$ & 338 & 173 & & 72 & -37 & 20 \\
\hline $2 / 3$ & 327 & 166 & $170^{\circ}$ & 74 & -37 & 17 \\
\hline $3 / 4$ & 162 & $165^{\circ}$ & 70 & -42 & 15 \\
\hline $\mathrm{X}$ & 332 & 167 & $167.5^{\circ}$ & 72 & -38.6 & 17.3 \\
\hline $\mathrm{T}$ & 7.8 & 5.2 & $3.5^{\circ}$ & 2 & 2.9 & 2.5 \\
\hline $\mathrm{n}$ & 2 & 3 & 2 & 3 & 3 & 3 \\
\hline
\end{tabular}

\begin{tabular}{|c|c|c|c|c|c|c|c|c|c|c|c|c|c|c|c|}
\hline \multicolumn{16}{|c|}{ Huellas de Limayichnus major - MUCPv-65 } \\
\hline & \multirow{2}{*}{$\begin{array}{l}\text { Ancho } \\
\text { pisada }\end{array}$} & \multirow{2}{*}{$\begin{array}{l}\text { Largo } \\
\text { pisada }\end{array}$} & \multirow{2}{*}{$\begin{array}{l}\text { Paso } \\
\text { doble / } \\
\text { Largo } \\
\text { pisada }\end{array}$} & \multirow{2}{*}{$\begin{array}{c}\text { Ancho } \\
\text { externo/ } \\
\text { Largo } \\
\text { pisada }\end{array}$} & \multirow{2}{*}{$\begin{array}{l}\text { Largo } \\
\text { pisada/ } \\
\text { Ancho } \\
\text { pisada }\end{array}$} & \multirow{2}{*}{$\begin{array}{c}\text { Campo } \\
\text { variación }\end{array}$} & \multicolumn{3}{|c|}{ Largo dedo } & \multicolumn{3}{|c|}{ Ancho dedo } & \multicolumn{3}{|c|}{ Divergencia } \\
\hline & & & & & & & II & III & IV & II & III & IV & II & III & IV \\
\hline 1 & 51 & 61 & 5.5 & 1.4 & 2.1 & -9 & - & - & - & - & - & - & - & - & - \\
\hline 2 & 52 & 61 & 5.5 & 1.5 & 1.9 & -17 & - & 35 & - & 14 & 17 & 14 & $25^{\circ}$ & $25^{\circ}$ & $50^{\circ}$ \\
\hline 3 & 54 & 57 & 5.7 & 1.85 & 2.2 & 5 & - & - & - & 11 & 15 & 11 & $26^{\circ}$ & $24^{\circ}$ & $47^{\circ}$ \\
\hline 4 & 51 & 61 & 5.5 & 1.7 & 2.3 & -7 & - & - & - & 11 & 16 & - & $32^{\circ}$ & $25^{\circ}$ & $55^{\circ}$ \\
\hline $\mathrm{X}$ & 52 & 60 & 5.5 & 1.4 & 1.16 & - & - & - & - & 12 & 15.5 & 12.5 & $27.6^{\circ}$ & $24.6^{\circ}$ & $50.6^{\circ}$ \\
\hline $\mathrm{T}$ & 1.4 & 2 & 0.15 & 0.03 & 0.07 & - & - & - & - & 1.7 & 1.3 & 2.1 & 3.78 & 0.6 & 4.04 \\
\hline $\mathrm{n}$ & 4 & 4 & 4 & 4 & 4 & - & - & - & - & 3 & 3 & 2 & 3 & 3 & 3 \\
\hline
\end{tabular}




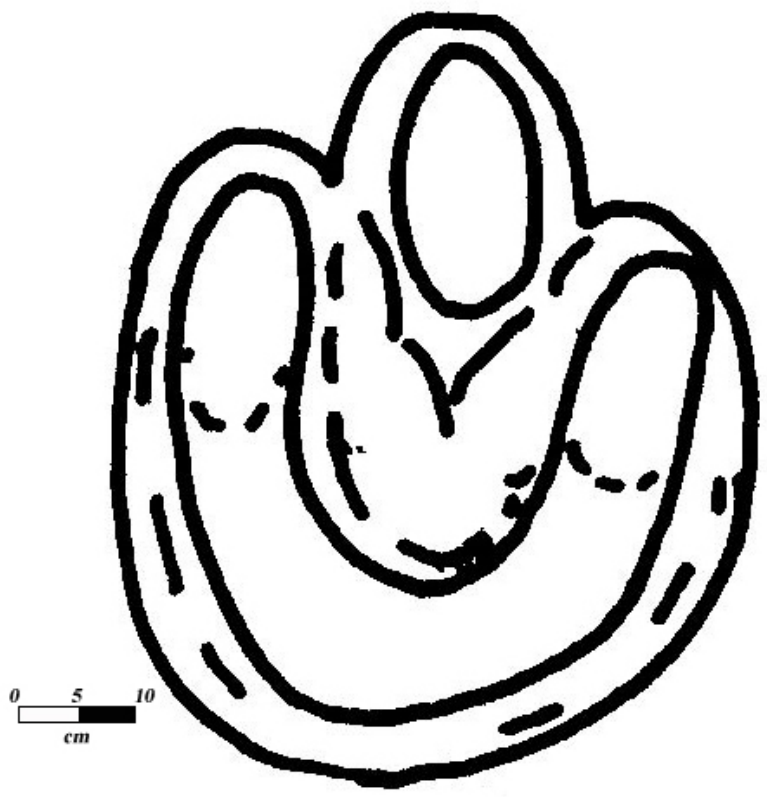

Figura 16 Dibujo del holotipo de Limayichnus major (Calvo, 1991). La huella tiene $65 \mathrm{~cm}$ de largo.

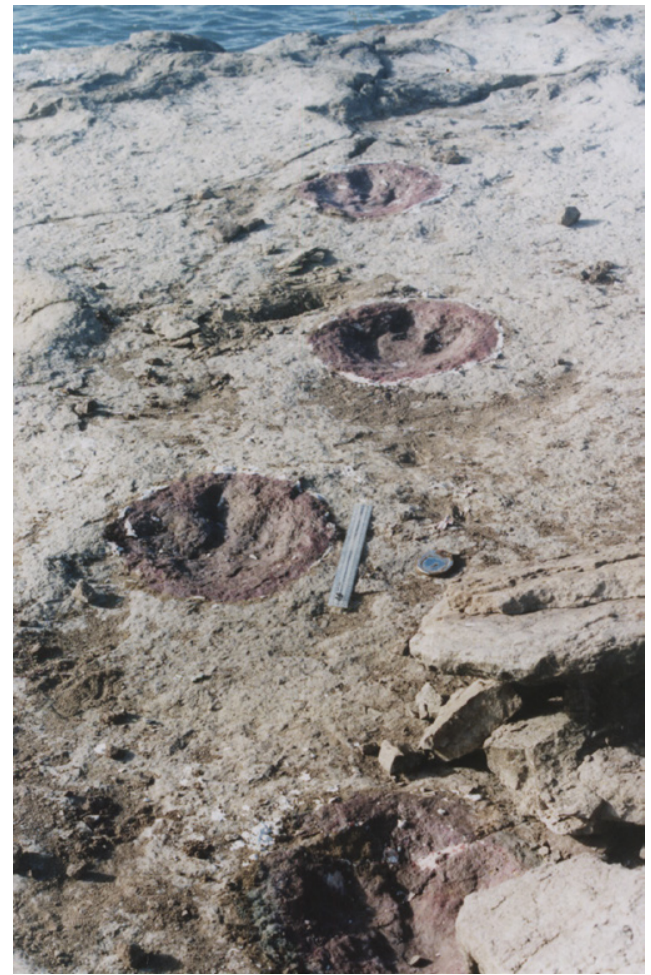

Figura 18 Vista de una de las pistas del holotipo de Limayichnus major (Calvo, 1991) en el sitio Punta de Pescadores (la regla mide $50 \mathrm{~cm})$.

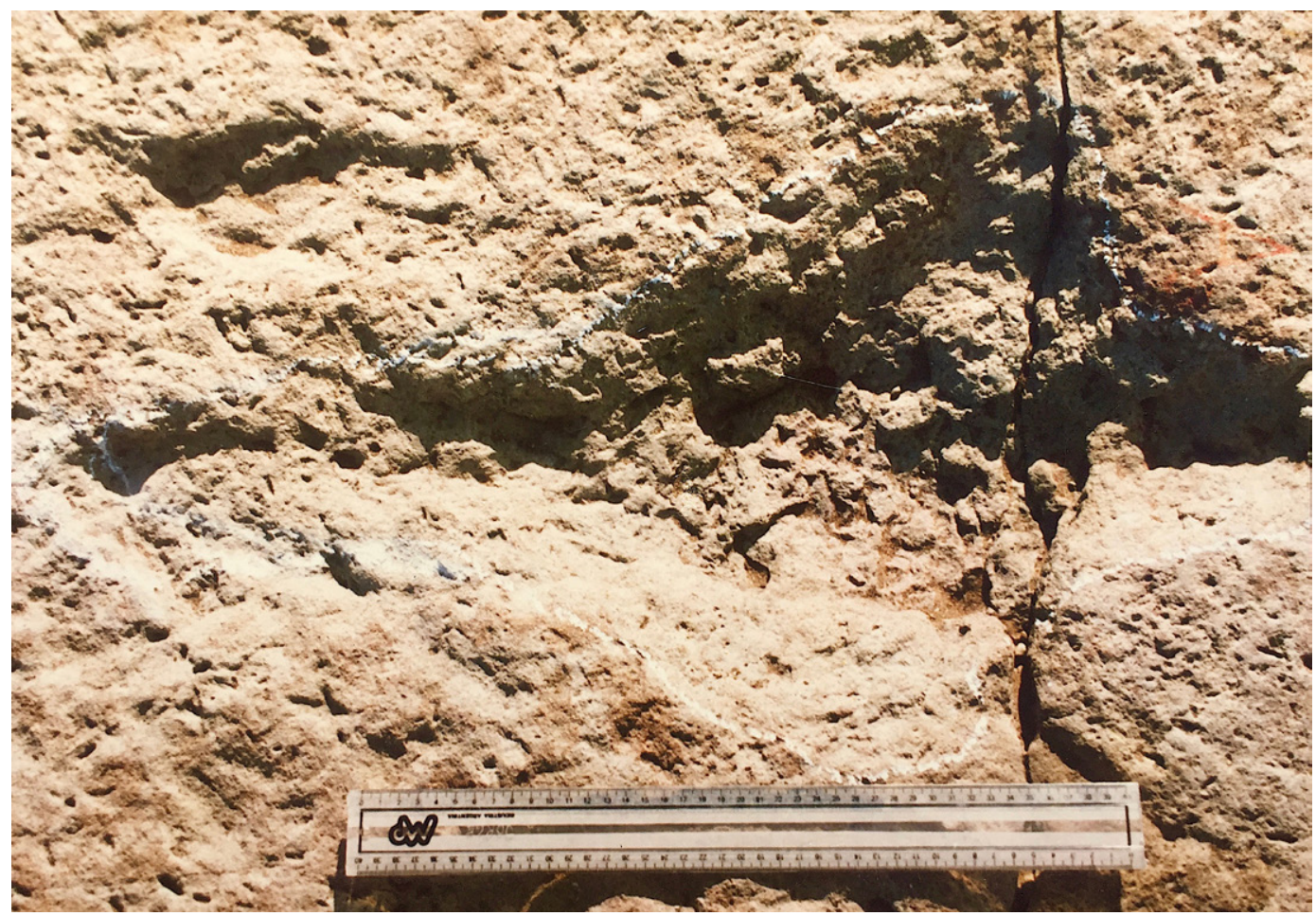

Figura 17 Impresión en roca de la huella de Limayichnus major o "Bonaparteichnium tali” (Calvo, 1991, 1999) en sitio Punta de Pescadores. Observe la impresión del talón en posición de agazapamiento del individuo. 
Tabla 7. Datos del holotipo de Limayichnus major MUCPv-67. Medidas en cm.

\begin{tabular}{|c|c|c|c|c|c|c|}
\hline \multicolumn{7}{|c|}{ Pista de Limayichnus major - MUCPv-67 } \\
\hline & Paso doble & Paso oblicuo & Ángulo paso & $\begin{array}{c}\text { Ancho } \\
\text { externo }\end{array}$ & $\begin{array}{c}\text { Ancho } \\
\text { interno }\end{array}$ & Ancho paso \\
\hline $1 / 2$ & 238 & 125 & $156^{\circ}$ & 68 & -16 & 25 \\
\hline $2 / 3$ & 232 & 120 & $150^{\circ}$ & 77 & -2 & 34 \\
\hline $3 / 4$ & & 125 & & 80 & 0 & 39 \\
\hline $\mathrm{X}$ & 235 & 123 & $153^{\circ}$ & 73 & -6 & 33 \\
\hline $\mathrm{T}$ & 4.2 & 2.9 & 4.2 & 6.2 & 9.9 & 7.1 \\
\hline $\mathrm{n}$ & 2 & 3 & 2 & 3 & 2 & 3 \\
\hline
\end{tabular}

\begin{tabular}{|c|c|c|c|c|c|c|c|c|c|c|c|c|c|c|c|}
\hline \multicolumn{16}{|c|}{ Huellas de Limayichnus major - MUCPv-67 } \\
\hline & \multirow{2}{*}{$\begin{array}{l}\text { Ancho } \\
\text { pisada }\end{array}$} & \multirow{2}{*}{$\begin{array}{l}\text { Largo } \\
\text { pisada }\end{array}$} & \multirow{2}{*}{$\begin{array}{l}\text { Paso } \\
\text { doble / } \\
\text { Largo } \\
\text { pisada }\end{array}$} & \multirow{2}{*}{$\begin{array}{c}\text { Ancho } \\
\text { externo/ } \\
\text { Largo } \\
\text { pisada }\end{array}$} & \multirow{2}{*}{$\begin{array}{c}\text { Largo } \\
\text { pisada/ } \\
\text { Ancho } \\
\text { pisada }\end{array}$} & \multirow{2}{*}{$\begin{array}{c}\text { Campo } \\
\text { variación }\end{array}$} & \multicolumn{3}{|c|}{ Largo dedo } & \multicolumn{3}{|c|}{ Ancho dedo } & \multicolumn{3}{|c|}{ Divergencia } \\
\hline & & & & & & & II & III & IV & II & III & IV & II & III & IV \\
\hline 1 & 35 & 42 & 5.7 & 1.9 & 1.2 & $10^{\circ}$ & 19 & 22 & 19 & 7 & 8 & 8 & $20^{\circ}$ & $18^{\circ}$ & $38^{\circ}$ \\
\hline 2 & 35 & 42 & 5.7 & 2.1 & 1.2 & $-7^{\circ}$ & 12 & 20 & 15 & 7 & 8 & 7 & $23^{\circ}$ & $22^{\circ}$ & $45^{\circ}$ \\
\hline 3 & 35 & 42 & 5.6 & 2.3 & 1.2 & $11^{\circ}$ & - & 20 & - & 8 & - & - & $20^{\circ}$ & $22^{\circ}$ & $42^{\circ}$ \\
\hline 4 & 35 & 42 & 5.5 & 2.3 & 1.2 & $3^{\circ}$ & 15 & 21 & 14 & - & - & - & $20^{\circ}$ & $25^{\circ}$ & $45^{\circ}$ \\
\hline $\mathrm{X}$ & 35 & 42 & 5.6 & 2.1 & 1.2 & - & 15 & 21 & 16 & 7 & 8 & 7.5 & $21^{\circ}$ & $22^{\circ}$ & $42.5^{\circ}$ \\
\hline $\mathrm{T}$ & 0 & 0 & 0.1 & 0.2 & 0 & - & 3.5 & 0.1 & 2.6 & 0.6 & 0 & 0.7 & 1.5 & 2.8 & 3.3 \\
\hline $\mathrm{n}$ & 4 & 4 & 4 & 4 & 4 & - & 3 & 4 & 3 & 3 & 2 & 2 & 4 & 4 & 4 \\
\hline
\end{tabular}

Tabla 8. Datos del holotipo de Limayichnus major MUCPv-73. Medidas en cm.

\begin{tabular}{|c|c|c|c|c|c|c|}
\hline \multicolumn{7}{|c|}{ Pista de Limayichnus major -MUCPv-73 } \\
\hline & Paso doble & Paso oblicuo & Ángulo paso & $\begin{array}{c}\text { Ancho } \\
\text { externo }\end{array}$ & $\begin{array}{c}\text { Ancho } \\
\text { interno }\end{array}$ & Ancho paso \\
\hline $1 / 2$ & - & - & $162^{\circ}$ & - & - & - \\
\hline
\end{tabular}

\begin{tabular}{|c|c|c|c|c|c|c|c|c|c|c|c|c|c|c|c|}
\hline \multicolumn{16}{|c|}{ Huellas de Limayichnus major -MUCPv-73 } \\
\hline & \multirow{2}{*}{$\begin{array}{l}\text { Ancho } \\
\text { pisada }\end{array}$} & \multirow{2}{*}{$\begin{array}{l}\text { Largo } \\
\text { pisada }\end{array}$} & \multirow{2}{*}{$\begin{array}{c}\text { Paso } \\
\text { doble / } \\
\text { Largo } \\
\text { pisada }\end{array}$} & \multirow{2}{*}{$\begin{array}{c}\text { Ancho } \\
\text { externo/ } \\
\text { Largo } \\
\text { pisada }\end{array}$} & \multirow{2}{*}{$\begin{array}{l}\text { Largo } \\
\text { pisada/ } \\
\text { Ancho } \\
\text { pisada }\end{array}$} & \multirow{2}{*}{$\begin{array}{c}\text { Campo } \\
\text { variación }\end{array}$} & \multicolumn{3}{|c|}{ Largo dedo } & \multicolumn{3}{|c|}{ Ancho dedo } & \multicolumn{3}{|c|}{ Divergencia } \\
\hline & & & & & & & II & III & IV & II & III & IV & II & III & IV \\
\hline 1 & 50 & 59 & - & - & 1.2 & - & - & - & - & - & 14 & - & $24^{\circ}$ & $20^{\circ}$ & $45^{\circ}$ \\
\hline 2 & 51 & 51 & - & - & 1 & - & 25 & 38 & 25 & 11 & 14 & 11 & $26^{\circ}$ & $22^{\circ}$ & $47^{\circ}$ \\
\hline $\mathrm{X}$ & 50.5 & 5.5 & - & - & 1.1 & - & - & - & - & - & 14 & - & $24.5^{\circ}$ & $21^{\circ}$ & $46^{\circ}$ \\
\hline $\mathrm{T}$ & 0.7 & 5.6 & - & - & 0.14 & - & & - & & & 0 & - & 0.7 & 1.41 & 1.41 \\
\hline $\mathrm{n}$ & 2 & 2 & - & - & 2 & - & & - & & & 2 & - & 2 & 2 & 2 \\
\hline
\end{tabular}

Diagnosis. Esta icnita ha sido referida genéricamente al icnogénero Sousaichnium de Brasil (Leonardi, 1979). Es una huella tridáctila con el dígito central un poco más largo que los laterales. El dígito IV más largo que el II. La separación entre los dígitos II y III es mayor que entre los dígitos II y IV. Tanto el dígito III como el talón están dirigidos internamente. El dígito III muestra bordes paralelos y el hypex de forma subangular, lo que lo diferencia de S. pricei (Leonardi, 1979).

Horizonte y localidad. Nivel inferior de la Formación Candeleros (Albiano?-Cenomaniano)Punta de Pescadores, Península Nueva, Picún Leufú, Neuquén. 
Tabla 9. Datos del holotipo de Limayichnus major (Calvo, 1991) MUCPv-64. Medidas en cm.

\begin{tabular}{|c|c|c|c|c|c|c|}
\hline \multicolumn{7}{|c|}{ Pista de Limayichnus major “Bonaparteichnium tali” } \\
\hline & Paso doble & Paso oblicuo & Ángulo paso & $\begin{array}{c}\text { Ancho } \\
\text { externo }\end{array}$ & $\begin{array}{c}\text { Ancho } \\
\text { interno }\end{array}$ & Ancho paso \\
\hline $1 / 2$ & 258 & 134 & & 40 & -25 & 6 \\
\hline $2 / 3$ & 251 & 125 & $174^{\circ}$ & 50 & -22 & 14 \\
\hline $3 / 4$ & 260 & 128 & $170^{\circ}$ & 50 & -20 & 15 \\
\hline $4 / 5$ & & 133 & $171^{\circ}$ & 40 & -20 & 8 \\
\hline $\mathrm{X}$ & 256.3 & 130 & $170.3^{\circ}$ & 45 & -21.75 & 10.75 \\
\hline $\mathrm{T}$ & 4.7 & 4.2 & 0.6 & 5.8 & 2.3 & 4.4 \\
\hline $\mathrm{n}$ & 3 & 4 & 3 & 4 & 4 & 4 \\
\hline
\end{tabular}

\begin{tabular}{|c|c|c|c|c|c|c|c|c|c|c|c|c|c|c|c|c|c|}
\hline \multicolumn{18}{|c|}{ Huellas de Limayichnus major "Bonaparteichnium tali" MUCPv-64 } \\
\hline & \multirow{2}{*}{$\begin{array}{l}\text { Ancho } \\
\text { pisada }\end{array}$} & \multirow{2}{*}{$\begin{array}{l}\text { Largo } \\
\text { pisada }\end{array}$} & \multirow{2}{*}{$\begin{array}{c}\text { Paso } \\
\text { doble/ } \\
\text { Largo } \\
\text { pisada }\end{array}$} & \multirow{2}{*}{$\begin{array}{c}\text { Ancho } \\
\text { externo/ } \\
\text { Largo } \\
\text { pisada }\end{array}$} & \multirow{2}{*}{$\begin{array}{c}\text { Largo } \\
\text { pisada/ } \\
\text { Ancho } \\
\text { pisada }\end{array}$} & \multirow{2}{*}{$\begin{array}{c}\text { Campo } \\
\text { variación }\end{array}$} & \multicolumn{3}{|c|}{ Largo dedo } & \multicolumn{3}{|c|}{ Ancho dedo } & \multicolumn{3}{|c|}{ Divergencia } & \multirow{2}{*}{$\begin{array}{c}\text { Largo } \\
\text { talón }\end{array}$} & \multirow{2}{*}{$\begin{array}{c}\text { Ancho } \\
\text { talón }\end{array}$} \\
\hline & & & & & & & II & III & IV & II & III & IV & II & III & IV & & \\
\hline 1 & 28 & 59 & 4.4 & 1.4 & 2.1 & $0^{\circ}$ & 9 & 15 & 10 & 7 & 8 & 7 & $22^{\circ}$ & $32^{\circ}$ & $54^{\circ}$ & 24 & 8.5 \\
\hline 2 & 30 & 58 & 4.4 & 1.5 & 1.9 & $2^{\circ}$ & - & 19 & 12 & - & 7 & 8 & $38^{\circ}$ & $32^{\circ}$ & $70^{\circ}$ & 25 & 10 \\
\hline 3 & 27 & 59 & 4.25 & 1.85 & 2.2 & $1^{\circ}$ & - & 19 & 13 & - & - & - & $37^{\circ}$ & $33^{\circ}$ & $70^{\circ}$ & 27 & 9 \\
\hline 4 & 26 & 59 & 4.4 & 1.7 & 2.3 & $5^{\circ}$ & - & - & - & - & 7 & - & $28^{\circ}$ & $13^{\circ}$ & - & 26 & 10 \\
\hline 5 & 27 & 58 & 4.5 & 1.4 & 2.1 & $-4^{\circ}$ & - & 15 & - & - & 7 & - & $39^{\circ}$ & $29^{\circ}$ & $68^{\circ}$ & 26 & 10 \\
\hline $\mathrm{X}$ & 27.6 & 58.6 & 4.4 & 1.6 & 2.1 & & 9 & 17 & 11.6 & 7 & 7.25 & 7.5 & $32.8^{\circ}$ & $27.8^{\circ}$ & $65.6^{\circ}$ & 25.6 & 9.5 \\
\hline $\mathrm{T}$ & 1.5 & 0.5 & 0.1 & 0.2 & 0.1 & & 0 & 2.3 & 1.5 & 0 & 0.5 & 0.7 & 7.4 & 8.4 & 7.7 & 1.1 & 0.7 \\
\hline $\mathrm{n}$ & 5 & 5 & 5 & 5 & 5 & & 1 & 4 & 3 & 1 & 4 & 2 & 5 & 5 & 4 & 5 & 5 \\
\hline
\end{tabular}

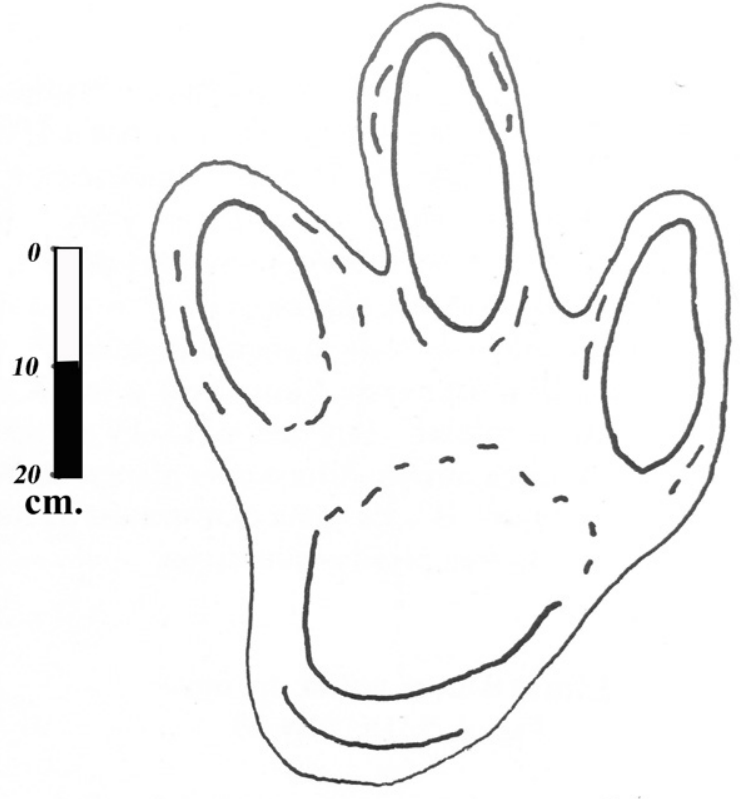

Figura 19 Dibujo del holotipo de Sousaichnium monettae (tomado de Calvo, 1991).

\section{Los yacimientos icnológicos}

\subsection{EL YAGIMIENTO PUNTA DE PESGADORES}

Punta de Pescadores es el sitio paleontológico más importante de la costa del embalse Ezequiel Ramos Mexía debido a que allí fueron descritas todas las icnoespecies conocidas (Calvo, 1991). El mismo se encuentra a $15 \mathrm{~km}$ al sureste de la ciudad de Picún Leufú, sobre la costa norte de la Península Nueva (Figura 1). Las icnitas se encuentran distribuidas en 5 niveles en un paquete sedimentario de $4 \mathrm{~m}$ de potencia que corresponde a parte de la sección inferior de la Formación Candeleros (Figura 20). La roca se compone de una alternancia de areniscas finas y medianas intercaladas con areniscas arcillosas o arcilitas. Las descripciones sistemáticas ya fueron mencionadas en las icnoespecies por lo 
que no describiremos las mismas y remitimos al lector al trabajo original (Calvo, 1991). Las icnoespecies reconocidas son:

\section{Sauropoda:}

Sauropodichnus giganteus. Holotipo in situ. Registro fotográfico MUCPv 145 y 146. Se identificaron dos pistas con 15 huellas en total.

\section{Theropoda:}

Deferrariischnium mapuchensis. Plastotipo, MUCPv-6; plastohipodigma, MUCPv-63. Especímenes referidos. MUCPv-66. Se identificaron tres pistas con 15 huellas en total.

Abelichnus astigarrae. Plastotipo, MUCPv-74; plastohipodigma, MUCPv-148. Se identificaron dos pistas con nueve huellas en total.

Picunichnus benedettoi. Holotipo, MUCPv-72. Se identificó una huella (Figura 8; Tabla 11).

Bressanichnus patagonicus. Plastotipo, MUCPv-60 (Figura 5), plastohipodigma, MUCPV-61.

Ejemplares referidos. MUCPv-68 y 69. Se identificaron cuatro pistas con 40 huellas en total.

\section{Iguanodontia:}

Limayichnus major. Plastotipo, MUCPv-65; plastohipodigma, MUCPv-64 y 67 (Figura 18), 70 y 73. Se identificaron seis pistas con 17 huellas en total.

Sousaichnium monettae. Plastotipo, MUCPv71. Una huella izquierda en molde e in situ. Como se describió en el trabajo original (Calvo, 1991), las pistas de dinosaurios se hallaron en 5 niveles diferentes (Figura 20). La coexistencia de dinosaurios ornitópodos, saurópodos y terópodos en un mismo nivel se repite en los distintos estratos que conservan las huellas. Recientes trabajos de campo realizados durante el 2016 y 2017, tanto en la costa norte como en la costa este de la Punta de Pescadores, han dado como resultado el hallazgo de nuevos materiales icnológicos con huellas in situ y moldes naturales. Seguidamente describimos los nuevos registros que se asignaron a las formas conocidas hasta la fecha. Durante el 2016 y 2017 se realizaron viajes de campo a la Península Nueva y se revisaron colecciones antiguas depositadas en el Museo de Geología y Paleontología de la Universidad Nacional del Comahue. Los estudios de campo permitieron hallar nuevos materiales y realizar una columna estratigráfica nueva (Figura 21). Un estudio preliminar permitió identificar, en el sector este de la península, nuevos materiales que permitieron interpretar los paleoambientes como sistemas meandrosos de baja energía que desembocaban en lagunas someras (Rivera y Calvo, 2016).

\section{Sauropodichnus giganteus}

Se han preservado huellas aisladas y en algunos casos pares de huellas de saurópodos de diferentes tamaños. La plataforma donde se encuentran es de apenas $3 \mathrm{~m}$ de ancho, por lo cual no es posible proseguir una pista. No se posee molde por el estado de preservación de las mismas y por ello se adjuntan las fotos solamente. Las huellas de Sauropodichnus corresponden a patas traseras no muy bien preservadas de $80 \mathrm{~cm}$ diámetro y delanteras de $50 \mathrm{~cm}$ de diámetro (figuras 22C y 23). Otros ejemplares con patas delanteras aisladas de forma arriñonada de $70 \mathrm{~cm}$ de ancho y $38 \mathrm{~cm}$ de largo (Figura 24).

\section{Deferrariischnium mapuchensis}

MUCPv-857: molde en roca no muy bien preservado producido por un dinosaurio bípedo de talla pequeña, huellas tridáctilas (Figura 25; Tabla 11). Sus dimensiones alcanzan un ancho de $12 \mathrm{~cm}$ y un largo de $14 \mathrm{~cm}$. La impronta del talón es pequeña y subredondeada. El dedo III es más largo que los laterales. La impresión de las garras es notable.

MUCPv-1482: molde natural de huella de dinosaurio bípedo, tridáctilo y de talla pequeña (Figura 26; Tabla 11). La misma posee un ancho de 17 cm y un largo de $22 \mathrm{~cm}$. El dedo III es más largo y robusto que sus laterales. La impronta del talón es subaguda.

\section{Abelichnus astigarrae}

De este icnogénero se halló una pista in situ y varias huellas aisladas en roca que se pudieron recolectar. La pista presenta tres huellas bien 

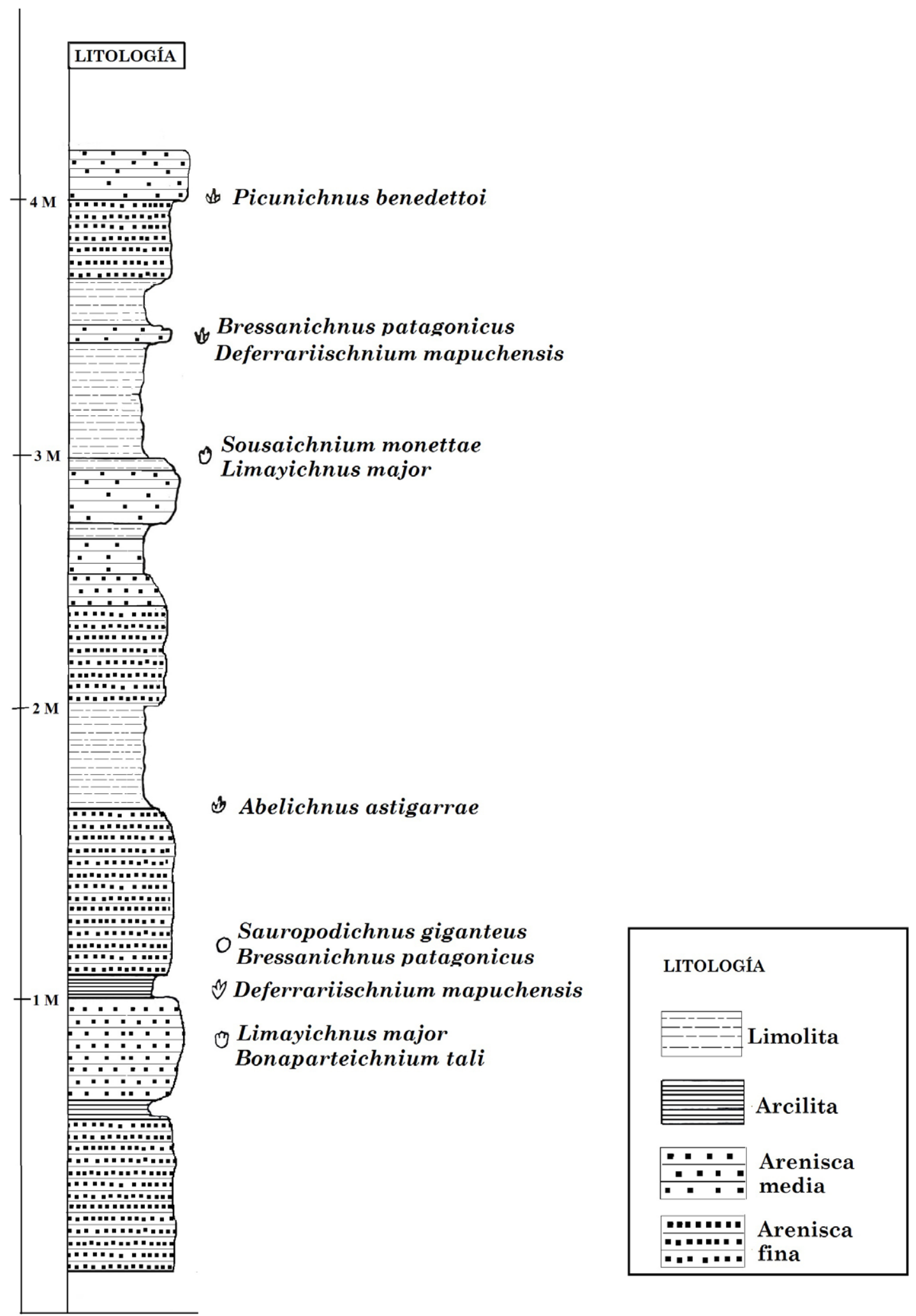

Figura 20 Columna estratigráfica de parte de la base de la Formación Candeleros en la Punta de Pescadores con la ubicación de los holotipos descritos por Calvo (1991) (modificado de Calvo, 1991). 


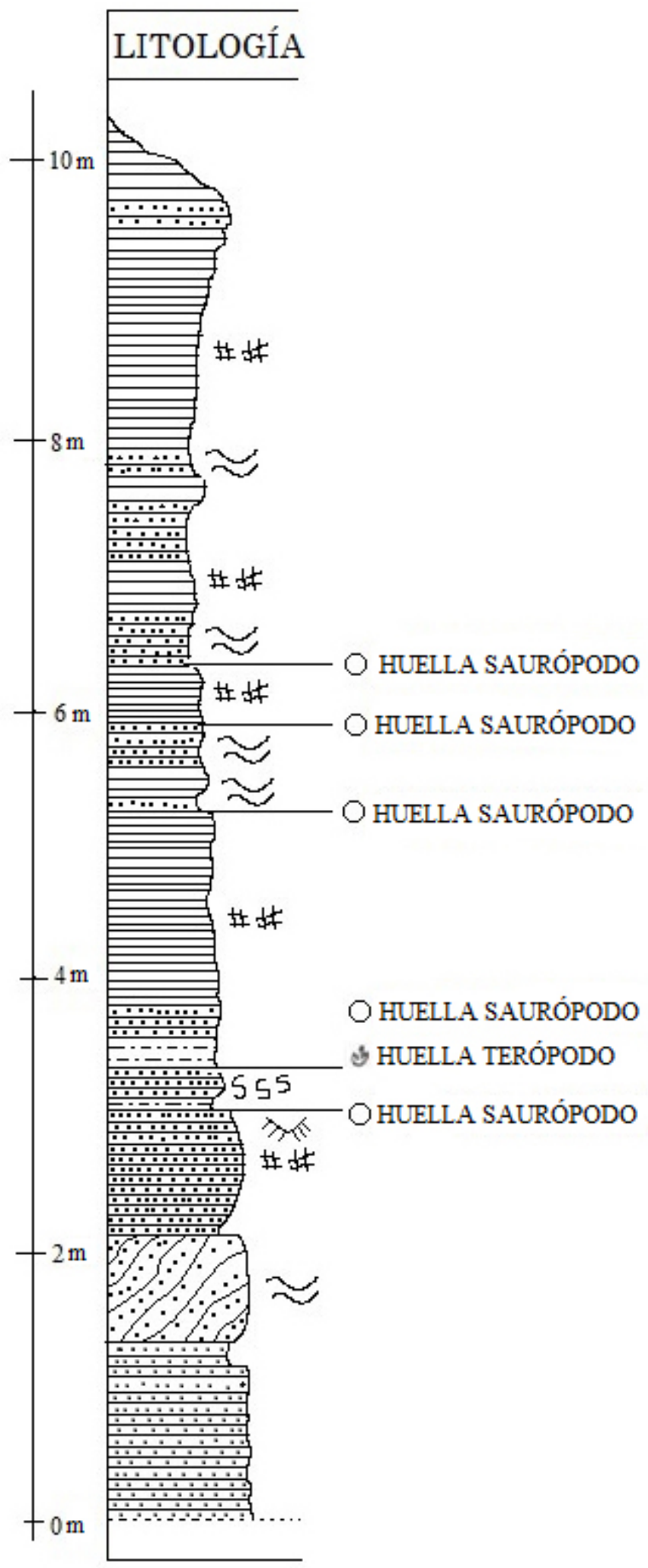

ESTRUCTURAS:

ZIAMINACIÓN ONDULITICA

555 BIOTURBACIONES

$\curvearrowright$ GRIETAS DE DESECACIÓN

柆 ESPEJOS DE FRICCIÓN

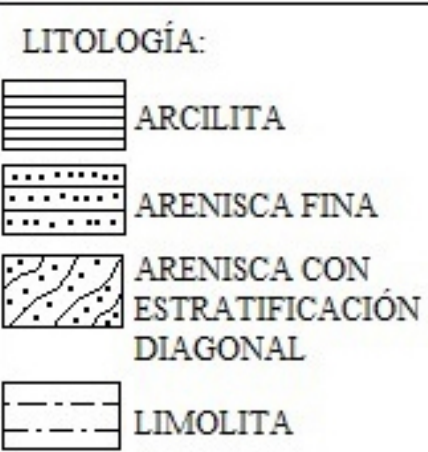

Figura 21 Columna estratigráfica del sector este de la Punta de Pescadores (donde se ubicaron las nuevas icnitas). 


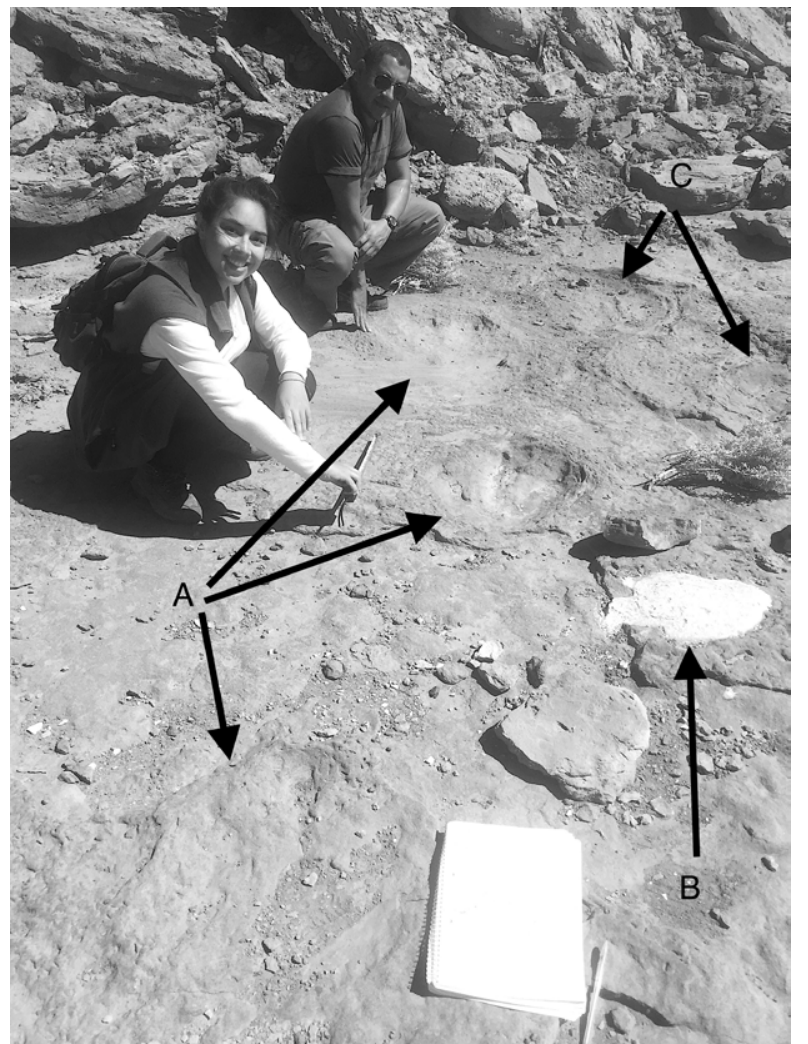

Figura 22 Vista de las icnitas del sector este de Punta de Pescadores. (A) Huellas de Limayichnus major, (B) Huella con calco de Abelichnus astigarrae y (C) Huella de Sauropodichnus giganteus. preservadas (Figura 27). El ángulo de paso es de $150^{\circ}$ y la longitud de paso de $114 \mathrm{~cm}$ (Figura 23). Las icnitas tienen un largo de $33 \mathrm{~cm}$ y un ancho de $31 \mathrm{~cm}$ aproximadamente (Figura 28). Dedos largos y gruesos con almohadillas. El dedo III más desarrollado que los laterales. Presencia de garra en los dedos, más profunda en el III y desplazada hacia el interior. Dedo IV más largo que el II con garra desplazada hacia afuera (Figura 28). La divergencia de los dedos es de aproximadamente $38^{\circ}$. La palma tiene un borde subredondeado y superficie reducida.

MUCPv-972 (Figura 29): huella producida por un dinosaurio bípedo tridáctilo de talla mediana. Tiene una longitud de $38 \mathrm{~cm}$ y una anchura de 28.5 $\mathrm{cm}$. El dedo III es más largo que sus laterales. La impronta del talón es pequeña y subredondeada. MUCPv-1088: huella producida por un dinosaurio bípedo tridáctilo de mediano tamaño. Sus dimensiones alcanzan un largo de $22 \mathrm{~cm}$ y el ancho no se puede deducir por su mal preservación. La impronta del talón es grande y subredondeada. El dedo III es más largo que sus laterales.

MUCPv-1096 (Figura 30; Tabla 11): huella producida por un dinosaurio bípedo de talla mediana.

$\uparrow_{\text {s }}$

Abelichnus astigarrae
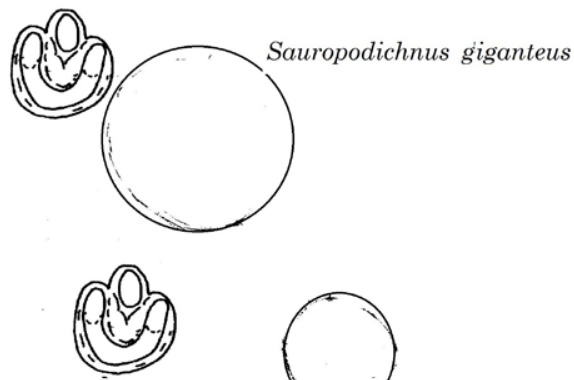

Cra
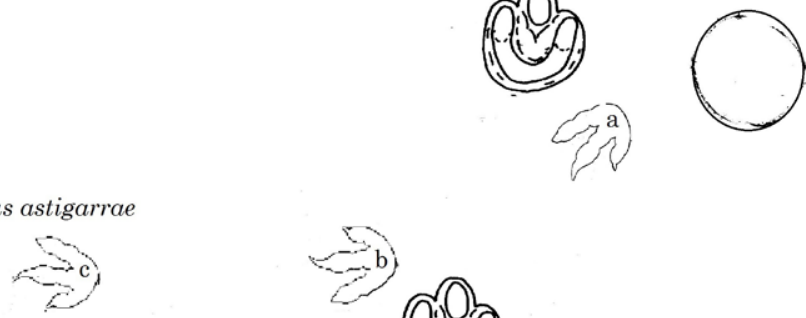

Limayichnus major

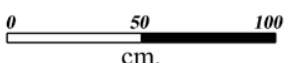

Figura 23 Vista en planta de la Figura 22 con las icnitas halladas en el sector este de Punta de Pescadores. Las letras identifican a las distintas huellas de la pista. 


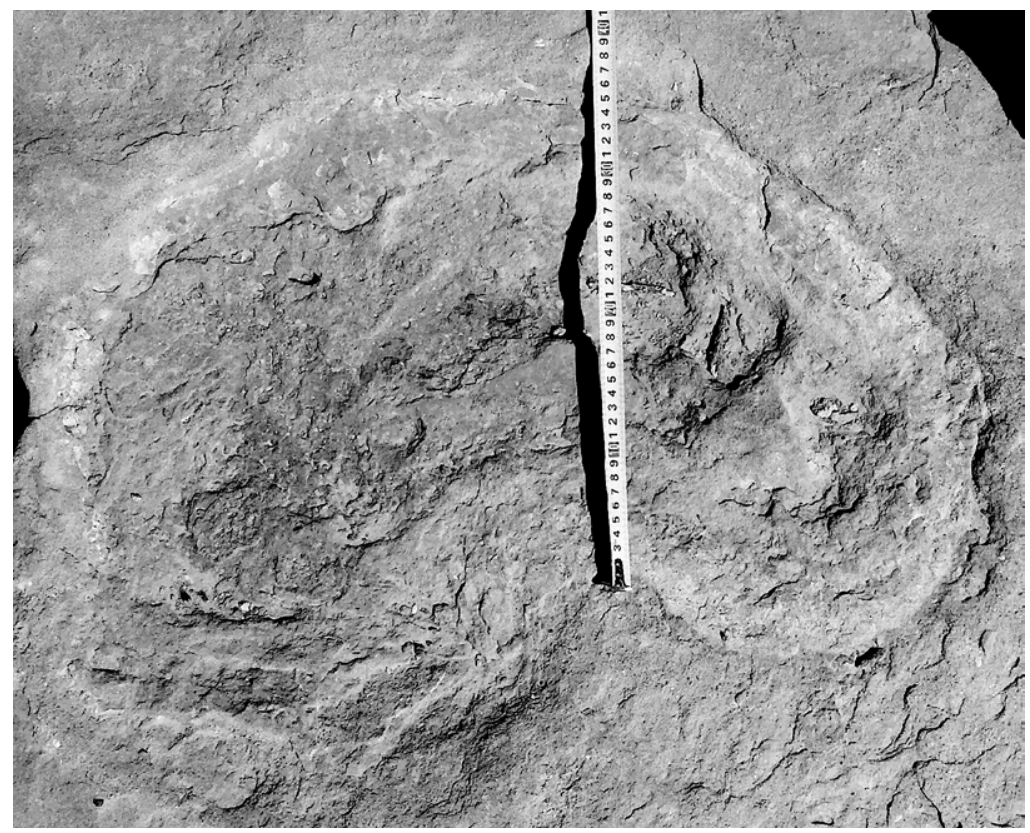

Figura 24 Huella de la pata delantera de Sauropodichnus giganteus, en la costa este de Punta de Pescadores. Observe la forma arriñonada típica de la icnoespecie.
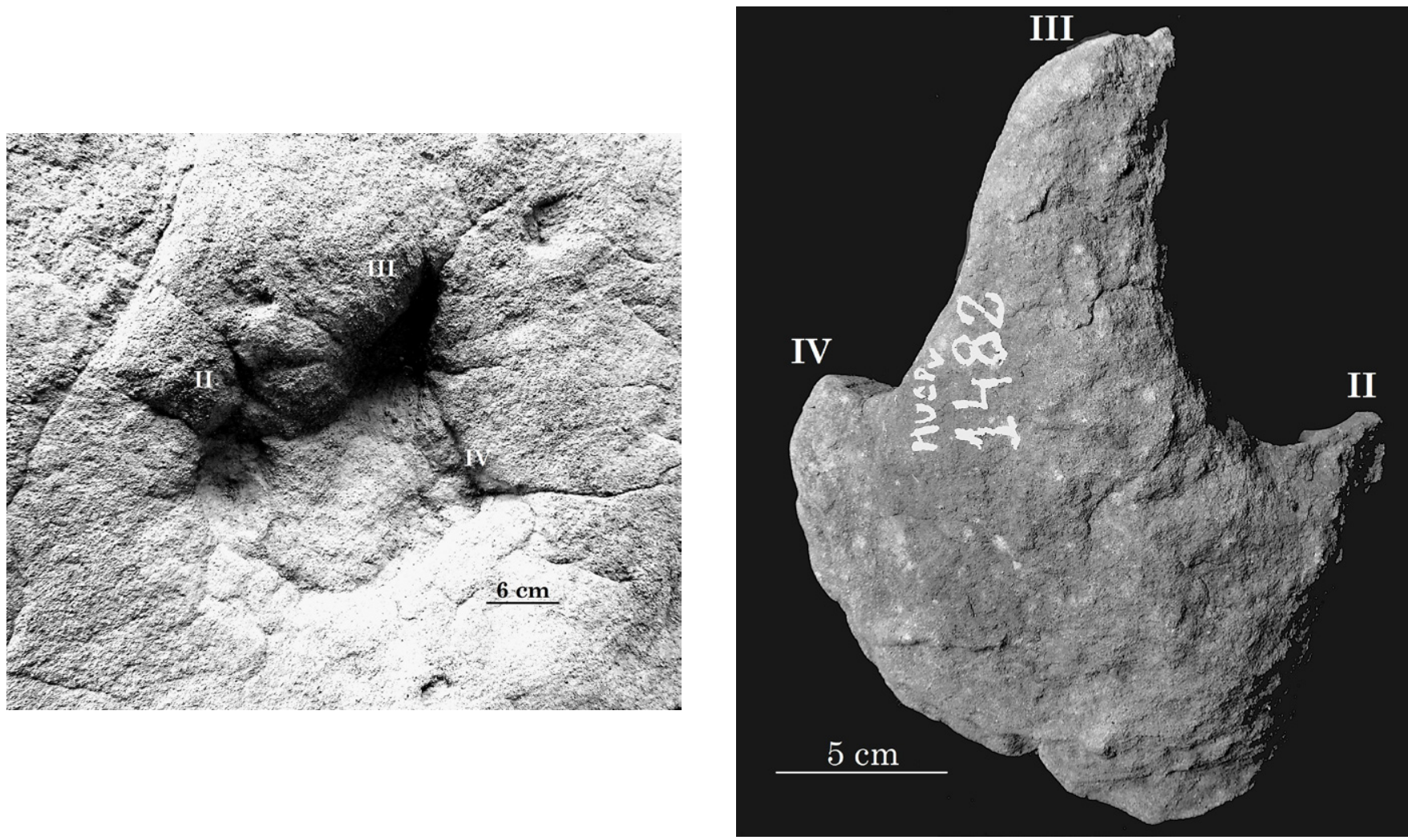

Figura 25 MUCPv-857, molde en roca de Deferrariischnium mapuchensis en Punta de Pescadores. II, III, IV indican nombre de los dígitos.
Figura 26 MUCPv-1482, molde natural de Deferrariischnium mapuchensis en Punta de Pescadores. II, III, IV indican nombre de los dígitos. 


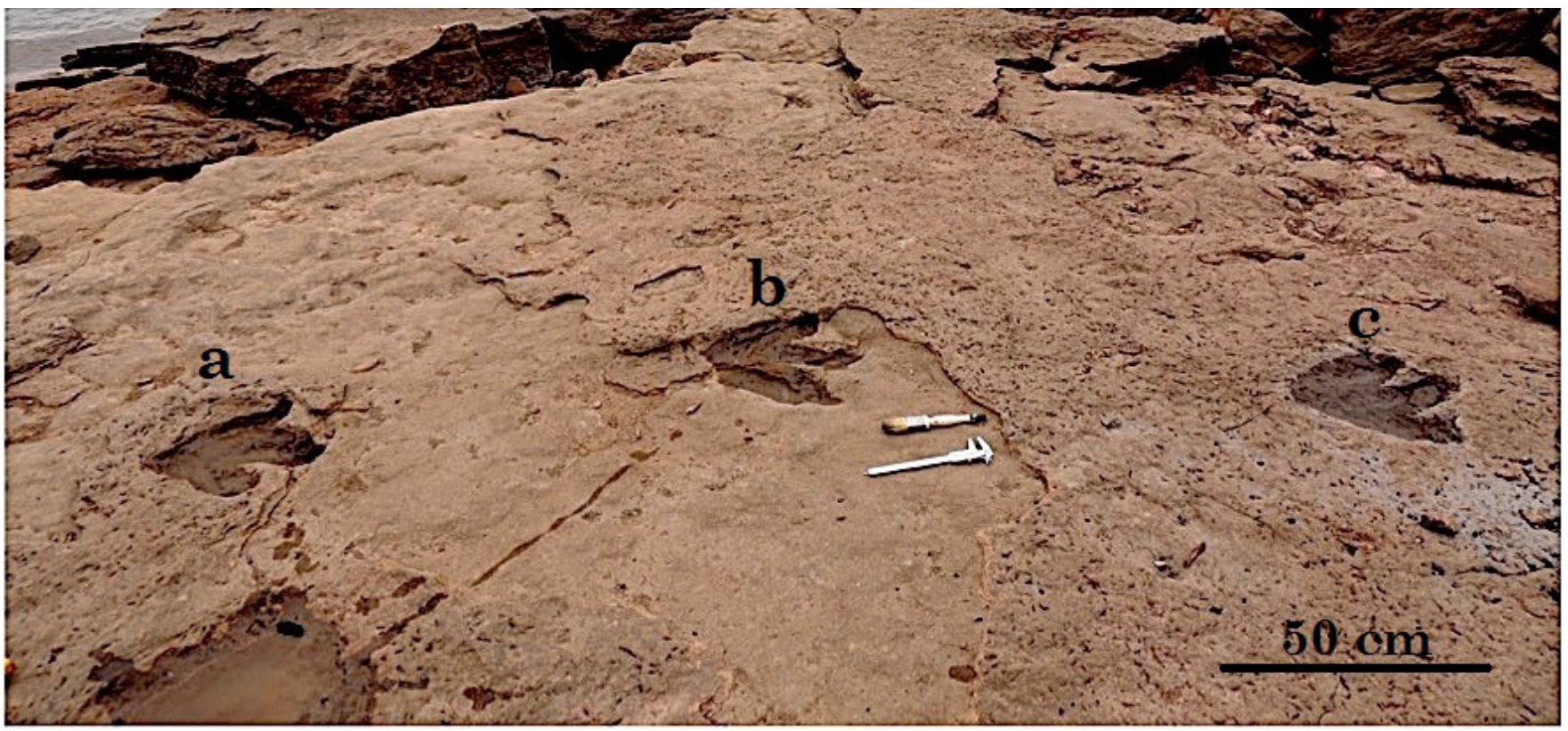

Figura 27 Vista de la pista de Abelichnus astigarrae del sector este de Punta de Pescadores (en Figura 23 el dibujo de la misma). Las letras identifican las huellas como se observa en la Figura 23.

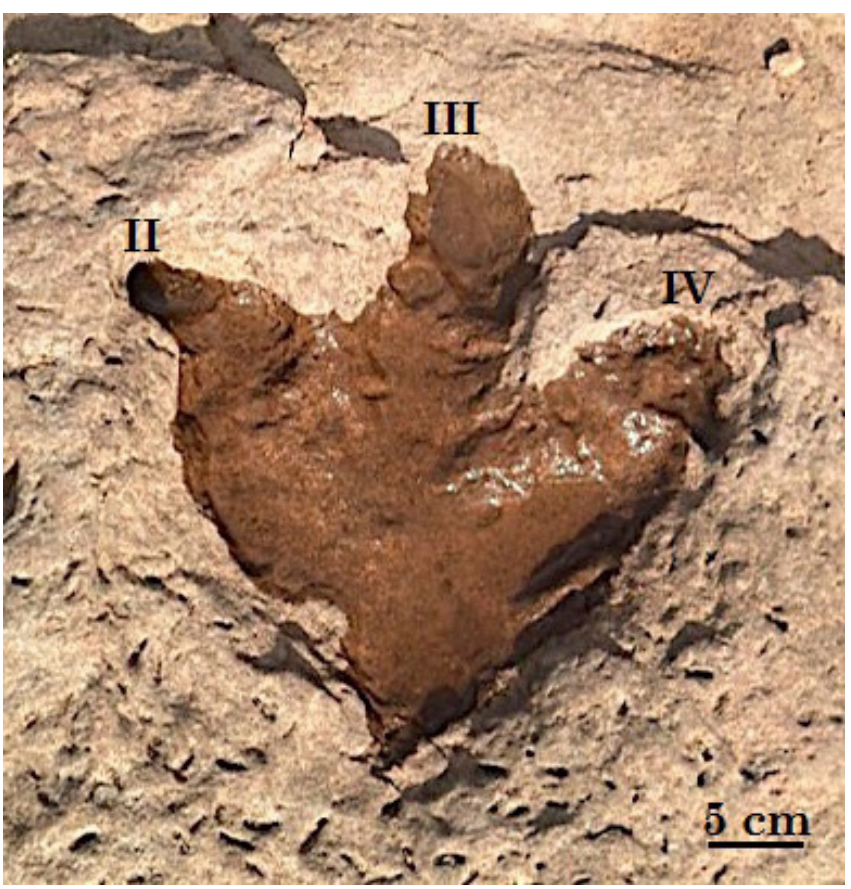

Figura 28 Vista de la huella de Abelichnus astigarrae del sector este de Punta de Pescadores (en Figura 23 el dibujo de la misma). II, III, IV indican nombre de los dígitos.

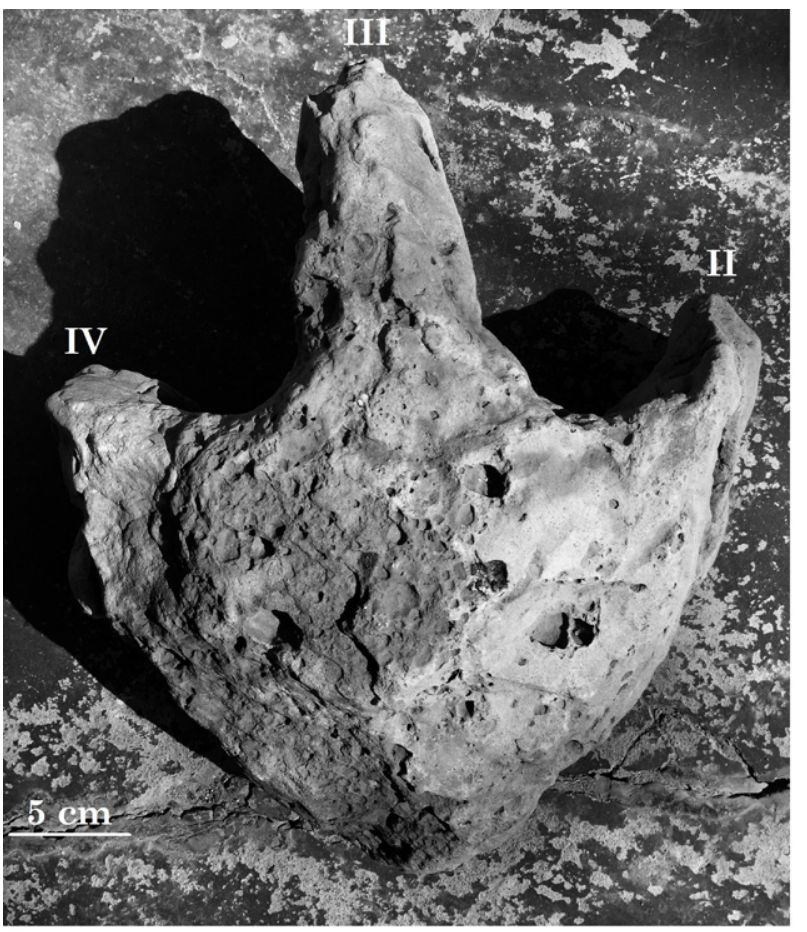

Figura 29 MUCPv-972, calco en roca de Abelichnus astigarrae hallado en Punta de Pescadores. II, III, IV indican nombre de los dígitos. 
Tiene una longitud de $26 \mathrm{~cm}$ y una anchura de $29 \mathrm{~cm}$. Son tridáctilas con presencia de marca de garras en los extremos de los dedos. La impronta del talón es de contorno subredondeado.

MUCPv-874: huella tridáctila de gran tamaño de $27 \mathrm{~cm}$ de largo y $26 \mathrm{~cm}$ de ancho (Figura 31; Tabla 11). Si bien se encuentra mal preservada, se observa la silueta de los dedos II y III, el dedo IV faltante. El ángulo interdigital es $45^{\circ}$. Se puede observar la impresión de garra en los extremos de los dedos. La impronta del talón es subredondeada.

\section{Picunichnus benedettoi}

MUCPv-75: se trata de dos huellas paralelas que indican el descanso de un dinosaurio terópodo tridáctilo (Figura 32; Tabla 11). Las huellas tienen $20 \mathrm{~cm}$ de longitud y $10 \mathrm{~cm}$ de ancho en promedio. Se puede apreciar que el $80 \%$ de su longitud es ocupado por los dedos, de los cuales el III es el más largo y robusto que los laterales. La impronta del talón es pequeña. El dedo IV es más pequeño que el II con una leve impresión de garra.

MUCPv-313: producida por un dinosaurio bípedo tridáctilo de talla pequeña (Figura 33; Tabla 11). La misma está representada por una longitud de $20 \mathrm{~cm}$ y $10.5 \mathrm{~cm}$ de anchura. El largo está representado, en su mayoría, por el dedo III que a su vez es más largo y robusto que sus laterales. El dedo II muestra las falanges gruesas y cortas y su impresión de garra, el dedo III presenta las tres falanges con poca impresión de la garra, mientras que el dedo IV no permite diferenciar las falanges. La impronta del talón es pequeña.

MUCPv-840: huella impresa en roca que pertenece a un dinosaurio bípedo tridáctilo de pequeño tamaño (Figura 34; Tabla 11). Icnita de $11 \mathrm{~cm}$ de ancho y $20 \mathrm{~cm}$ de largo. El dedo III es más largo que los laterales. Presenta impresión de garras e impresiones falangeales. La impronta del talón es pequeña y subredondeada.

\section{Bressanichnus patagonicus}

MUCPv-841: molde de huella impresa en roca bien preservada producida por un dinosaurio bípedo tridáctilo de talla pequeña (Figura 35; Tabla

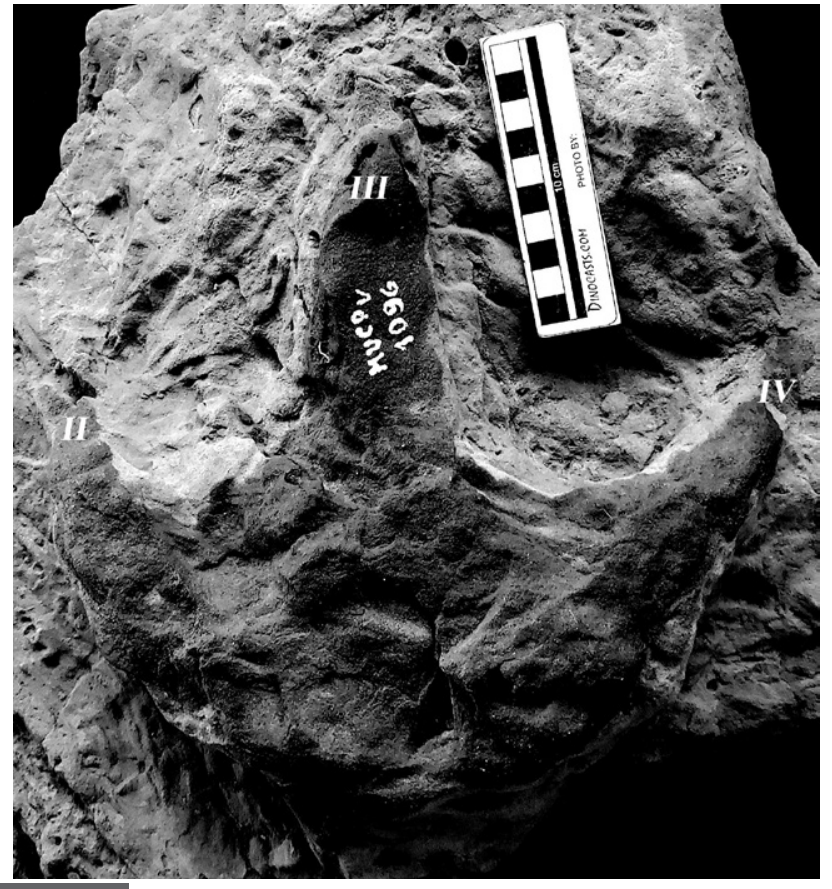

Figura 30 MUCPv-1096, calco en roca de Abelichnus astigarrae hallado en Punta de Pescadores. II, III, IV indican nombre de los dígitos.

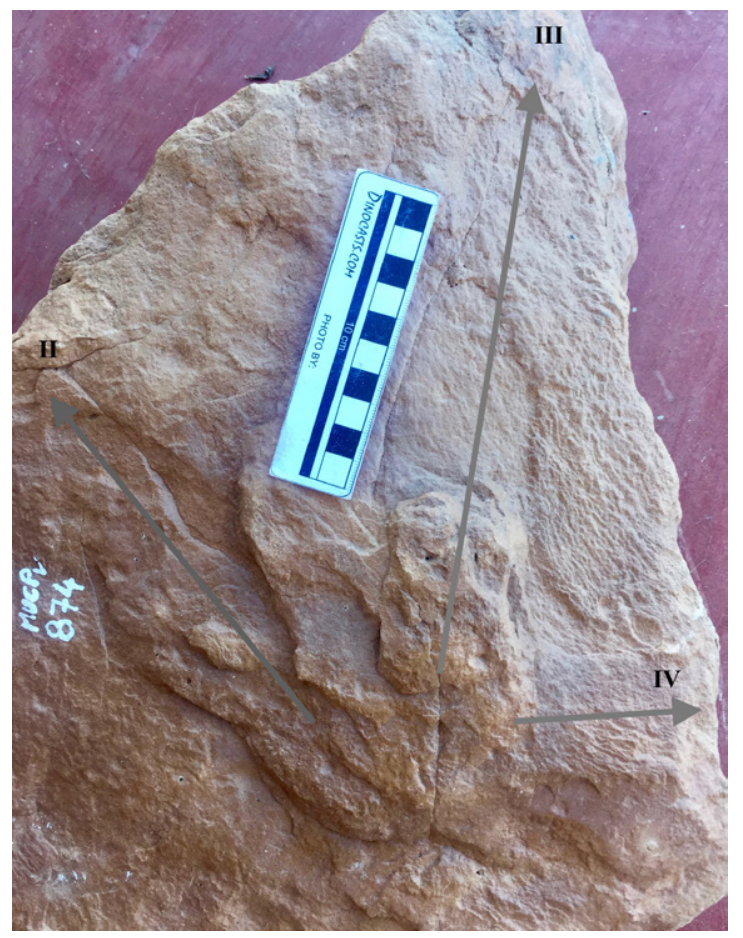

Figura 31 MUCPv-874, huella de Abelichnus astigarrae mal preservada que muestra la silueta de los dedos II y III, el dedo IV faltante. Las flechas grises marcan los ejes de los dedos. II, III, IV indican nombre de los dígitos. 


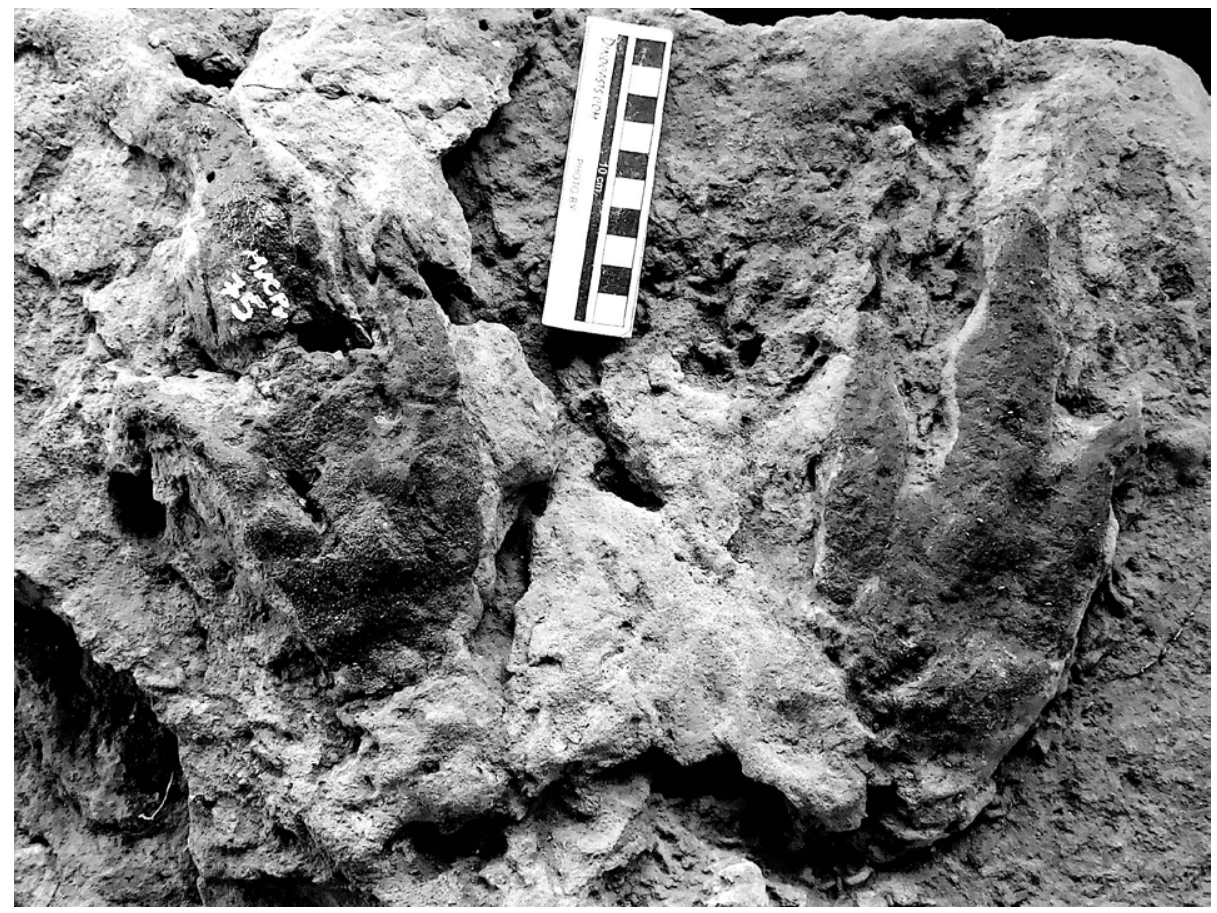

Figura 32 MUCPv-75, imagen de dos huellas a la par que indican el descanso de un dinosaurio terópodo tridáctilo, Picunichnus benedettoi, en Punta de Pescadores.

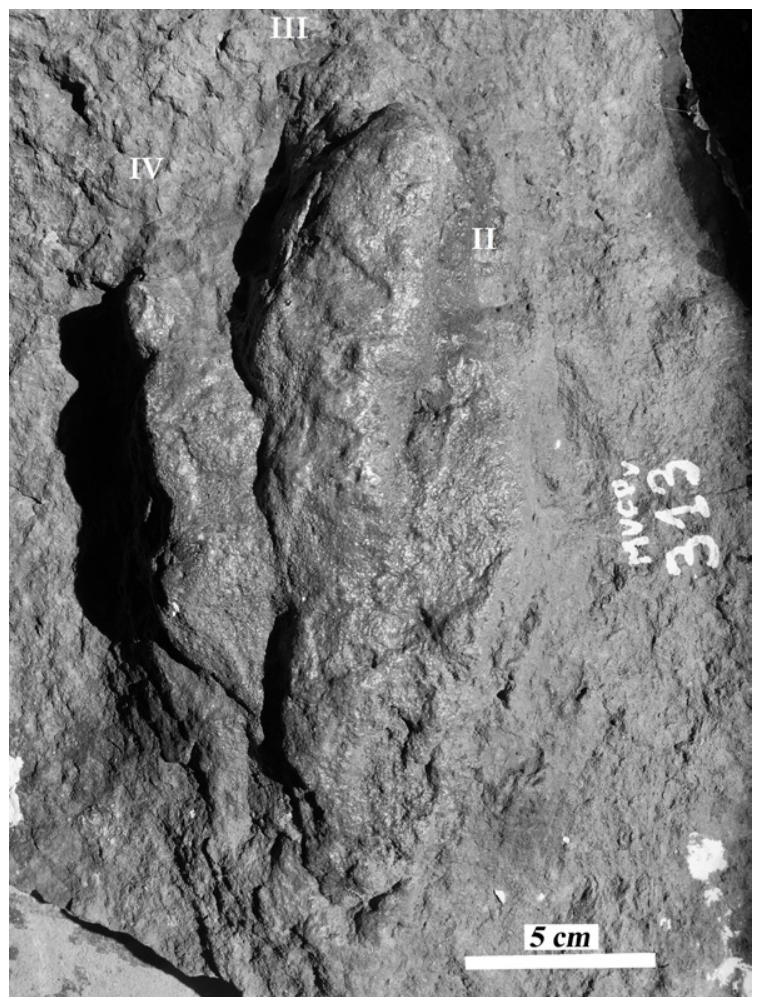

Figura 33 MUCPv-313, calco en roca producida por un dinosaurio bípedo tridáctilo de talla pequeña, Picunichnus benedettoi, en Punta de Pescadores. II, III, IV indican nombre de los dígitos

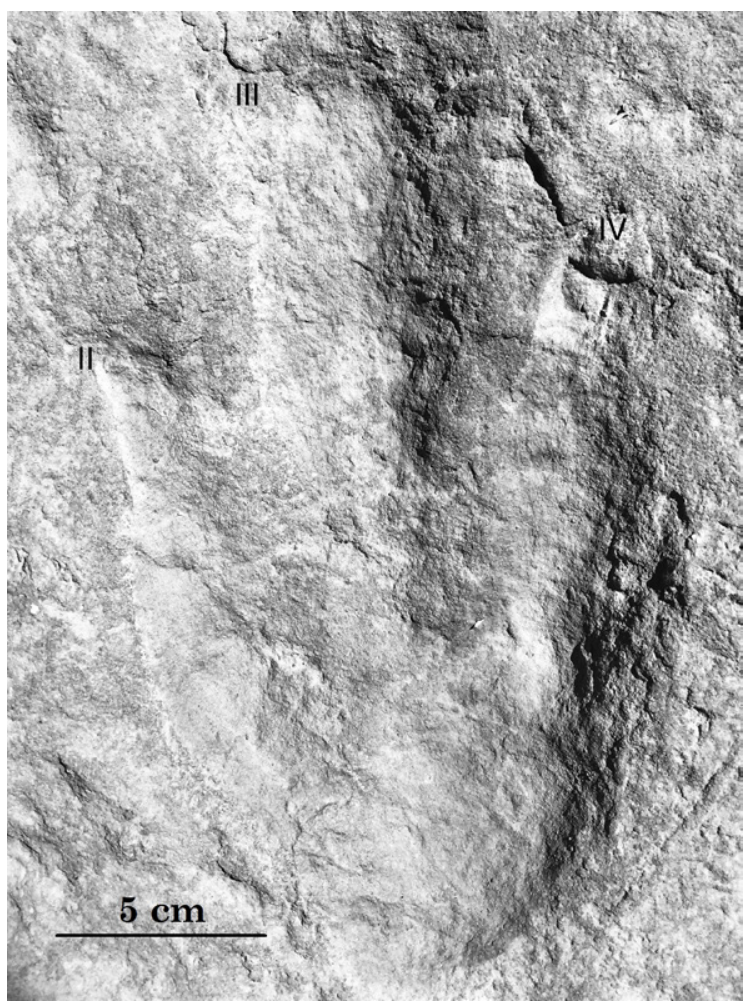

Figura 34 MUCPv-840, huella impresa en roca de Picunichnus benedettoi, en Punta de Pescadores. II, III, IV indican nombre de los dígitos. 
11). Sus dimensiones alcanzan un largo de $21 \mathrm{~cm}$ y un ancho de $13 \mathrm{~cm}$. El dedo III es más largo que los laterales. Las falanges del dedo III están bien marcadas no así la de los dedos II y IV. La impronta del talón es pequeña y subredondeada.

MUCPv-315: molde de huella impresa en roca, no muy bien preservada, que pertenece a un dinosaurio bípedo tridáctilo de talla pequeña; posee un largo de $22 \mathrm{~cm}$ y un ancho de $11 \mathrm{~cm}$ (Tabla 11). Se pueden observar algunas depresiones más profundas que corresponderían a las falanges. Se observa la impresión de garras. La impronta del talón es pequeña.

\section{Limayichnus major}

MUCPv-1481: huella de dinosaurio bípedo tridáctilo de gran tamaño (Figura 36; Tabla 11). Posee un ancho de $30 \mathrm{~cm}$ y un largo de $43 \mathrm{~cm}$. El dedo IV es levemente más largo que el dedo II. El dedo III es más largo que los laterales. El talón no está bien preservado, pero es de forma subredondeada. Por otro lado, se han registrado tres huellas in situ de Limayichnus asociadas en la misma plancha de Abelichnus y Sauropodichnus (figuras 22 y 23). Las huellas tienen $46 \mathrm{~cm}$ de largo por $43 \mathrm{~cm}$ de ancho, sus dedos no están bien preservados. El paso es de $127 \mathrm{~cm}$ de largo y el ángulo de paso es de $150^{\circ}$.

\section{Sousaichnium monettae}

No se han registrado nuevos registros para esta icnoespecie.

\subsection{EL YACIMIENTO BALNEARIO PICÚN LEUFÚ}

Este sitio icnológico se conoce desde el 2007 pero no se había realizado estudio alguno sobre las huellas allí existentes. Se ubica a $15 \mathrm{~km}$ al sureste de la ciudad de Picún Leufú, sobre la costa sur de la Península Nueva (Figura 1). En este trabajo describimos las huellas y pistas descubiertas en el 2017. Su preservación no es muy buena pero su registro amplía su distribución en la costa del embalse.

\section{Sauropodichnus giganteus}

Hay varias huellas de esta icnoespecie que se encuentran muy bien representadas en la costa

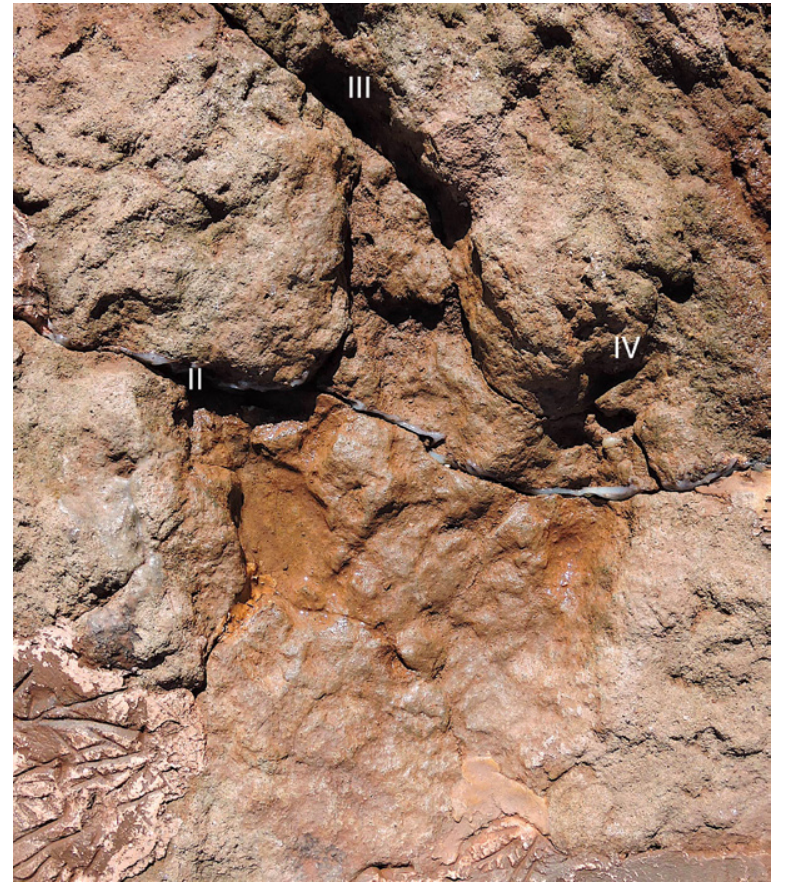

Figura 35 MUCPV-841, molde en roca de huella impresa en roca bien preservada producida por Bressanichnus patagonicus, en Punta de Pescadores (largo de la huella $21 \mathrm{~cm}$ ). II, III, IV indican nombre de los dígitos.

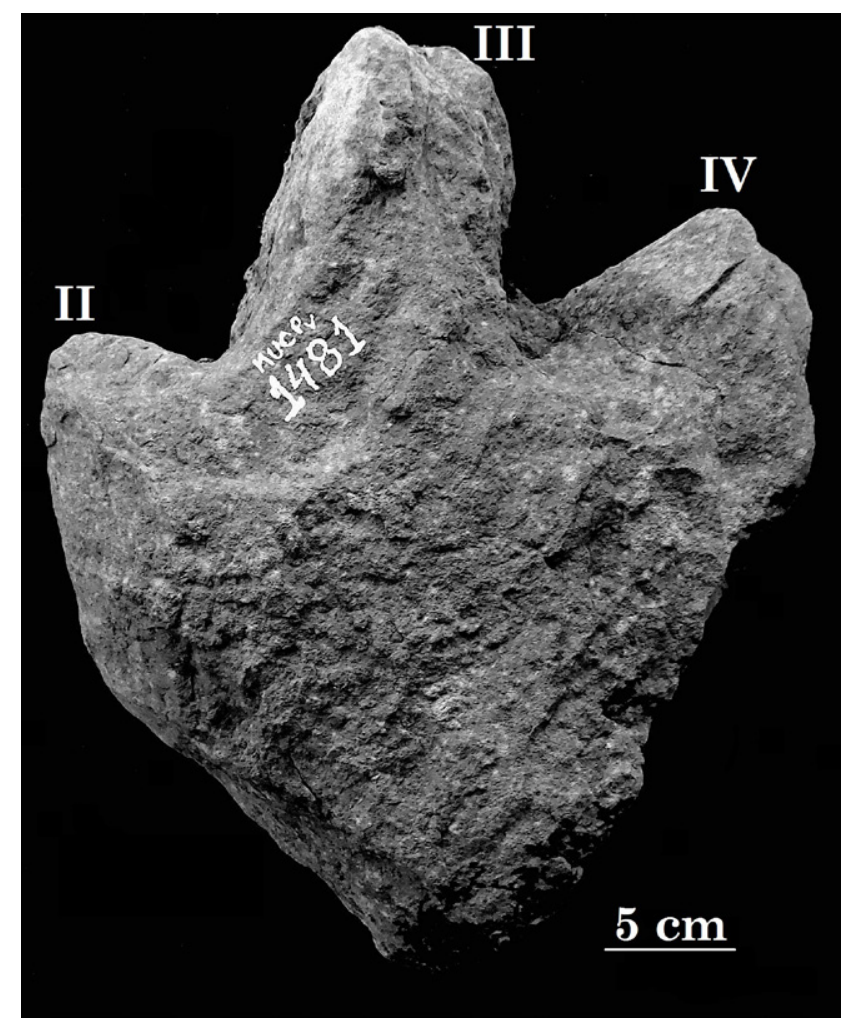

Figura 36 MUCPv-1481, huella de Limayichnus major en Punta de Pescadores. II, III, IV indican nombre de los dígitos. 
norte de la Península Nueva. En el sitio Balneario Picún Leufú se han detectado decenas de icnitas de saurópodos. La huella que estaba mejor preservada poseía $1 \mathrm{~m}$ de diámetro y $20 \mathrm{~cm}$ de profundidad, sin impresión de falanges (Figura 37). La rebaba en los bordes es muy prominente. En la actualidad la misma está semidestruida (Figura 38). Se han encontrado además nuevas huellas sin mucho detalle pero que muestran pistas (Figura 39). Las mismas tienen $100 \mathrm{~cm}$ de diámetro y no hay detalles morfológicos de dedos ni talón (Figura 40). El ancho de la pista es de $220 \mathrm{~cm}$ y la separación entre las patas delanteras es de $33 \mathrm{~cm}$ por lo que nos indica un animal de cadera ancha. Las huellas de la pata delantera no son reconocibles como ocurrió en la Punta de Pescadores de la Península Nueva (Calvo, 1991). El paso entre huellas traseras es de $165 \mathrm{~cm}$. En otros sectores se han encontrado huellas traseras subtriangulares que muestran parecidos con los registrados en la Isla Cerrito del Bote (Calvo y Mazzetta, 2004).

\section{Picunichnus benedettoi}

De esta icnoespecie no hay moldes ni originales en roca ya que las huellas están in situ y sólo se dispone de fotografias y mapas (figuras 9 y 41). Se ha descubierto una pista con 14 huellas en una superficie rocosa que presenta otros registros icnológicos pero estas huellas no están muy bien preservadas aunque muestran algunos detalles morfológicos interesantes. La pista tiene $10.1 \mathrm{~m}$ de largo y una separación entre huellas de $74 \mathrm{~cm}$. $\mathrm{El}$ ángulo de paso es de $170^{\circ}$. La huella número 4 es la mejor preservada y tiene una longitud de $19 \mathrm{~cm}$ y un ancho de $14 \mathrm{~cm}$ (Figura 42). El dedo III posee una longitud de $14 \mathrm{~cm}$, el II de $11 \mathrm{~cm}$ y el IV de $8 \mathrm{~cm}$. Un estudio comparativo con el holotipo de Picunichnus muestra grandes similitudes en el ángulo interdigital reducido, las impresiones falangeales, la disposición de los dedos y el talón reducido. La única diferencia es la falta del dedo I que tiene el holotipo, pero creemos se trata de un problema de preservación en las huellas que se describen.

\section{Bressanichnus patagonicus}

Sólo dos icnitas fueron reconocidas en este yacimiento y se encuentran en la misma plataforma rocosa que las de Picunichnus. El largo de paso es de $70 \mathrm{~cm}$ (Figura 43). La huella tiene $18 \mathrm{~cm}$ de largo y $13 \mathrm{~cm}$ de ancho. Son huellas no muy bien conservadas, con el dedo III más desarrollado que los laterales; el dedo II apenas supera en largo al dedo IV. La palma es subredondeada.

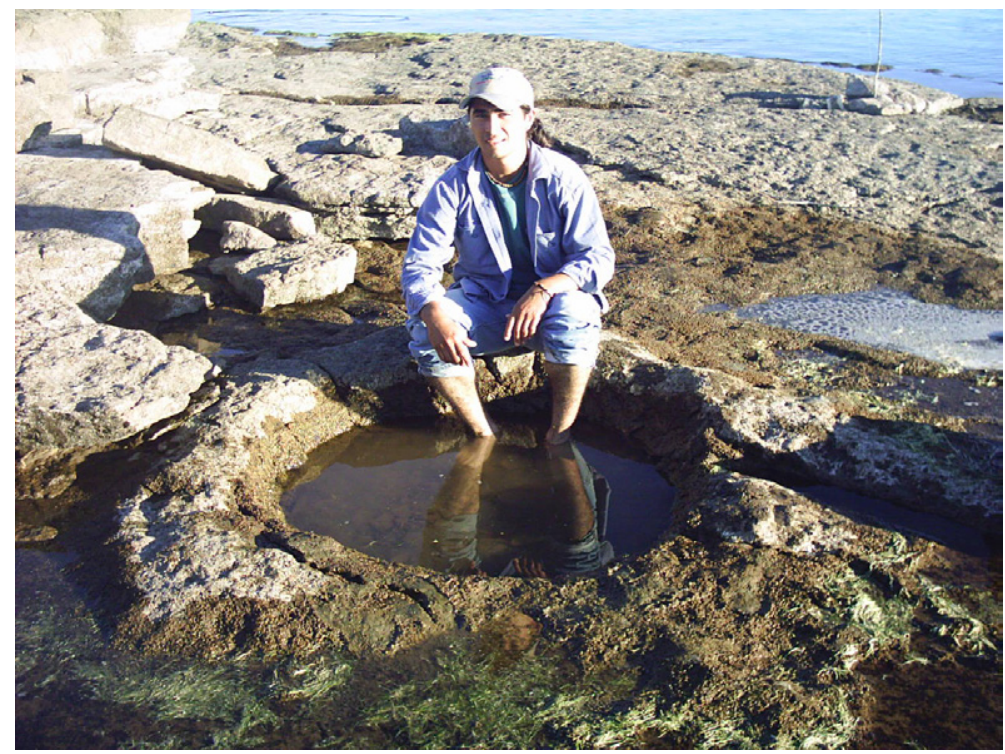

Figura 37 Vista de la huella más grande de Sauropodichnus giganteus hallada en la Península Nueva en el sitio Balneario Picún Leufú (foto tomada en el 2007; diámetro $100 \mathrm{~cm}$ ). 


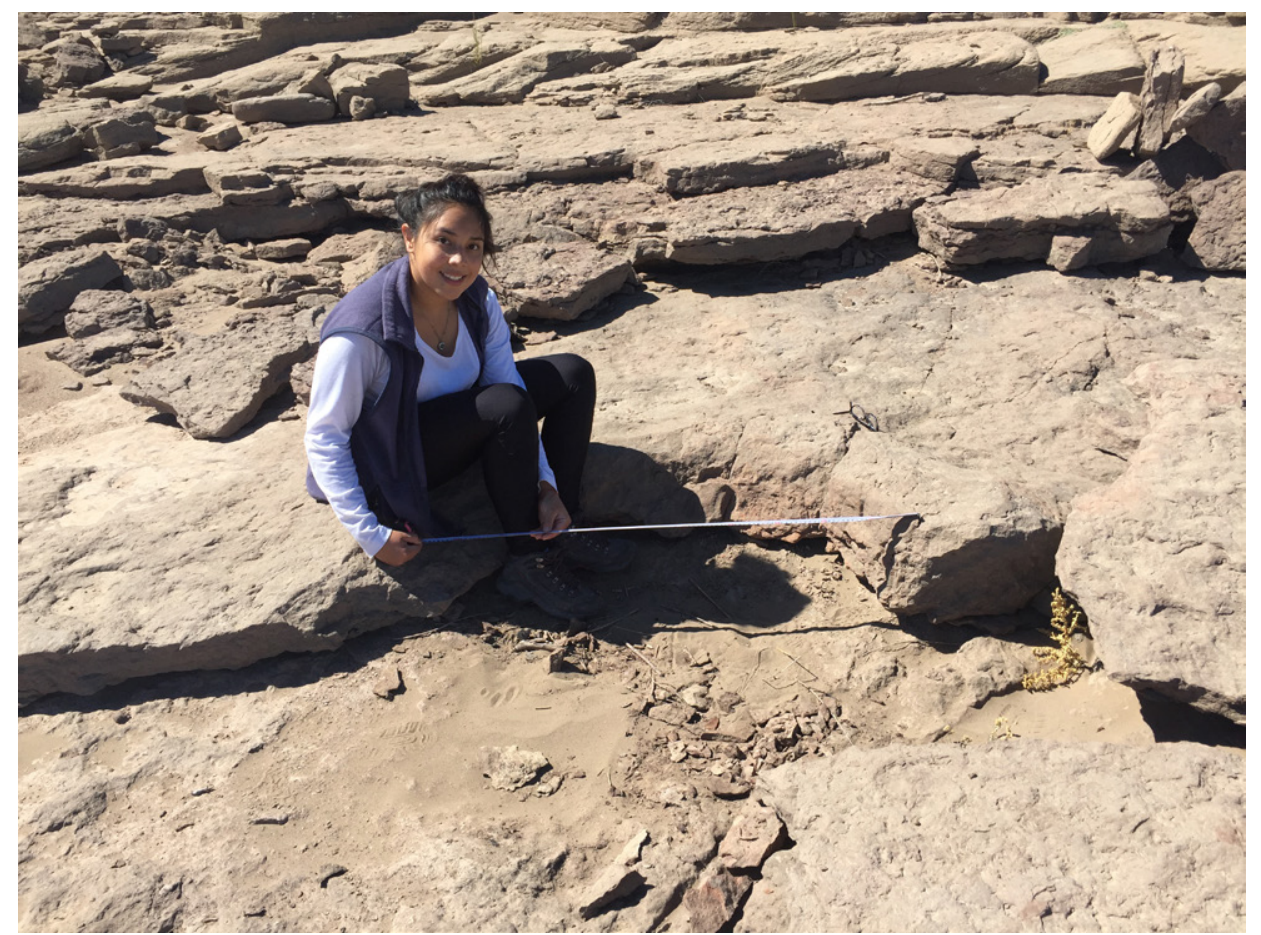

Figura 38 Vista de la pista de Sauropodichnus giganteus en Balneario Picún Leufú (la regla mide $100 \mathrm{~cm}$ ).

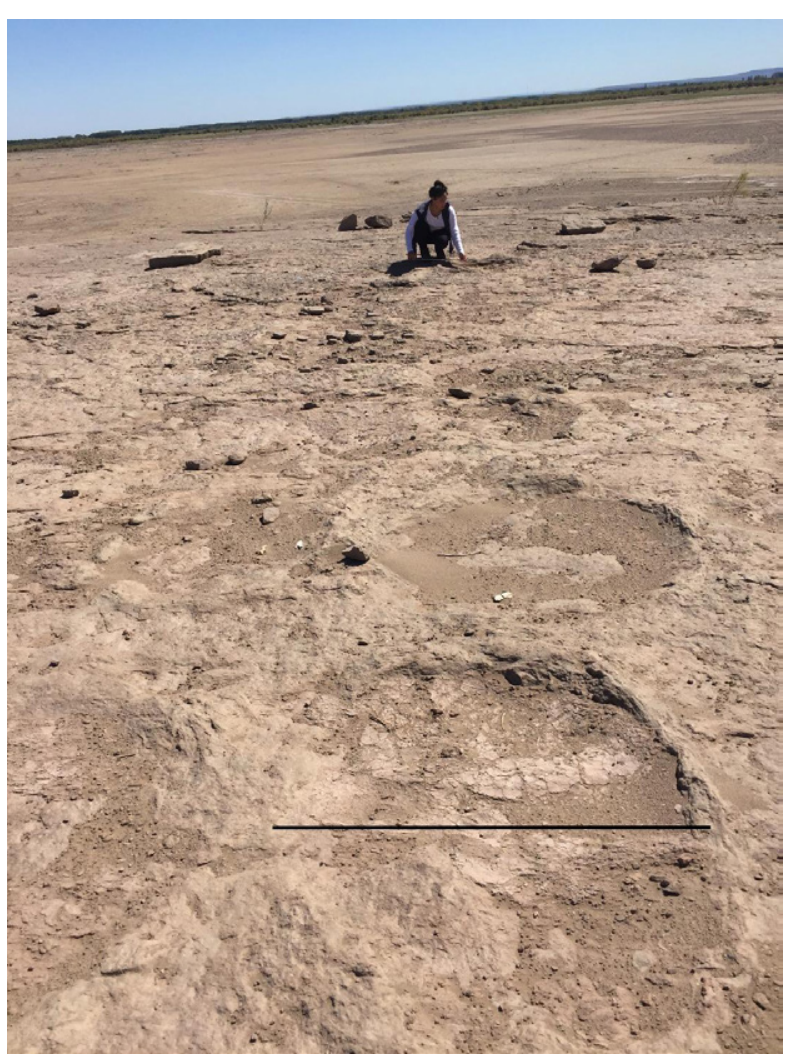

Figura 39 Vista de la huella de Sauropodichnus giganteus en Balneario Picún Leufú; huellas de las patas traseras (línea mide $100 \mathrm{~cm}$ ).

\section{Deferrariischnium mapuchensis}

Las dos icnitas que fueron reconocidas en este yacimiento están asociadas a las de Bressanichnus y Picunichnus. Las huellas están separadas $71 \mathrm{~cm}$ y poseen $20 \mathrm{~cm}$ de largo y 12 de ancho (figuras 9 y 44). El dedo III es más del doble de largo que de los dedos II y IV. Los dedos II y IV están poco desarrollados y casi se confunden dentro de la almohadilla plantar. La palma es de forma subredondeada.

\section{Limayichnus major}

Una sola huella fue reconocida en el sitio, la cual se encuentra muy deteriorada. La icnita se encuentra en el mismo nivel rocoso que Deferrariischnium, Picunichnus y Bressanichnus (figuras 9 y 45). Tiene un largo de $77 \mathrm{~cm}$ por $68 \mathrm{~cm}$ de ancho, talón redondeado y dedos romos sin impresión de garras.

\subsection{EL YAGIMIENTO DE ISLA GERRITO DEL BOTE}

Las icnitas de Isla Cerrito del Bote se encuentran ubicadas a $600 \mathrm{~m}$ al noreste del yacimiento 


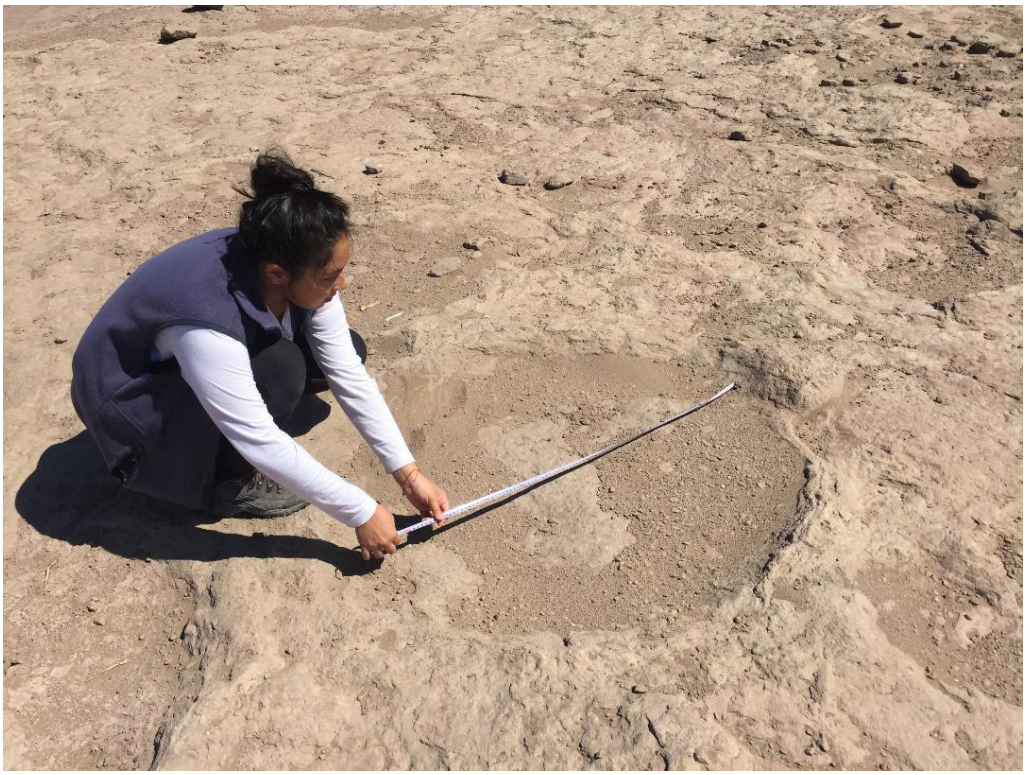

Figura 40 Vista de la huella de Sauropodichnus giganteus en Balneario Picún Leufú; huellas de las patas traseras con $100 \mathrm{~cm}$ de diámetro (la regla tiene $100 \mathrm{~cm}$ ).

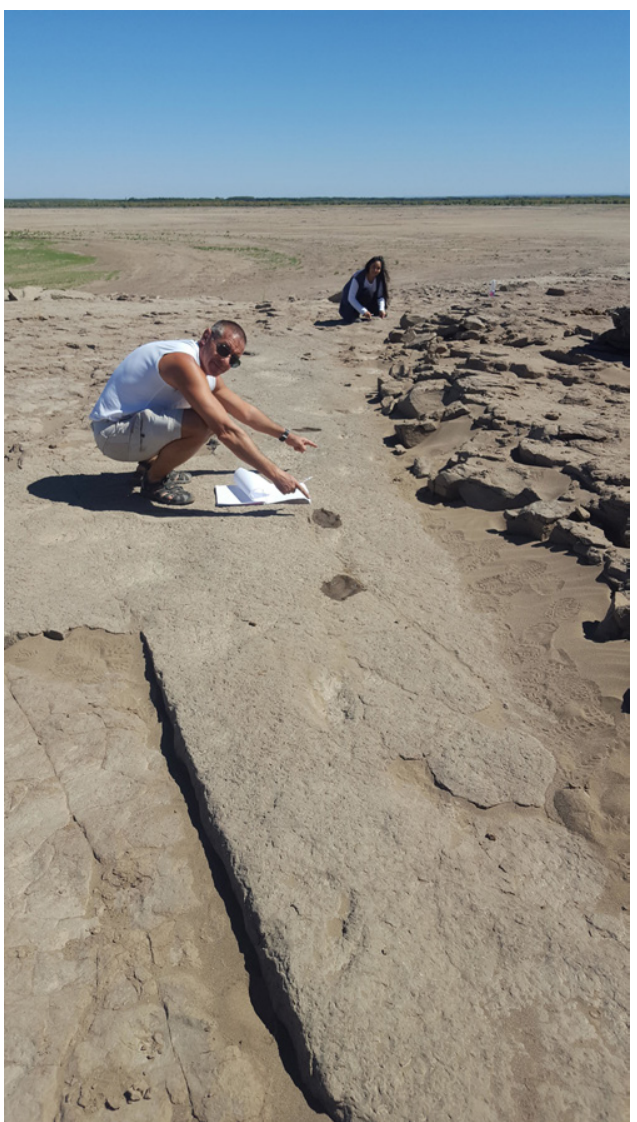

Figura 41 Vista de la plataforma con la pista de Picunichnus benedettoi en primer plano. Sitio Balneario Picún Leufú (dibujo de la pista en Figura 9). El Dr. Calvo muestra la distancia entre dos huellas sucesivas.

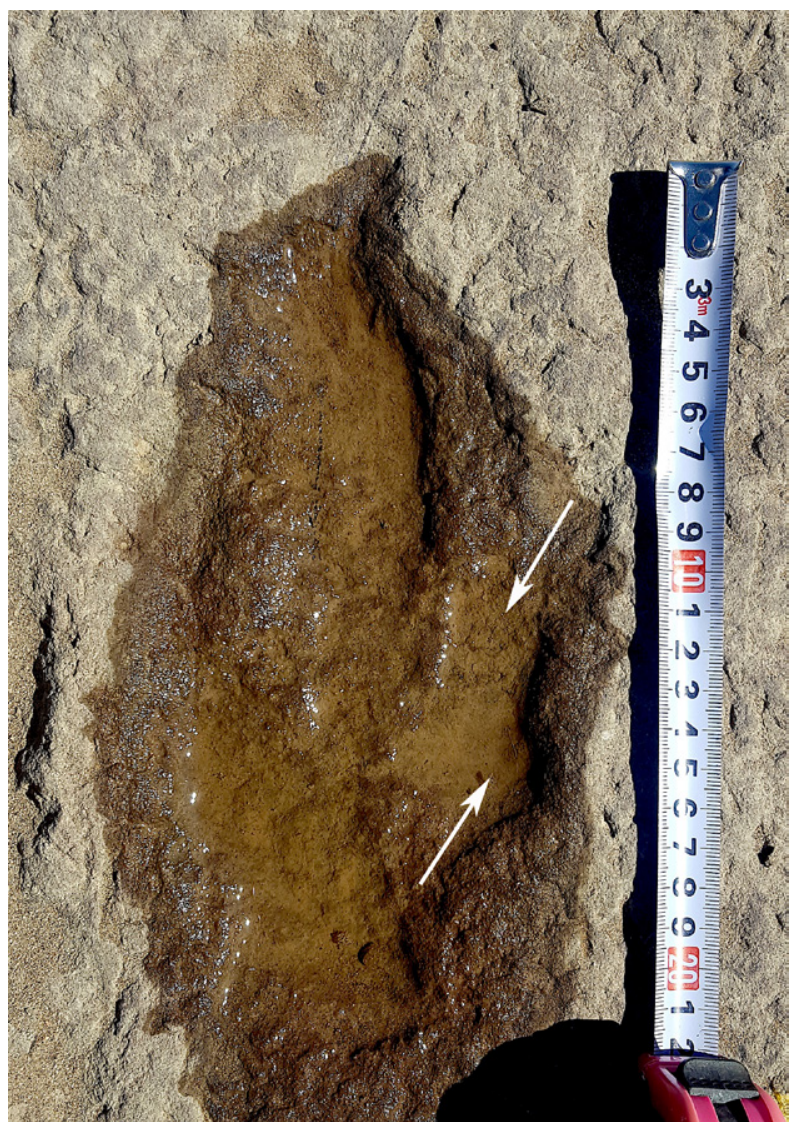

Figura 42 Vista de la huella de Picunichnus benedettoi en el sitio Balneario Picún Leufú en donde se observan las impresiones falangeales (flechas blancas). 


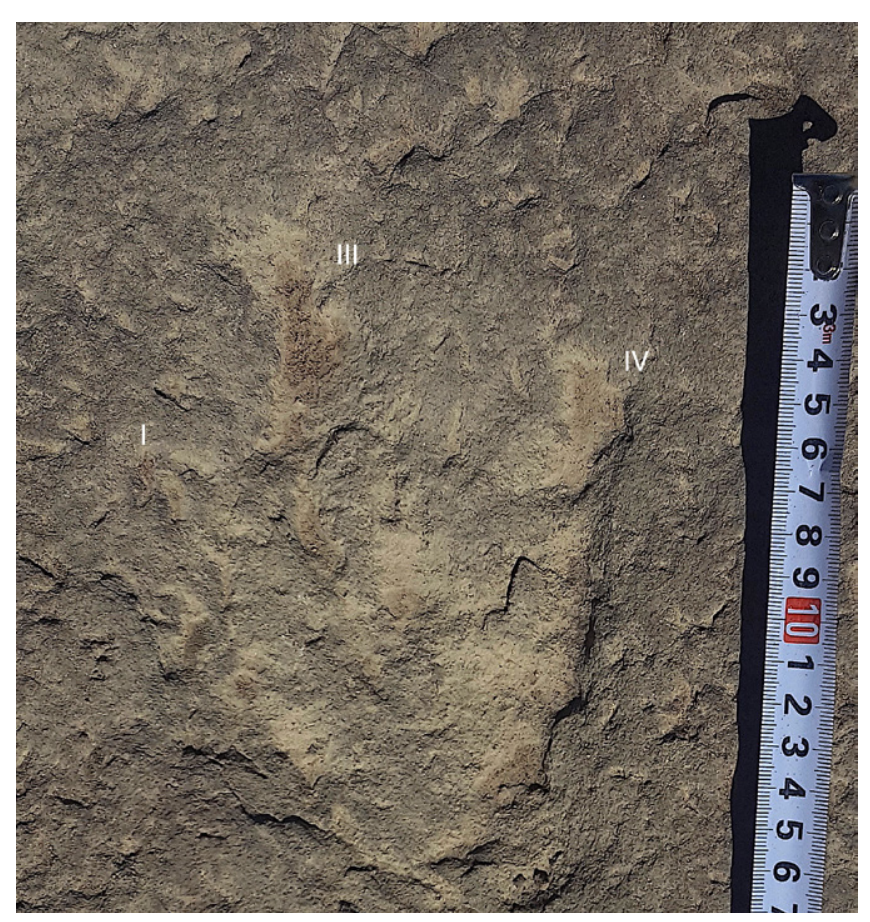

Figura 43 Vista de la huella de Bressanichnus patagonicus en el sitio Balneario Picún Leufú (dibujo de la pista en Figura 9). II, III, IV indican nombre de los dígitos.

Península Nueva en Picún Leufú (Figura 1). Calvo y Mazzetta (2004) describieron en detalle las icnitas del sitio, por lo que sólo incorporaremos datos generales de las mismas e información adicional sobre algunas pistas. Por un lado, se asignan las huellas de terópodos pequeños a la nueva icnoespecie definida anteriormente. Por otro lado, se redescriben brevemente las huellas de Abelichnus y Sauropodichnus (Calvo, 1991); estas últimas con muy buena preservación lo que permitió ampliar la diagnosis de ese icnogénero (Calvo, 1999; Calvo y Mazzetta, 2004). Se ha incorporado un perfil geológico donde se ubican las huellas descritas en esos trabajos (Figura 46).

\section{LOS NIVELES GON HUELLAS}

Se reconocen 7 pistas con las siglas CB 1 a 7 (Calvo y Mazzetta, 2004). Las pistas CB 1 a 6 fueron halladas en la misma superficie, mientras que la pista CB-7 se encuentra en niveles superiores. La secuencia local corresponde a una intercalación de areniscas y pelitas (Figura 46). En el nivel 1 se han detectado cinco pistas, cuatro de las cuales

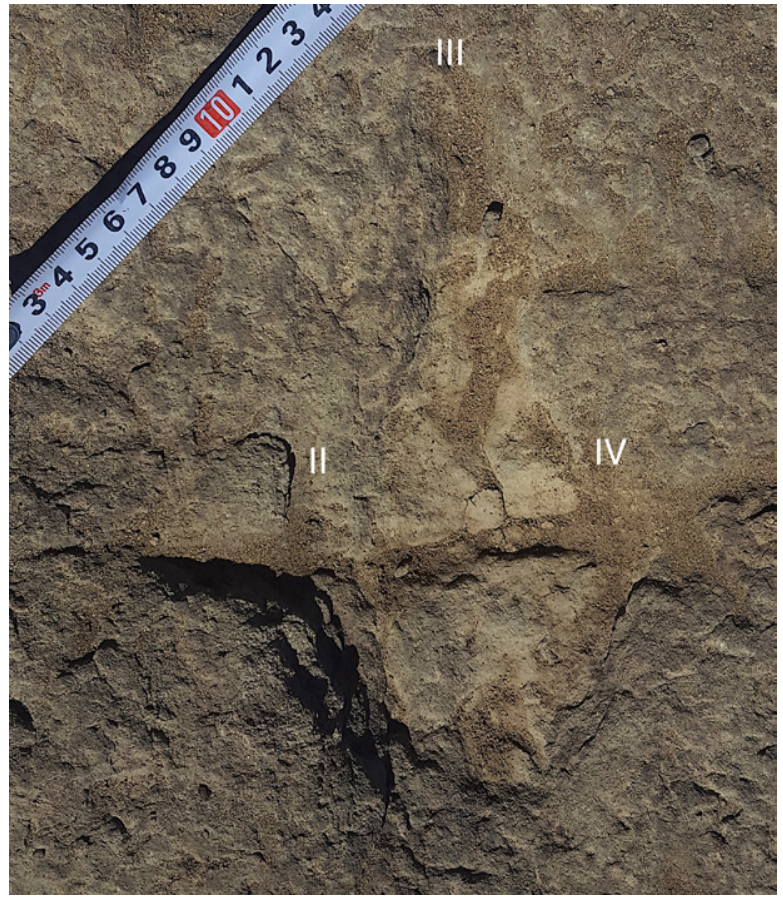

Figura 44 Vista de la huella de Deferrariischnium mapuchensis en el sitio Balneario Picún Leufú (dibujo de la pista en Figura 9). II, III, IV indican nombre de los dígitos.

corresponden a dinosaurios terópodos (CB-2 a CB-6) y una a un dinosaurio saurópodo (CB-1). En el nivel 2 hay sólo una huella de un gran terópodo (CB-7).

Sauropodichnus giganteus Calvo, 1991, 1999

Pista de dinosaurio cuadrúpedo de $6 \mathrm{~m}$ de longitud y 12 huellas impresas con una pobre morfología de detalle en los dedos (CB-1) (Figura 14). El eje de la pista pasa a unos $15 \mathrm{~cm}$ del borde póstero-ventral de las huellas traseras. El ángulo de paso de las huellas delanteras oscila entre 75 y $95^{\circ}$ y el de las huellas traseras entre 100 y $120^{\circ}$, respectivamente. $\mathrm{El}$ ancho externo es de $1.4 \mathrm{~m}, \mathrm{y}$ el interno de $0.6 \mathrm{~m}$. El largo de paso oscila entre 2 y $2.2 \mathrm{~m}$ (Calvo y Mazzetta, 2004). Las huellas traseras son más grandes que las delanteras y tienen una forma subtriangular de $70 \mathrm{~cm}$ de largo por $60 \mathrm{~cm}$ de ancho, sin detalle de separación entre dedos y talón. Las huellas delanteras son de forma arriñonada, levemente cóncavas en la parte posterior. Tienen $25 \mathrm{~cm}$ de largo por $40 \mathrm{~cm}$ de ancho. 


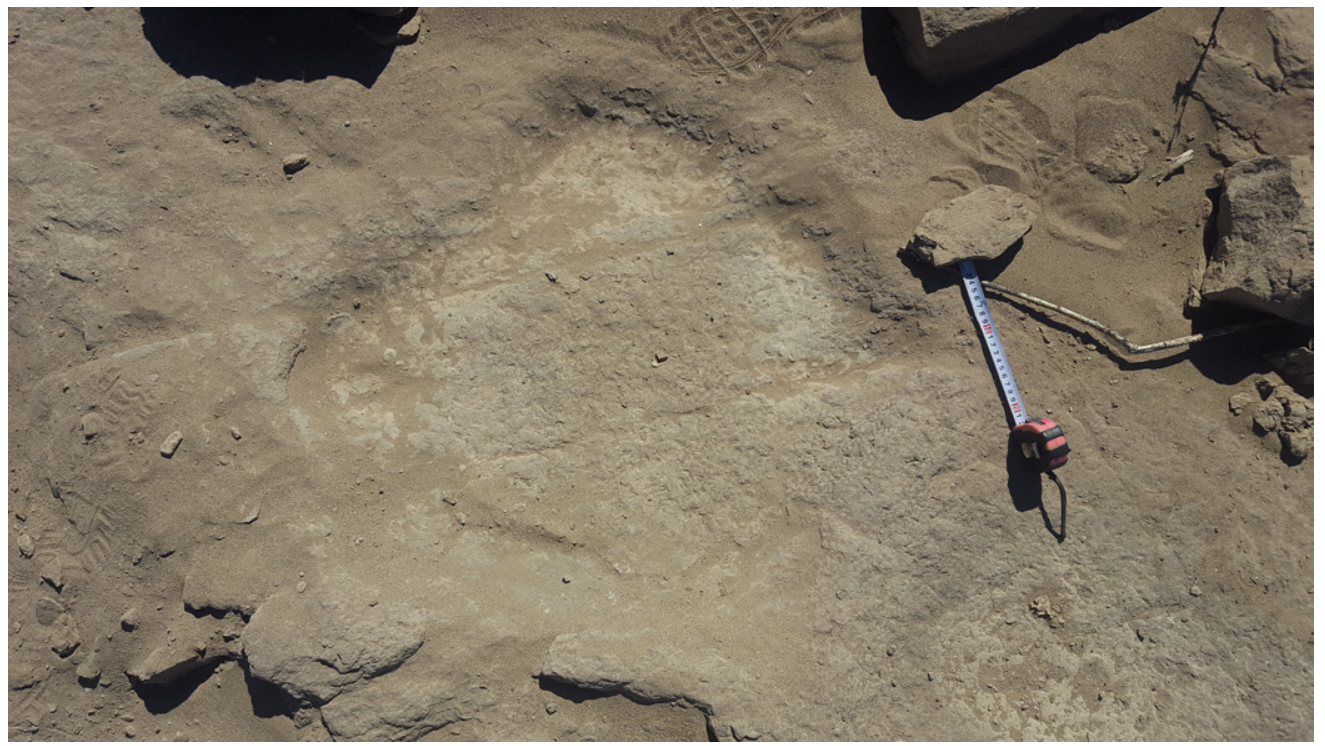

Vista de la huella de Limayichnus major en el sitio Balneario Picún Leufú (dibujo de la pista en Figura 9).

El borde posterior levemente cóncavo tiene una separación de $2.34 \mathrm{~m}$ para las huellas derechas y de $2.2 \mathrm{~m}$ para las izquierdas. Esta diferencia se debe a la curvatura hacia la izquierda de la pista.

\section{Abelichnus astigarrae Galvo, 1991}

Se trata de un par de huellas de un dinosaurio carnívoro de gran tamaño (CB-7) con rumbo $55^{\circ}$ (plastotipo MUCPv-139), con un paso de $146 \mathrm{~cm}$. Las huellas bien conservadas tienen $47 \mathrm{~cm}$ de largo por $42 \mathrm{~cm}$ de ancho. Las huellas son tridáctilas con presencia de garras en los extremos de los dedos (Figura 7; Calvo y Mazzetta, 2004). El dedo III es el más largo de todos. El dedo II es más corto que el IV y ambos presentan poderosas impresiones de garras desplazadas hacia afuera. La divergencia entre los dedos es de un ángulo bajo. El talón es pequeño y de borde subredondeado.

Candeleroichnus canalei nov. gen, nov. sp. Calvo y Rivera (este trabajo)

Ver detalle en la descripción de la icnoespecie Candeleroichnus canalei (Figura 10). Calvo y Mazzetta (2004) describieron 5 pistas atribuibles a esta icnoespecie con un total de 34 huellas de $10 \mathrm{~cm}$ de largo de promedio y $5 \mathrm{~cm}$ de ancho, en donde el 80\% lo ocupan los dedos (Figura 12). Las pistas son extremadamente estrechas y rectilíneas, con un ángulo de paso que oscila entre 175 y $180^{\circ}$. Las mismas se dirigen al este o este-sudeste, con los siguientes rumbos y detalles:

MUCPv-133: corresponde a la pista CB-2 con rumbo $107^{\circ} \mathrm{y}$ cinco huellas mal preservadas (plastotipo de huella).

MUCPv-135: corresponde a la pista CB-3 con rumbo $115^{\circ}$ y siete huellas (plastotipo de huella). MUCPv-134: corresponde a la pista CB-5 con rumbo $108^{\circ}$ y nueve huellas (plastotipo de huella). La pista CB-4 tiene un rumbo de $105^{\circ}$ y seis huellas. La pista CB-6 con rumbo de $90^{\circ}$ tiene ocho huellas. Excepto en el caso de la pista CB-6, las pistas de estos pequeños dinosaurios bípedos se disponen muy cercanas (la distancia entre las mismas no supera los $0.8 \mathrm{~m}$ ) y son aproximadamente paralelas entre sí, lo cual indica una misma dirección y sentido de desplazamiento. La pista CB-6, emplazada aproximadamente a $4 \mathrm{~m}$ de distancia de las restantes pistas de celurosaurios, revelaría una posible tendencia de su autor hacia el acercamiento a la trayectoria de estas últimas. 

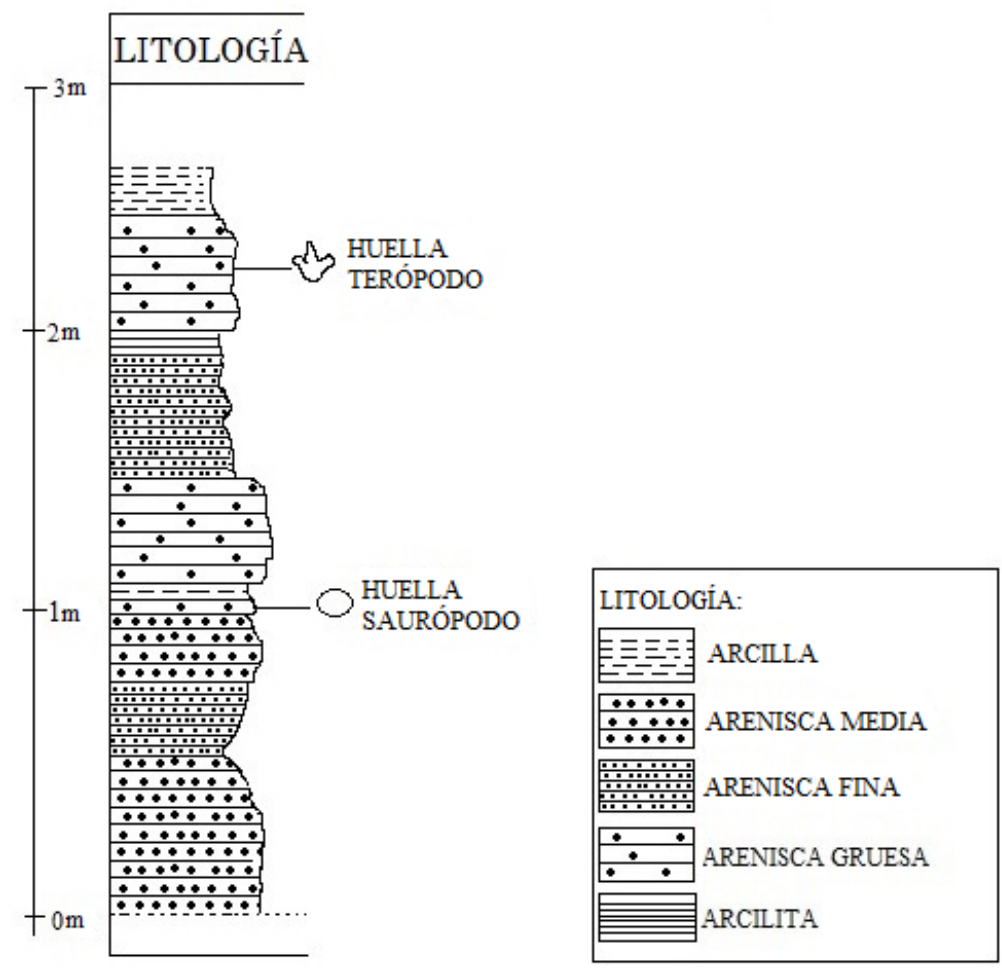

Figura 46 Columna estratigráfica en los hallazgos de la Isla Cerrito del Bote, donde se ubican las huellas halladas en el sector.

\subsection{EL YACIMIENTO GERRO MESA}

El sitio Cerro Mesa se encuentra en un área petrolífera denominada El Sauce a $5 \mathrm{~km}$ al noroeste de la ciudad de Picún Leufú. En esta zona se hallaron huellas de pterosaurios y de dinosaurios; estas últimas son las que se describen en este trabajo. Las huellas son de muy buena calidad y han permitido diagnosticar una nueva icnoespecie de terópodo Candeleroichnus canalei descrito en este trabajo en detalle.

\section{Candeleroichnus canalei Calvo y Rivera (este trabajo) \\ MUCPv-76 corresponde a dos bloques de roca} con 4 icnitas que son parte del holotipo de la icnoespecie Candeleroichnus canalei (figuras 11 y 13; Tabla 11). Las huellas son asimétricas, con la impronta del talón casi no preservada o muy pequeña y desplazada hacia el exterior. El dedo III imprime tres falanges y su garra. La impronta está distalmente desplazada hacia el interior. El dedo II, más pequeño que el IV en las huellas mejor preservadas, imprime dos falanges y su garra. La impronta de su extremo distal se desplaza hacia el interior o hacia adelante (Figura 11). El dedo IV, prácticamente recto, imprime tres falanges y su garra con indicio de la falange ungueal desplazada hacia el interior. La divergencia interdigital de la mayoría de las huellas no supera los $10^{\circ}$.

MUCPv-201: es una huella producida por un dinosaurio bípedo tridáctilo de talla pequeña (Tabla 11). Su preservación no es buena; sin embargo, muestra un esbozo de sus dedos y la impronta del talón es pequeña y aguda. Sus dimensiones alcanzan un ancho de $10 \mathrm{~cm}$ y un largo de $12 \mathrm{~cm}$.

\subsection{GAÑADÓN EL GARRIZO}

Este sitio paleontológico fue mencionado en comunicaciones paleontológicas pero nunca fue 


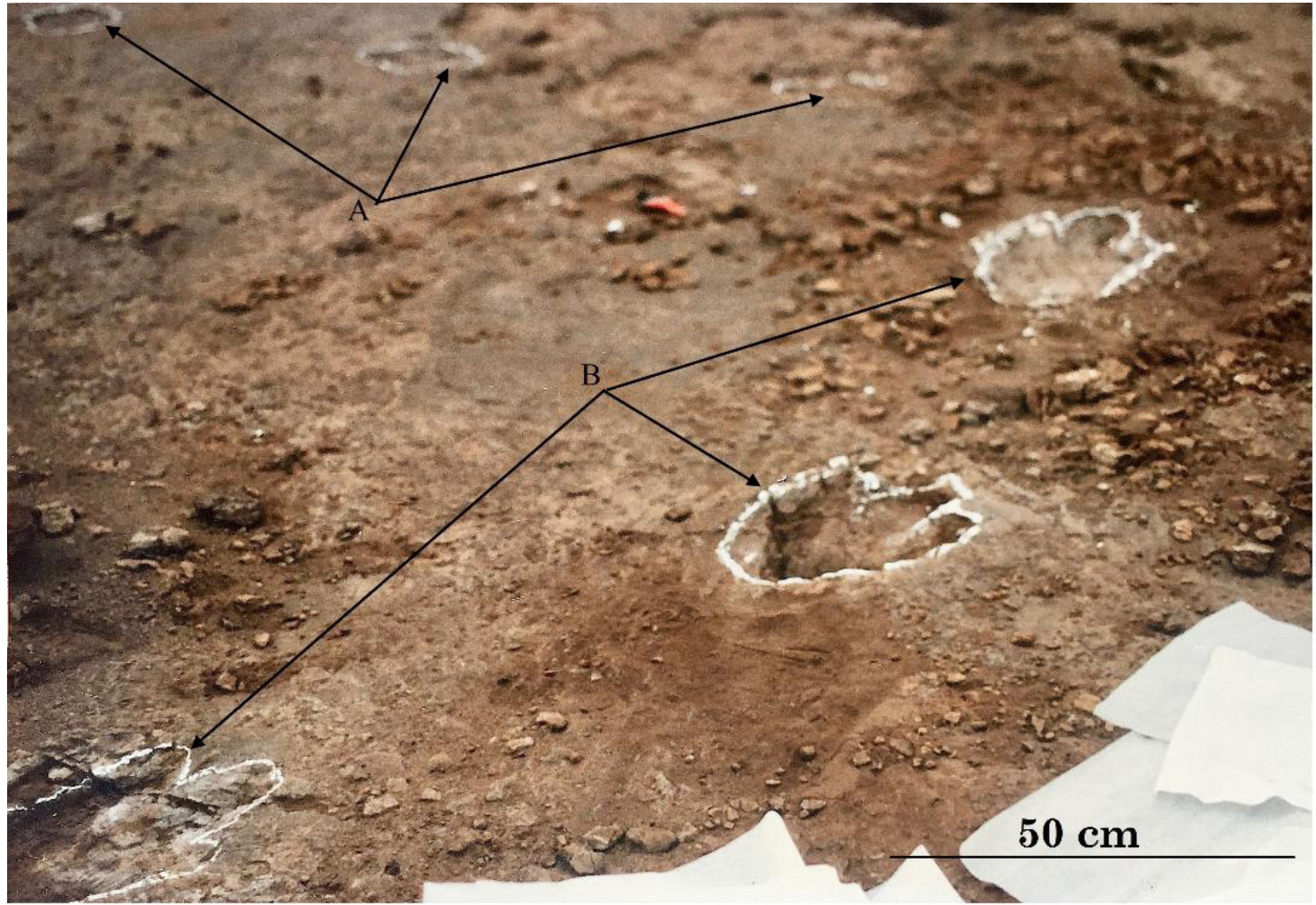

Figura 47 Limayichnus sp., pista con 3 huellas en primer plano (A) y 3 huellas en segundo plano (B) con ángulo de paso cercano a los $150^{\circ}$ hallada en Cañadón El Carrizo.

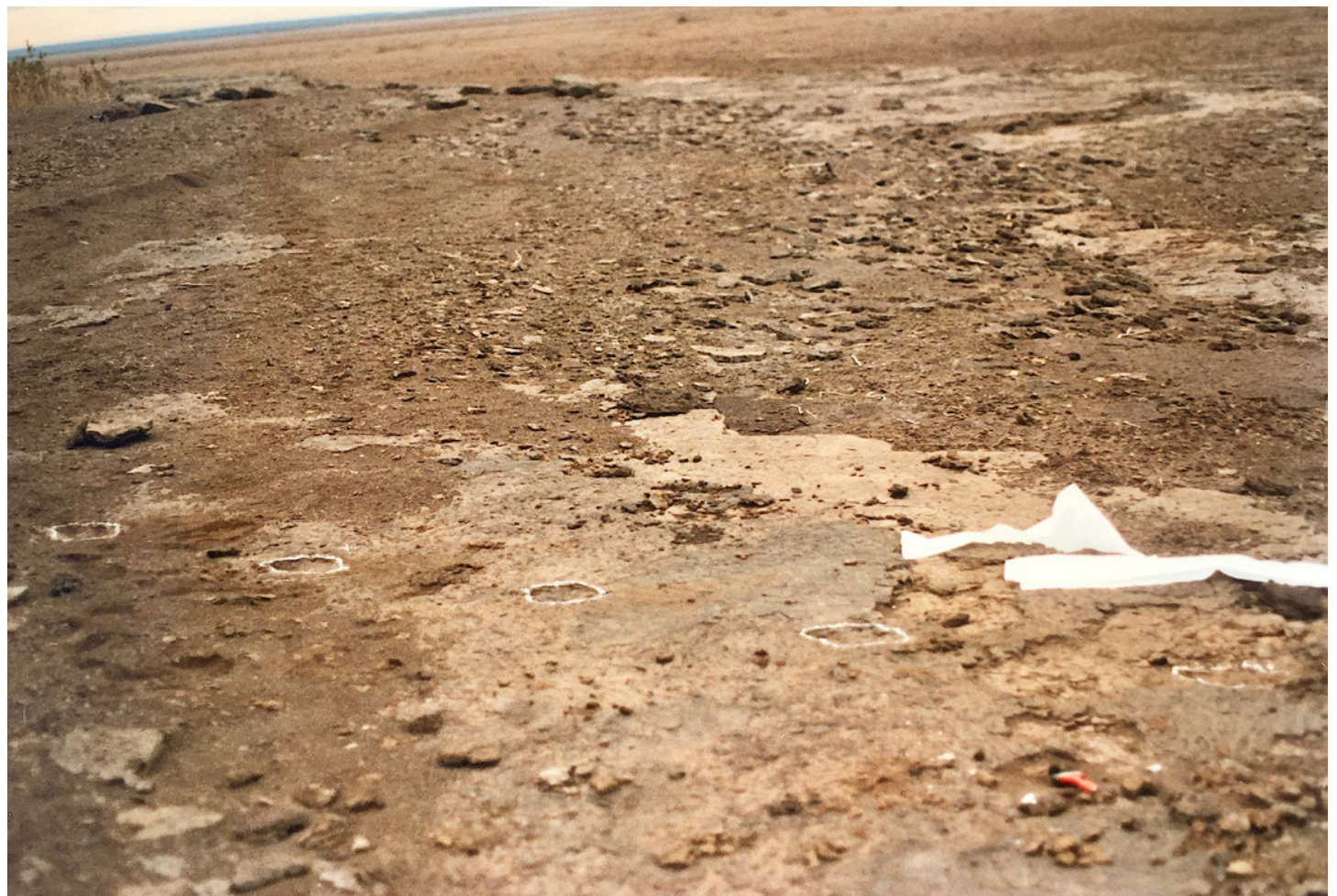

Figura 48 Limayichnus sp., pista con 5 huellas (rodeadas por borde blanco) Cañadón El Carrizo. 


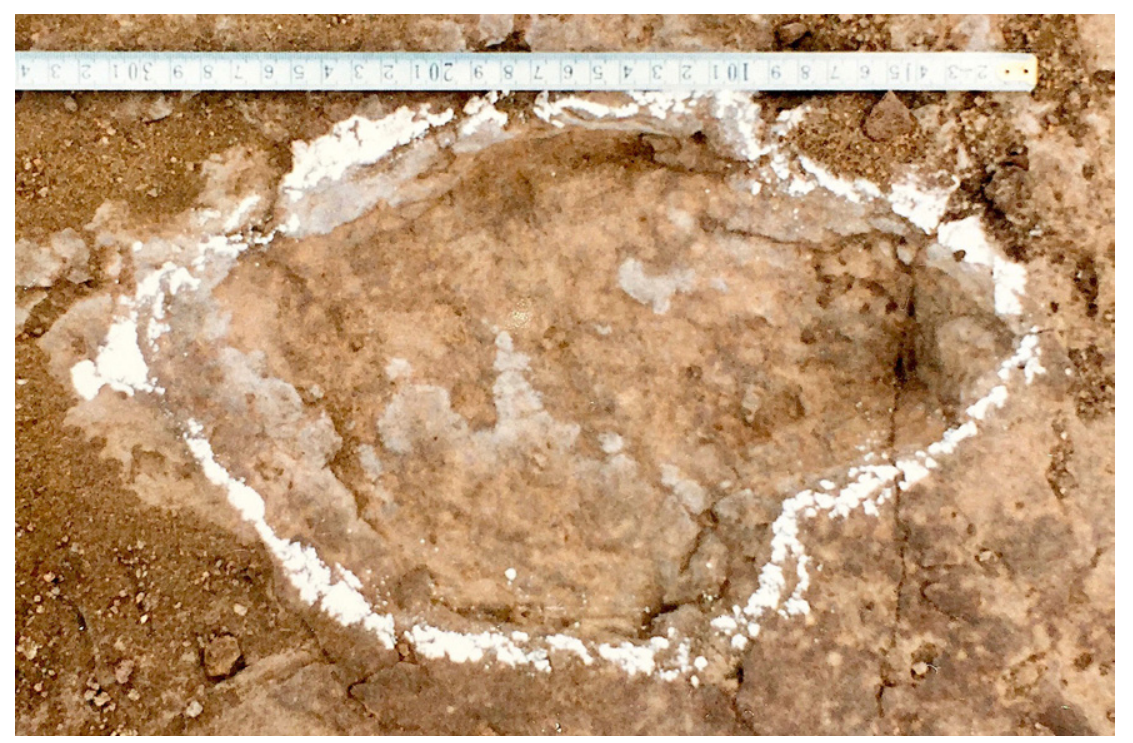

Figura 49 Limayichnus sp., huella mostrando los dedos romos y talón redondeado hallada en Cañadón El Carrizo.

dado a conocer en detalle (Calvo et al., 1989). En el presente trabajo describimos brevemente las dos pistas reconocidas en el sitio.

\section{Limayichnus sp.}

El productor de la huella de Limayichnus es muy probablemente un ornitópodo. Las mismas están mal preservadas. Una de las pistas presenta 5 huellas mientras que la otra conserva tres huellas con ángulo de paso cercano a los $150^{\circ}$ (figuras 47 y 48). Las huellas de $30 \mathrm{~cm}$ de largo y $20 \mathrm{~cm}$ de ancho no presentan detalles de impresiones falangeales, pero muestran un contorno de talón subredondeado y tres impresiones de dedo romos (Figura 49). No hay impresión de garras.

\subsection{GAÑADÓN DE LAS GAMPANAS}

Este sitio paleontológico fue dado a conocer en una tesis doctoral donde se reconocieron varios sitios con huellas (Krapovickas, 2010). El mismo se encuentra ubicado a aproximadamente $15 \mathrm{~km}$ al suroeste de la Villa El Chocón. Lamentablemente no podemos profundizar en el mismo ya que no está publicado por lo que sólo daremos datos generales.

\section{Bressanichnus patagonicus}

En su trabajo de tesis, Krapovickas (2010) describe para estas icnitas "Las huellas son tridáctilas, con marcas de garra bien definida, de un animal bípedo de talla mediana a grande (Ver figura en tesis). La impresión del dígito central (III) está curvado medialmente y más desarrollado que los dígitos laterales (II y IV). Las huellas son ligeramente asimétricas. El hipex entre los dígitos II-III está más atrás que entre III-IV. El margen posterior de la huella es subredondeado a angosto. Las impresiones digitales son relativamente angostas." La autora identifica a estas icnitas como pertenecientes a Irenesauripus (Sternberg, 1932) del Cretácico Inferior de Estados Unidos, aunque con base en el conocimiento de las huellas descriptas para la zona se corresponderían con la icnoforma de Bressanichnus del Cretácico Inferior de Sudamérica.

\section{Sauropodichnus sp.}

En el Cañadón de las Campanas se han reconocido numerosas huellas de saurópodos; sin embargo, no hay pistas definidas (Krapovickas, 2010). Las icnitas presentan impresión de manos redondeadas o en forma de riñón sin impresión 
de dígitos (ver figura en tesis). El análisis realizado por Krapovickas (2010) asigna estas huellas al icnogénero Brontopodus de Estados Unidos; sin embargo, por la morfología, la distancia entre las huellas, etc., muestra que correspondería con el icnogénero local Sauropodichnus.

\subsection{EL YAGIMIENTO DE GAÑADÓN DE GORIA}

El Cañadón de Coria es un río seco que desemboca en el embalse Ezequiel Ramos Mexía, a 5 km al sur de Villa El Chocón. En algunos sectores se observan bloques caídos con impresiones de huellas o bien en las paredes del cañadón se ven las siluetas de las icnitas en corte transversal. En este trabajo nos restringimos a los hallazgos en el cauce de la parte media del cañadón donde se pudieron determinar varias icnitas in situ. El área de huellas se restringe a un sector de $100 \mathrm{~m}$ de largo por 5

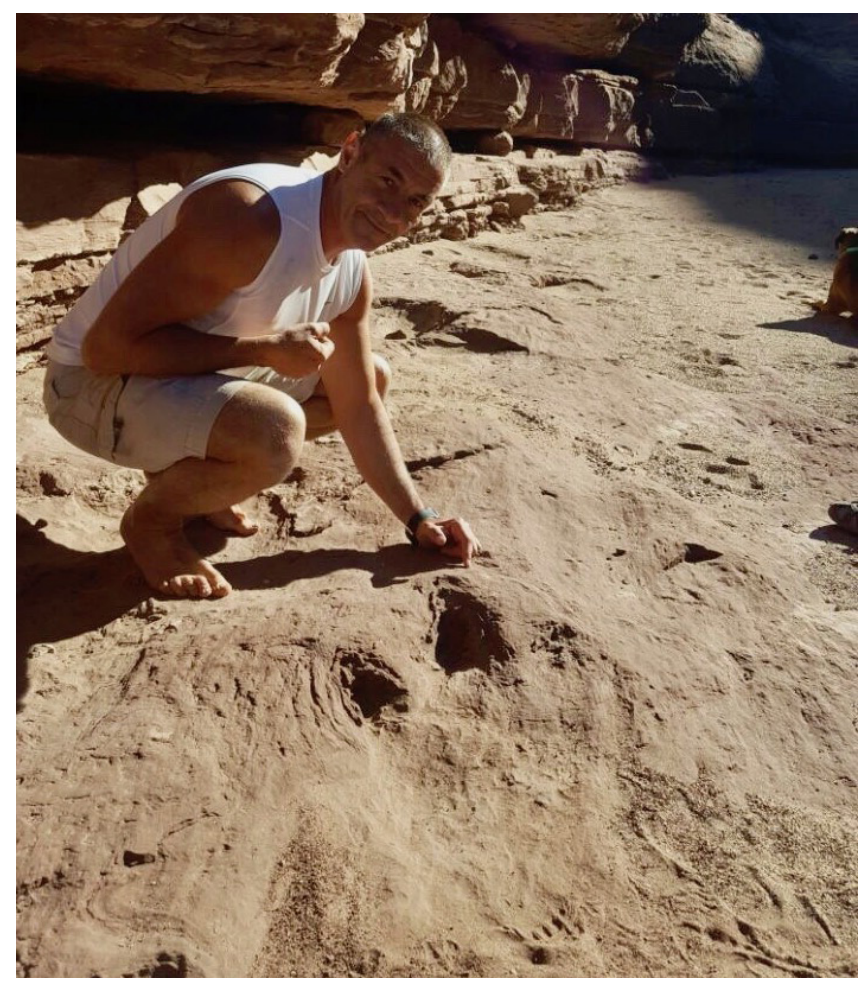

Figura 50 Vista de la icnita de Abelichnus astigarrae en Cañadón de Coria. Largo de la huella $60 \mathrm{~cm}$.

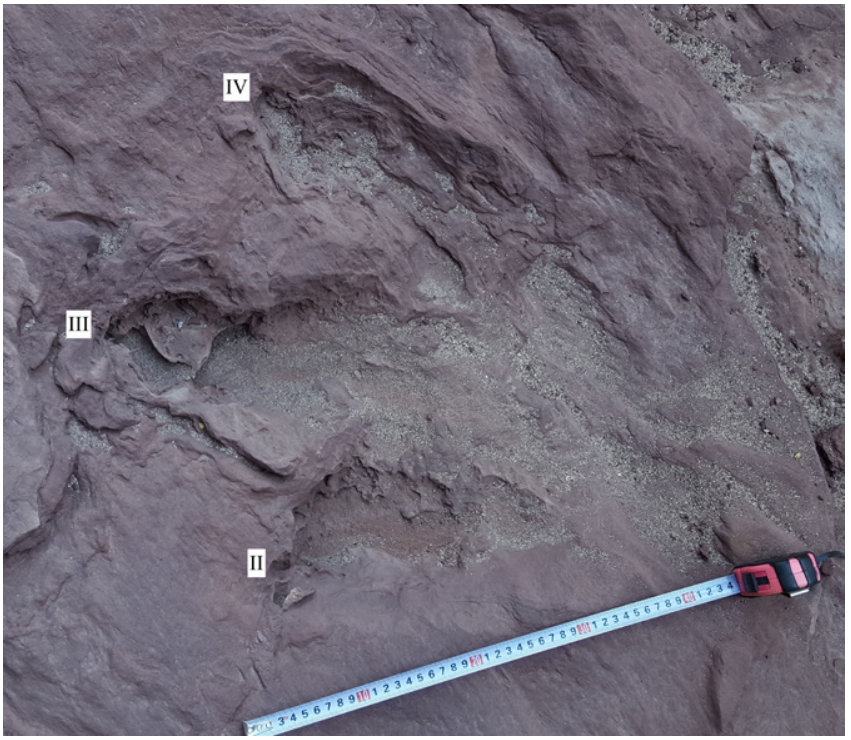

Figura 51 Vista de la icnita de Abelichnus astigarrae en Cañadón de Coria. Largo de la huella $53 \mathrm{~cm}$. Observe el desplazamiento de la garra del dedo II típica de la icnoespecie. II, III, IV indican nombre de los dígitos.
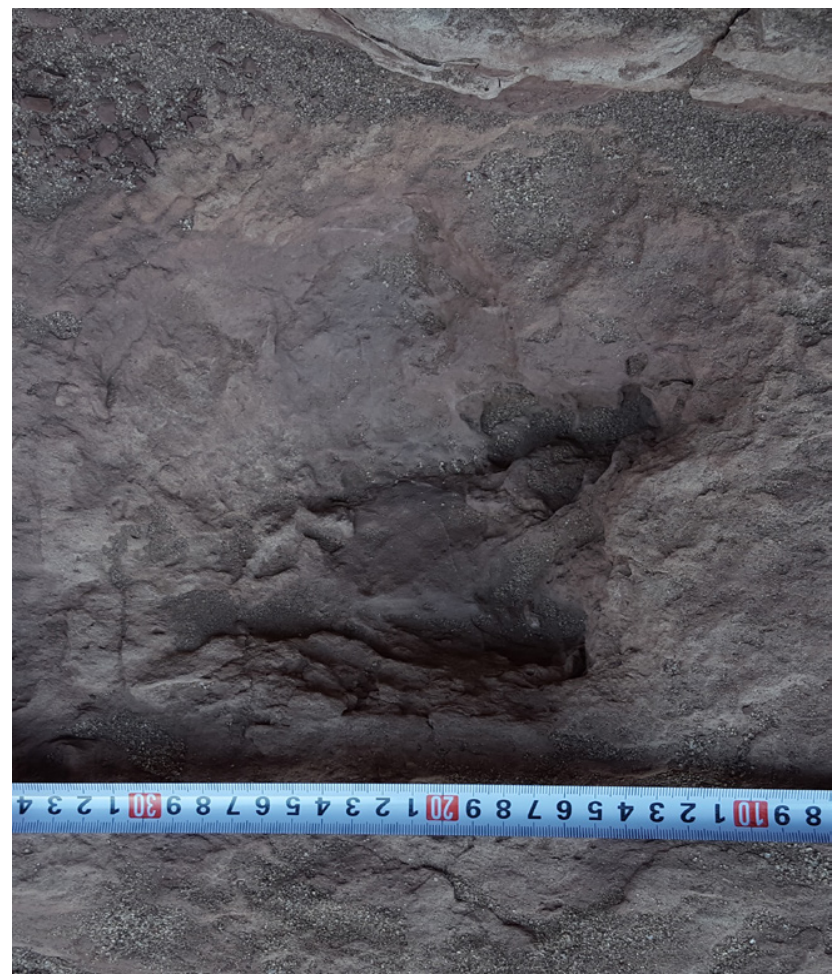

Figura 52 Vista de la icnita de Abelichnus astigarrae en Cañadón de Coria. Se observa en detalle el dedo III y IV. III, IV indican nombre de los dígitos. 
$\mathrm{m}$ de ancho donde predominan huellas de dinosaurios saurópodos (asignables a Sauropodichnus), con algunas huellas de ornitópodos (Limayichnus), y terópodos (Abelichnus).

\section{Abelichnus astigarrae}

Se han podido identificar varias huellas de esta icnoespecie. Una de ellas, ubicada en el extremo norte de la plataforma, es de gran tamaño: $60 \mathrm{~cm}$ de largo por $38 \mathrm{~cm}$ de ancho (Figura 50). Presenta una fuerte impresión de garras y una pobre impresión del talón y la base de los dedos. De cualquier manera, la falange III del dígito III, tiene $27 \mathrm{~cm}$ de largo, las falanges III y IV del dígito IV ocupan $24 \mathrm{~cm}$, y la falange II del dígito II tiene $5 \mathrm{~cm}$ de longitud. Las otras huellas bien conservadas se encuentran en el sector sur de la plataforma. Una de ellas posee un largo de $53 \mathrm{~cm}$ y un ancho de $48 \mathrm{~cm}$ con fuertes impresiones de garras (Figura 51). A $3 \mathrm{~m}$ de esta última se encuentra otra icnita de mediano tamaño con poco detalle (Figura 52). Finalmente, hay otro registro en el sector medio de la plataforma de una huella grande bien preservada (Figura 53).

\section{Limayichnus major}

Sólo se ha podido identificar una huella de esta icnoespecie y no muy bien conservada (Figura 54). Su largo es de $68 \mathrm{~cm}$ por $60 \mathrm{~cm}$ de ancho, el talón es subredondeado y los dedos son romos. No hay mucho detalle de las falanges pero el dedo III posee $30 \mathrm{~cm}$ de largo por $11.3 \mathrm{~cm}$ de ancho y los dedos laterales $20 \mathrm{~cm}$ de largo por $14 \mathrm{~cm}$ de ancho. La morfología de la huella y el tamaño de los dedos sin impresión de garras nos permite confirmar que corresponde a un ornitópodo del tipo Limayichnus. La asociación de Limayichnus con Sauropodichnus y Abelichnus se presenta también en otros sitios.

\section{Sauropodichnus giganteus}

En este sector abundan huellas de saurópodos pero la mayoría corresponden a siluetas o están muy erosionadas. Son de destacar las manos delanteras de los saurópodos que tienen la forma característica de riñón con tamaños que rondan

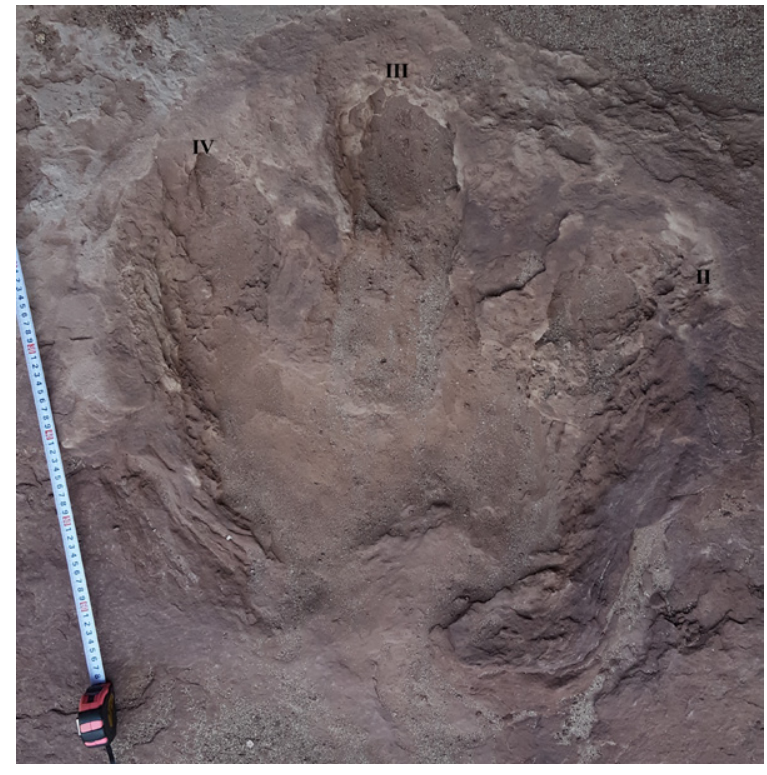

Figura 53 Vista de la icnita de Abelichnus astigarrae en Cañadón de Coria. Observe el desplazamiento de la garra del dedo II típica de la icnoespecie. II,III,IV indican nombre de los dígitos.

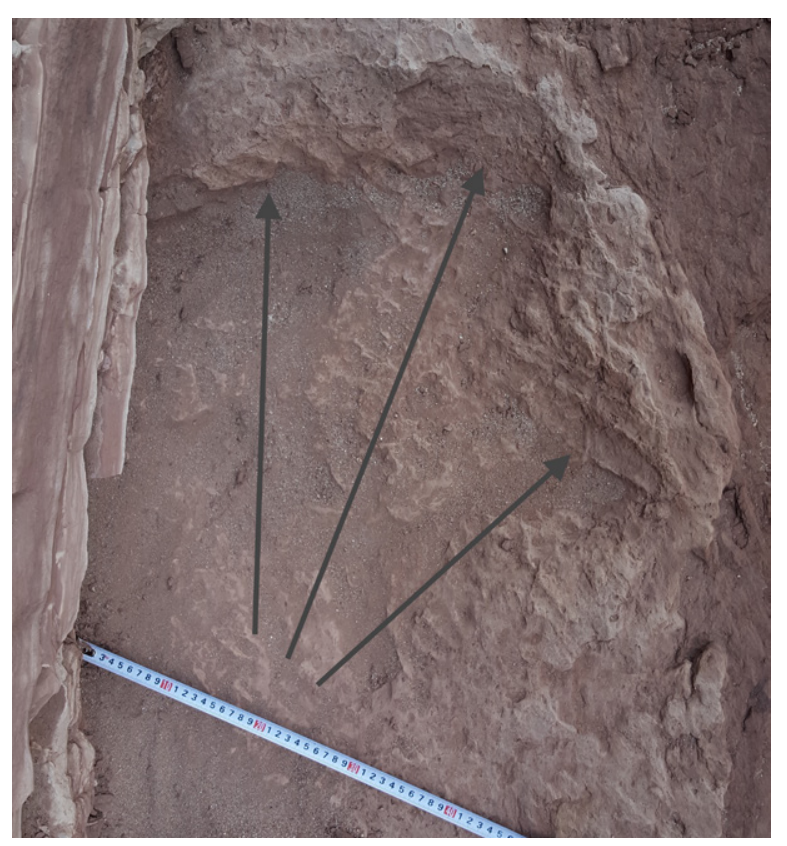

Figura 54 Limayichnus major en el Cañadón de Coria. Las flechas indican la dirección de los dedos.

los $80 \mathrm{~cm}$ de ancho por $40 \mathrm{~cm}$ de largo (Figura 55). Esta forma es muy particular y ya ha sido registrada en Isla Cerrito del Bote y en Península Nueva, en la localidad de Picún Leufú. 
Tabla 10. Medidas de las pistas de dinosaurios en el yacimiento Balneario El Chocón. Medidas en cm.

\begin{tabular}{|c|c|c|c|c|c|c|c|c|c|}
\hline Pista & Rumbo & Long. & $\alpha$ & $\mathbf{N}$ & \multicolumn{2}{|c|}{ Largo } & \multicolumn{2}{|c|}{ Ancho } & Clasificación \\
\hline BECh-1 & $50 \mathrm{NE}$ & 93 & $175^{\circ}$ & $4 ?$ & \multicolumn{2}{|c|}{30} & \multicolumn{2}{|c|}{24} & Abelichnus \\
\hline BECh-2 & $65 \mathrm{NW}$ & - & - & 1 & \multicolumn{2}{|c|}{50} & \multicolumn{2}{|c|}{74} & Sauropodichnus \\
\hline BECh-3 & $\mathrm{E}$ & - & - & 1 & \multicolumn{2}{|c|}{36} & \multicolumn{2}{|c|}{57} & Sauropodichnus \\
\hline BECh-4 & $55 \mathrm{SW}$ & 170 & $? 133^{\circ}$ & 2 & \multicolumn{2}{|c|}{60} & \multicolumn{2}{|c|}{80} & Sauropodichnus \\
\hline BECh-5 & $78 \mathrm{NE}$ & 100 & - & 2 & \multicolumn{2}{|c|}{28} & \multicolumn{2}{|c|}{21} & Bresanichnus \\
\hline BECh-6 & $46 \mathrm{NE}$ & - & - & 1 & \multicolumn{2}{|c|}{65} & \multicolumn{2}{|c|}{53} & Limayichnus \\
\hline BECh-7 & $30 \mathrm{SW}$ & - & - & 1 & \multicolumn{2}{|c|}{60} & \multicolumn{2}{|c|}{70} & Sauropodichnus \\
\hline BECh-8 & $20 \mathrm{SW}$ & - & - & 2 & \multicolumn{2}{|c|}{100} & \multicolumn{2}{|c|}{100} & Sauropodichnus \\
\hline BECh-9 & $\mathrm{N}$ & 161 & $165^{\circ}$ & 2 & \multicolumn{2}{|c|}{59} & \multicolumn{2}{|c|}{60} & Abelichnus \\
\hline BECh-10 & $40 \mathrm{NE}$ & - & $103^{\circ}$ & 2 & \multicolumn{2}{|c|}{26} & \multicolumn{2}{|c|}{22} & Theropoda \\
\hline BECh-11 & $\mathrm{N}$ & - & - & 1 & \multicolumn{2}{|c|}{50} & \multicolumn{2}{|c|}{45} & Limayichnus \\
\hline BECh-12 & 83 ?SW & - & - & ? & \multicolumn{2}{|c|}{ - } & & & Sauropodo \\
\hline BECh-13 & $10 \mathrm{SW}$ & - & - & 2 & 65 & 84 & 87 & 86 & Sauropodichnus \\
\hline BECh-14 & $85 \mathrm{NE}$ & 100 & $176^{\circ}$ & 4 & & & & & Bresanichnus \\
\hline BECh-15 & $35 \mathrm{SW}$ & - & - & 2 & 72 & 83 & 84 & 84 & Sauropodichnus \\
\hline BECh-16 & $25 \mathrm{NW}$ & 144 & - & 2 & & & & & Theropoda \\
\hline BECh-17 & $45 \mathrm{NW}$ & - & - & 1 & & & & & Limayichnus \\
\hline BECh-18 & $80 \mathrm{SE}$ & 175 & - & 2 & & & & & Limayichnus \\
\hline BECh-19 & $38 \mathrm{NE}$ & 150 & $168^{\circ}$ & 4 & & & & & Limayichnus \\
\hline BECh-20 & $20 \mathrm{NE}$ & 175 & $165^{\circ}$ & 3 & & & & & Limayichnus \\
\hline BECh-21 & $20 \mathrm{NE}$ & - & - & 1 & & & & & Limayichnus \\
\hline BECh-22 & $48 \mathrm{NW}$ & 170 & - & 2 & & & & & Limayichnus \\
\hline BECh-23 & $50 \mathrm{SW}$ & 185 & $166^{\circ}$ & 2 & & & & & Limayichnus \\
\hline BECh-24 & $15 \mathrm{NE}$ & 173 & - & 2 & & & & & Limayichnus \\
\hline BECh-25 & $22 \mathrm{NE}$ & - & - & 1 & & & & & Theropoda \\
\hline BECh-26 & $25 \mathrm{NE}$ & - & - & 1 & & & & & Limayichnus \\
\hline BECh-27 & $85 \mathrm{SW}$ & - & - & 1 & & & & & Limayichnus \\
\hline BECh-28 & $65 \mathrm{NW}$ & - & - & 2 & 56 & 80 & 84 & 81 & Sauropodichnus \\
\hline BECh-29 & $32 \mathrm{NE}$ & 160 & - & 2 & & & & & Limayichnus \\
\hline BECh-30 & $85 \mathrm{NW}$ & 170 & $165^{\circ}$ & 8 & & & & & Limayichnus \\
\hline BECh-31 & $55 \mathrm{NE}$ & 167 & - & 2 & & & & & Limayichnus \\
\hline BECh-32 & $80 \mathrm{NE}$ & 185 & $165^{\circ}$ & 22 & & & & & Limayichnus \\
\hline BECh-33 & $75 \mathrm{NE}$ & 100 & $175^{\circ}$ & 4 & & & & & Theropoda \\
\hline BECh-34 & $80 \mathrm{NE}$ & 165 & $165^{\circ}$ & 3 & & & & & Limayichnus \\
\hline BECh-35 & N-S & - & - & 1 & & & & & Abelichnus? \\
\hline BECh-36 & $5 \mathrm{NE}$ & - & - & 1 & & & & & Limayichnus \\
\hline BECh-37 & $85 \mathrm{SE}$ & - & - & 3 & 70 & 40 & 87 & 85 & Sauropodichnus \\
\hline BECh-38 & $45 \mathrm{SW}$ & - & - & 1 & & & & & Abelichnus \\
\hline
\end{tabular}


Tabla 11. Huellas en la colección del Museo de Geología y Paleontología de la Universidad Nacional del Comahue. Medidas en cm.

\begin{tabular}{|c|c|c|c|c|c|c|c|c|c|c|c|}
\hline \multirow{2}{*}{ MUCPv } & \multirow{2}{*}{$\begin{array}{c}\text { Ancho } \\
\text { pisada }\end{array}$} & \multirow{2}{*}{$\begin{array}{c}\text { Largo } \\
\text { pisada }\end{array}$} & \multicolumn{3}{|c|}{ Largo dedo } & \multicolumn{3}{c|}{ Ancho dedo } & \multicolumn{3}{c|}{ Divergencia } \\
\cline { 3 - 13 } & & II & III & IV & II & III & IV & II & III & IV \\
\hline $\mathbf{1 0 9 6}$ & 29 & 26 & 19 & 26 & 22 & 19 & 5.5 & 4.5 & $40^{\circ}$ & $55^{\circ}$ & $95^{\circ}$ \\
\hline $\mathbf{7 5}$ & 9.5 & 27 & 15 & 27 & 17 & 2.5 & 4 & 2.5 & $20^{\circ}$ & $20^{\circ}$ & $40^{\circ}$ \\
\hline $\mathbf{8 5 7}$ & 10.5 & 20 & 14.5 & 20 & 14 & 2 & 4.5 & 2.5 & $30^{\circ}$ & $20^{\circ}$ & $50^{\circ}$ \\
\hline $\mathbf{1 0 8 8}$ & 12 & 14 & 10 & 14 & 11 & 1.5 & 3 & 1.5 & $40^{\circ}$ & $50^{\circ}$ & $90^{\circ}$ \\
\hline $\mathbf{9 7 2}$ & - & 22 & - & 28 & 22 & - & 5.5 & 7 & - & $40^{\circ}$ & - \\
\hline $\mathbf{3 1 3}$ & 10.5 & 38 & 29 & 38 & 30 & 5.5 & 5 & 6 & $30^{\circ}$ & $45^{\circ}$ & $75^{\circ}$ \\
\hline $\mathbf{1 4 8 2}$ & 17 & 22 & 15 & 22 & 15 & 3 & 5.5 & 2 & $65^{\circ}$ & $50^{\circ}$ & $115^{\circ}$ \\
\hline $\mathbf{1 4 8 1}$ & 30 & 43 & 37 & 43 & 34.5 & 8 & 10 & 7 & $50^{\circ}$ & $60^{\circ}$ & $110^{\circ}$ \\
\hline $\mathbf{9 7}$ & 8 & 14 & 10 & 14 & 8 & 2 & 3 & 2 & $25^{\circ}$ & $35^{\circ}$ & $60^{\circ}$ \\
\hline $\mathbf{8 4 0}$ & 11 & 19 & 14 & 19 & 16 & 2 & 4 & 2 & $25^{\circ}$ & $25^{\circ}$ & $50^{\circ}$ \\
\hline $\mathbf{3 1 5}$ & 11 & 22 & 14 & 22 & 13 & 2 & 3.5 & 2 & $20^{\circ}$ & $15^{\circ}$ & $35^{\circ}$ \\
\hline $\mathbf{8 7 4}$ & 11 & 16 & 14 & 16 & 13 & 4 & 4 & 3 & $20^{\circ}$ & $30^{\circ}$ & $50^{\circ}$ \\
\hline $\mathbf{8 4 1}$ & 13 & 21 & 15 & 21 & 13 & 3 & 4 & 2 & $30^{\circ}$ & $30^{\circ}$ & $60^{\circ}$ \\
\hline $\mathbf{7 6}$ & 6.5 & 11 & 8 & 11 & 8 & 1 & 2 & 1 & $15^{\circ}$ & $20^{\circ}$ & $35^{\circ}$ \\
\hline $\mathbf{2 0 1}$ & 10 & 12 & 10 & 12 & 10 & 1.5 & 2 & 1.5 & - & $20^{\circ}$ & - \\
\hline
\end{tabular}

\subsection{EL YAGIMIENTO DE BALNEARIO DE VILLA EL CHOCÓN}

El yacimiento de huellas de dinosaurios Balneario de Villa El Chocón (BECh) es el segundo en importancia por la variedad y calidad de las huellas, a tal punto que ha dado lugar a una exhibición in situ. En este sitio paleontológico se han detectado icnitas pertenecientes a dinosaurios saurópodos, terópodos y ornitópodos (Calvo y Salgado, 1995). Un reestudio de las mismas ha permitido reinterpretar su asignación e incluir nuevos ejemplares. En esta sección describimos y reidentificamos las icnitas presentes en el Balneario de Villa El Chocón (Figura 1; Tabla 10). Las huellas del yacimiento de Balneario Villa El Chocón no han podido ser extraídas, pero se han realizado algunos moldes y por ello se las denomina con una sigla local BECh. $\mathrm{El}$ yacimiento icnológico de Balneario Villa El Chocón (S 39¹6’20.1”, W 6849’44.0”) ocupa una franja muy reducida en ancho $(3 \mathrm{~m})$ pero relativamente extensa en longitud (500 m). En este yacimiento han sido reconocidas decenas de huellas de dinosaurios correspondientes a por lo menos 38 pistas (Tabla 10). Las mismas se hallan en una arenisca fina de color pardo. Se han detectado cuatro plataformas importantes con huellas (Figura 56). Asociadas a las huellas se presentan rebabas de sedimento producto del impacto de la pisada sobre un terreno blando y húmedo sin llegar al estado de saturación (Figura 15). En algunos sectores se observan ondulitas y abundante bioturbación de organismos excavadores. Los grupos que dejaron sus huellas corresponden a dinosaurios saurópodos, terópodos y ornitópodos. El rumbo y la ubicación de las pistas se pueden observar en la Tabla 10.

\section{Sauropodichnus giganteus}

Se han reconocido 9 pistas, algunas basadas en una sola huella. En la costa del embalse Ezequiel Ramos Mexía se ha detectado una sola icnoespecie, Sauropodichnus giganteus (Calvo, 1991, 


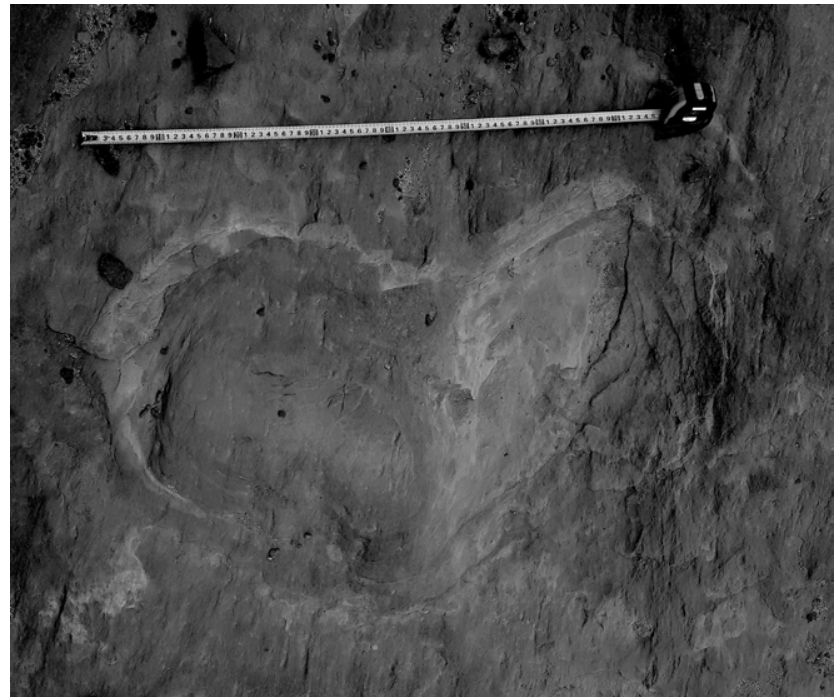

Figura 55 Huella de la pata delantera de Sauropodichnus giganteus en Cañadón de Coria. La mitad izquierda está hueca y la mitad derecha presenta relleno.
1999) (Figura 15). BECh 2, 3, 4, 7 y 28 son pistas representadas sólo por huellas delanteras (Figura 56). Las mismas tienen forma arriñonada con el borde anterior convexo, siendo el posterior cóncavo; el eje antero-posterior más corto que el lateromedial. Huellas de forma arriñonada están presentes en la Isla Cerrito del Bote y fueron asignadas a Sauropodichnus giganteus (Calvo, 1999). La pista BECh-28 conserva también una huella trasera de forma subtriangular muy parecida a la presente en la Isla Cerrito del Bote. BECh 8, 12, 13, 15 y 37 (Figura 56) presentan huellas delanteras como las descriptas anteriormente pero las traseras son de forma circular sin detalle de dedos, muy semejantes a Sauropodichnus giganteus (Calvo, 1991, 1999) descriptas en Península Nueva, Picún Leufú. Podemos decir que las pistas de saurópodos
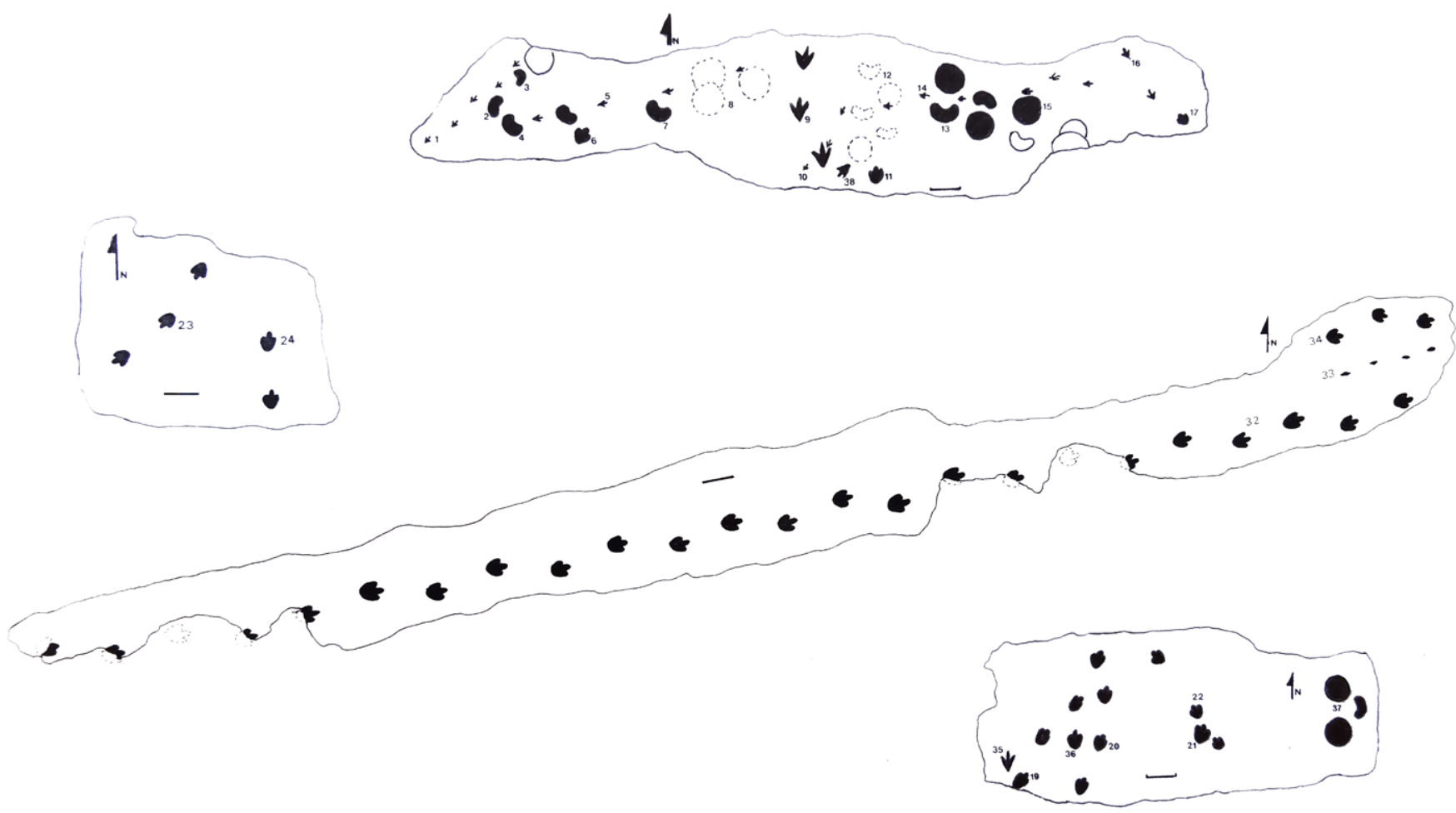

Figura 56 Vista de las plataformas con huellas de dinosaurios en el Balneario El Chocón, las cuales están distribuidas a lo largo de 300 m paralelos a la costa. La barra en cada plataforma equivale a $100 \mathrm{~cm}$ (modificado de Calvo y Salgado, 1995). Los números corresponden a las huellas o pistas de la Tabla 10 con la sigla de campo BECh. 


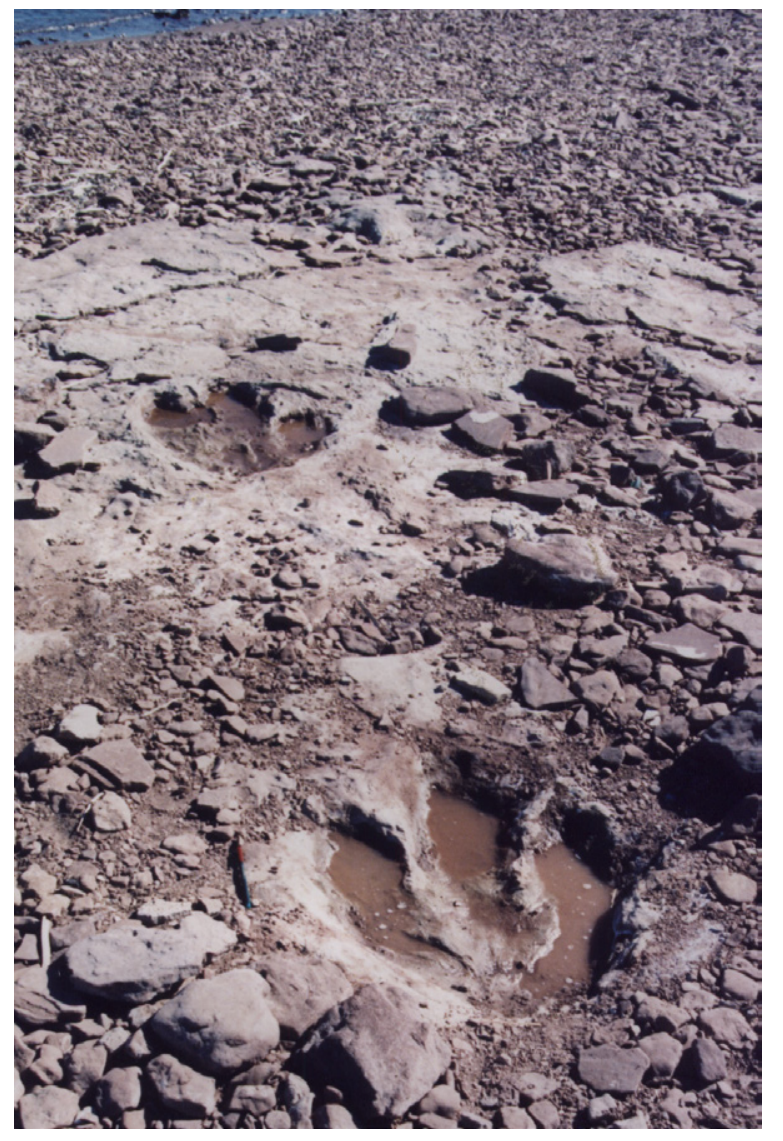

Figura 57 Vista de la pista y huellas de Limayichnus major en el sitio Balneario El Chocón (BECh23).

de Balneario Villa El Chocón corresponden a la icnoespecie presente en Picún Leufú e isla Cerrito del Bote asignadas a Sauropodichnus giganteus.

\section{Limayichnus major}

Las huellas y pistas BECh 6, 11, 17, 18, 19, 20, 21, 22, 23 (Calco MUCPv-83) (Figura 57), 24 (Calco MUCPv-84), 26, 27, 29, 30, 31, 32, 34 y 36 se corresponden con las de animales bípedos, tridáctilos y con un ángulo de paso elevado (Figura 56). Las huellas se caracterizan por ser masivas casi simétricas sin evidencia de uñas o talón. Los dedos son cortos y gruesos; el dedo III es el más largo y diverge muy poco de los laterales. El borde posterior de la huella es redondeado. Éstas son atribuidas a ornitópodos iguanodóntidos. En las pistas BECh 6, 19, 20, 21, 22, 23, 24, 27, 29, 31, 32 y 34 el dedo III preserva la impresión de las almohadillas plantares de forma ovalada. Datos de huellas y pistas muestran que la mayoría de los ejemplares eran adultos y se desplazaban principalmente con dirección suroeste-noreste. La morfología de detalle, de las huellas, se corresponden perfectamente con aquellas descritas para la localidad de Picún Leufú y que son asignadas a Limayichnus major (Calvo, 1991). Para las pistas BECh 30, 32 y 34 el ángulo de paso es de $165^{\circ}$.

\section{Bressanichnus patagonicus}

Las pistas BECh 1, 5 y 14 (Figura 56) poseen el dedo central un 50\% más largo que los laterales; en BECh 1, el dedo III tiene $14 \mathrm{~cm}$ de largo. El talón es de borde posterior subredondeado y los detalles de las impresiones falangeales no están bien preservados. Por su morfología general se establece que se trata de dinosaurios terópodos del tipo Bressanichnus (Calvo, 1991) a pesar de que las huellas de Villa El Chocón son relativamente más grandes que las descriptas en Picún Leufú.

\section{Abelichnus astigarrae}

BECh 9 (Calco MUCPv-89), 35 y 38 (Figura 56) son huellas de un terópodo grande. Los dedos divergen del central y se encuentran claramente separados. En las huellas se observa la presencia de garras que indican su condición de carnívoro. Huellas de este tipo fueron detectadas en Península Nueva (Calvo, 1991) y en Cañadón de Coria (Calvo, 1999). Las características de las huellas son idénticas a las observadas en Abelichnus astigarrae por lo que las mismas se asignan a esta icnoespecie.

\section{Theropoda indet.}

Descripción. Las pistas BECh 16, 25 y 33 (Figura 56) corresponden a animales bípedos de pequeño a mediano tamaño con ángulo de paso cercano a $\operatorname{los} 180^{\circ}$. Las huellas son tridáctilas y en su mayoría están mal conservadas. Esto no permite un análisis preciso, pero por la morfología de los dedos II, III y IV, con impresiones de garras en sus extremos, es posible clasificarlas dentro de los Theropoda. 


\section{Conclusiones}

Los estudios de reconocimiento de los sitios de huellas, el análisis de las mismas y la identificación y descripción de colecciones científicas han permitido un reordenamiento de todos los hallazgos realizados en 30 años en la costa oeste del embalse Ezequiel Ramos Mexía en la Provincia de Neuquén. Las pistas de dinosaurios corresponden a dinosaurios saurópodos, terópodos y ornitópodos. Las huellas de saurópodos corresponden a Sauropodichnus giganteus Calvo, 1991, icnotaxón reconocido por primera vez en el extremo sur del embalse Península Nueva (Calvo, 1991), y cuya diagnosis fue modificada mediante los hallazgos de Isla Cerrito del Bote, en Picún Leufú (Calvo, 1999). Si bien éstas son abundantes en toda la costa, sus pistas son dificiles de identificar y seguir debido a su mala preservación. Estas icnitas están presentes en casi todos los sitios icnológicos.

Con respecto a los ornitópodos se han identificado dos icnoespecies Sousaichnium monettae y Limayichnus major Calvo, 1991. Ambas descriptas originalmente en Península Nueva; siendo Limayichnus muy abundante también en todos los demás sitios estudiados. Sus huellas casi tan largas como anchas y de dedos romos, talón redondeado y su ángulo de paso cerrado, lo diferencia claramente de los dinosaurios terópodos. Sus tamaños varían pero prevalecen huellas de gran porte.

Las huellas de terópodos son las más variadas en cuanto a su morfología; las hay pequeñas como Bressanichnus patagonicus, Deferrariischnium mapuchensis, Picunichnus benedettoi Calvo, 1991 y Candeleroichnus canalei Calvo y Rivera (este trabajo), y de gran tamaño como en Abelichnus astigarrae Calvo, 1991. Bressanichnus y Abelichnus han sido registradas en otros sitios de la costa. La nueva icnoespecie, Candeleroichnus canalei, está restringida al Cerro Mesa e Isla Cerrito del Bote en el extremo sur del embalse y son de las más pequeñas registradas en la costa. Se amplía la diagnosis de Picunichnus benedettoi a partir del hallazgo de nuevos materiales. Se enmendó y mejoró la diagnosis de Deferrariïshnium mapuchensis con el hallazgo de mejores registros y se seleccionó un neotipo para las mismas.

Claramente hay sitios con menos diversidad de icnitas aunque ello podría deberse a la falta de trabajo de campo. Los niveles portadores de icnitas de la Formación Candeleros están por el momento restringidos a las secciones inferior y media, ya que las planicies de inundación son las que permitieron el desplazamiento de las formas de dinosaurios y su posterior preservación. El hecho de que las otras secciones de la unidad no presenten huellas es quizás un problema preservacional. La presencia de las mismas icnoespecies en sedimentitas, ambiente y nivel topográfico en la costa oeste del embalse Ezequiel Ramos Mexía, distantes $70 \mathrm{~km}$ una de otra, así como el hecho de que el ángulo de buzamiento del Grupo Neuquén a nivel regional es muy bajo, demuestra que las rocas portadoras de todas las huellas dispersas en la costa del embalse fueron formadas en un mismo ambiente durante un corto período de tiempo.

\section{Agradecimientos}

Este trabajo fue financiado por: proyectos de Investigación de la Universidad Nacional del Comahue 04/I082, ANPGyT; la empresa Chevron-San Jorge S.A.; la Fundación Luciérnaga y la municipalidad de la ciudad de Picún Leufú. Agradecemos a los revisores de este trabajo: el Dr. Leonardo Salgado y el M.Cs. Daniel Navarro Santillán que con su aporte han enriquecido enormemente el mismo.

\section{Referencias}

Apesteguía, S., de Valais, S., Ríos-Cordero, G., Medina-Ramírez, O., 201 1, New ichnological record from the Late Campanian Toro Toro Formation at Toro Toro, Potosí (Bolivia): First probable dromaeosaurid tracks from South America: Ameghiniana, 48(4) 662-667. 
Ardolino, A.A., Franchi, M.R., Fauqué, L., 1996, Carta Geológica, en Geología y Recursos Minerales del Departamento Añelo, Provincia del Neuquén, República Argentina, Escala 1:200000: Buenos Aires, Argentina, Cartas Geológicas y de Recursos Minerales de la Provincia del Neuquén, 3, 9-106.

Asurmendi, E., Sánchez, M.L., Fennell, L., 2017, Neuquén Group (Upper Cretaceous): a case of underfilled-overfilled cycles in an Andean foreland basin, Neuquen basin, Argentina: Journal of South American Earth Sciences, 80, 444-459.

Calvo, J.O., 1989, Nuevos hallazgos de huellas de dinosaurios en el Albiano-Cenomaniano de la localidad de Picún Leufú, Provincia del Neuquén, Patagonia, Argentina, en Actas de Resúmenes de la VI Jornada Argentina de Paleontología de Vertebrados: San Juan, Argentina, 68-70.

Calvo, J.O., 1991, Huellas fósiles de dinosaurios en la Formación Río Limay (AlbianoCenomaniano), Picún Leufú, Provincia del Neuquén, Argentina (OrnithischiaSaurischia: Saurópoda-Terópoda): Ameghiniana, 28(3-4), 241-258.

Calvo, J.O., 1999, Dinosaurs and other vertebrates of the Lake Ezequiel Ramos Mexía Area, Neuquén-Patagonia, Argentina, en Tomida, Y., Rich, T.H., Vickers-Rich, P. (eds.), Proceedings of the Second Gondwanan Dinosaur Symposium: Tokio, Japón, National Science Museum Monographs, 15, $13-45$.

Calvo, J.O., 2007, Ichnology, en Gasparini, Z., Salgado, L., Coria, R.A. (eds.), Patagonian Mesozoic Reptiles: Bloomington, E.U.A., Indiana University Press, 314-334.

Calvo,J.O., Bonaparte,J.F., 1991, Andesaurus delgadoi gen. et sp. nov. (Saurischia-Sauropoda), dinosaurio Titanosauridae de la Formación Río Limay (Albiano-Cenomaniano), Neuquén, Argentina: Ameghiniana, 28(3-4), 303-310.
Calvo, J.O., Coria, R., 1995, Huellas de dinosaurios en Neuquén: Ciencia Hoy, 5(29), 22-30.

Calvo, J.O., Gazzera, G.E., 1989, Paleoecología en el sector inferior del Miembro Candeleros (Formación Río Limay, Grupo Neuquén, Cretácico) en el área del embalse Ezequiel Ramos Mexía. Provincia del Neuquén, Patagonia, Argentina, en VI Jornadas Argentinas de Paleontología de Vertebrados: San Juan, Argentina, 3-5.

Calvo,J.O., Mazzetta, G.V., 2004, Nuevos hallazgos de huellas de Dinosaurios en la Formación Candeleros (Albiano-Cenomaniano), Picún Leufú, Neuquén, Argentina: Ameghiniana, $41(4), 545-554$.

Calvo, J.O., Salgado, L., 1995, Huellas de Dinosaurios en la localidad de El Chocón, Neuquén, en Actas de la Segunda Reunión Argentina de Icnología de Vertebrados: San Juan, Argentina, Universidad Nacional de San Juan, 23-26.

Calvo, J.O., Vejsbjerg, L., 2003, Propuesta de Desarrollo turístico para el Yacimiento de huellas de Dinosaurios de la Villa El Chocón: Realidad, Tendencias y Desafios en Turismo, 3, 64-79.

Calvo, J.O., Coria, R., Salgado, L., 1989, Nuevas localidades con huellas de dinosaurios del Miembro Candeleros (AlbianoCenomaniano) (Formación Río Limay, Grupo Neuquén): Provincia del Neuquén: Ameghiniana, 26, 241.

Calvo, J.O., Moreno, K., Rubilar, D., 2000, First record of Lower Cretaceous dinosaur tracks (Sauropoda-Theropoda) in Río Negro Province, Patagonia, Argentina, en $31^{\text {st }}$ International Geological Congress: Río de Janeiro, Brasil, International Geological Congress, 427.

Cazau, L.B., Uliana, M.A., 1973, El Cretácico Superior continental de la Cuenca Neuquina, en $5^{\circ}$ Congreso Geológico Argentino 1972: Villa Carlos Paz, Córdoba, Argentina, Asociación Geológica Argentina, 3, 131-163. 
Conrad, K., Lockley, M.G., Prince, N.K., 1987, Triassic and Jurassic Vertebrate-dominated Trace Fossil Assemblages of the Cimarron Valley Region: Implications for Paleoecology and Biostratigraphy, en Lucas, S.G., Hunt, A.P. (eds.), Northeastern New Mexico: New Mexico, E.U.A., New Mexico Geological Society, 38th Annual Fall Field Conference Guidebook, 127-138.

Cope, E.D., 1869, Synopsis of the extinct Batrachia, Reptilia and Aves of North America: Transactions of the American Philosophical Society, 14, 1-252.

Di Paola, E.C., 1973, Caracterización litoestratigráfica de la Formación Neuquén, en Actas del $5^{\circ}$ Congreso Geológico Argentino, 1972: Villa Carlos Paz, Córdoba, Argentina, Asociación Geológica Argentina, 3, 197-206.

Di Paola, E.C., Marchese, H.G., 1970, Relaciones litoestratigráficas entre las Formaciones Rayoso, Candeleros y Huincul, Provincia de Neuquén, República Argentina: Revista de la Asociación Geológica Argentina, 25(1), 111-120.

Digregorio, J.H., 1972, Neuquén, en Leanza, A.F. (ed.), Geología Regional Argentina: Córdoba, Argentina, Academia Nacional de Ciencias, 439-505.

Fennell, L., Folguera, A., Naipauer, M., Gianni, G., Rojas-Vera, E., Bottesi, G., Ramos, V., 2017, Cretaceous deformation of the southern Central Andes: synorogenic growth strata in the Neuquén Group $\left(35^{\circ} 30^{\prime}-37^{\circ} \mathrm{S}\right)$ : Basin Research, 29(S1), 51-72.

Garrido, A.C., 2010, Estratigrafia del Grupo Neuquén, Cretácico Superior de la Cuenca Neuquina (República Argentina); nueva propuesta de ordenamiento litoestratigráfico: Revista del Museo Argentino de Ciencias Naturales, 12(2), 121-177.

Gasparini, Z.B., Musacchio, E.A., 1979, Rastros de dinosaurios en los estratos rojos, próximos a la desembocadura del Picún Leufú en el embalse de El Chocón: La Plata, Argentina, Informe inédito Hidronor, Reporte técnico, Museo de la Plata, 12 p.

Gazzera, C.E., Spalletti, L.A., 1990, Modelo de sedimentación arenosa y fangosa en canales fluviales: Grupo Neuquén Inferior, Cretácico, Argentina Occidental: Revista Geológica de Chile, 17(2), 131-151.

Herrero-Ducloux, A., 1946, Contribución al conocimiento geológico del Neuquén extraandino: Boletín de Informaciones Petroleras, 23(266), 245-281.

Hitchcock, E., 1858, Ichnology of New England. A Report on the Sandstone of the Connecticut Valley and its Fossil Footmarks: Boston, E.U.A., White W, 232 p.

Hugo, G.A., Leanza, H.A., 2001, Hoja Geológica 3069-IV General Roca (escala 1:250000), Provincias de Río Negro y Neuquén: Buenos Aires, Argentina, Programa Nacional de Cartas Geológicas de la República Argentina, Instituto de Geología y Recursos Minerales, Servicio Geológico Minero Argentino, 308, $65 \mathrm{p}$.

Krapovickas, V., 2010, El rol de las trazas fósiles de tetrápodos en los modelos de icnofacies continentales en ambientes de climás áridos -semiáridos: Buenos Aires, Argentina, Universidad de Buenos Aires, tesis doctoral, $358 \mathrm{p}$.

Leanza, H.A., 1999, The Jurassic and Cretaceous terrestrial beds from Southern Neuquén Basin, Argentina: San Miguel de Tucumán, Argentina, Universidad Nacional de Tucumán, Instituto Superior de Correlación Geológica, Field Guide, Miscelánea, 4, 30 p.

Leanza, H.A., 2003, Las sedimentitas huitrinianas y rayosianas (Cretácico inferior) en el ámbito central y meridional de la cuenca Neuquina, Argentina: Buenos Aires, Argentina, Servicio Geológico Minero Argentino, Serie Contribuciones Técnicas Geología 2, 1-31. 
Leanza, H.A., Hugo, C.A., 1995, Revisión estratigráfica del Cretácico inferior continental en el ámbito sudoriental de la Cuenca Neuquina: Revista Asociación Geológica Argentina, 50(1-4), 30-32.

Leanza, H.A., Hugo, C.A., 1997, Hoja Geológica 3969-III, Picún Leufú, provincias del Neuquén y Río Negro: Buenos Aires, Argentina, Programa Nacional de Cartas Geológica, Escala 1:250000, Instituto de Geología y Recursos Naturales, 218, 1-135 p.

Leanza, H.A., Hugo, C.A., 2001, Gretaceous red beds from southern Neuquén basin (Argentina): age, distribution and stratigraphic discontinuities (resumen), en Abstracts 7th International Symposium on Mesozoic Terrestrial Ecosystems, 1999: Buenos Aires, Argentina, Asociación Paleontológica Argentina, 37.

Leanza, H.A., Hugo, C.A., Repol, D., 2001, Hoja geológica 3969-I, Zapala, Provincia del Neuquén: Buenos Aires, Argentina, Programa Nacional de Cartas Geológicas de la República Argentina, escala 1: 250000, Instituto de Geología y Recursos Minerales, Servicio Geológico Minero Argentino, 275, $128 \mathrm{p}$.

Leonardi, G., 1979, Nota preliminar sobre seis pistas de dinosaurios Ornithischia da Bacia do Rio da Peixe, em Sousa, Paraíba, Brasil: Anais da Academia Brasileira de Ciências, 71(3), 501-516.

Leonardi, G., 1981, As localidades com rastros fósseis de Tetrápodes na America Latina, en Anais II Congreso Latinoamericano de Paleontología: Porto Alegre, Rio Grande do Sul, Brasil, 2, 929-940.

Leonardi, G., 1994, Annotated atlas of South America Tetrapod footprints (Devonian to Holocene) with appendix on Mexico and Central America: Brasilia, Brasil, Ministério de Minas e Energia, Companhia de Pesquisa de Recursos Minerais, Geological Services of Brazil, 247 p.

Li, R., Lockley, M.G., Makovicky, P.J., Matsukawa, M., Norell, M.A., Harris, J.D., Liu, M., 2008, Behavioral and faunal implications of Early Cretaceous deinonychosaur trackways from China: Naturwissenschaften, 95(3), 185-191.

Lockley, M.G., 1998, Philosophical perspectives on theropod track morphology: blending qualities and quantities in the science of ichnology: Gaia, 15, 279-300.

Lull, R.S., 1904, Fossil footprints of the Jura-Trias of North America: Memoirs of the Boston Society of Natural History, 5(2), 461-557.

Marchese, H., 1971, Litoestratigrafía y variaciones faciales de las sedimentitas mesozoicas de la Cuenca Neuquina, Provincia del Neuquén, República Argentina: Revista de la Asociación Geológica Argentina, 26(3), 343-410.

Marsh, O.C., 1878, Principal characters of American Jurassic dinosaurs. Part I: American Journal of Science, 16, 411-416.

Marsh, O.G., 1881, Principal characters of American Jurassic dinosaurs. Part V: American Journal of Sciences, 21, 417-423.

Mazzetta, G., Blanco, R., 2001, Speeds of dinosaurs from the Albian-Cenomanian of Patagonia and sauropod stance and gait: Acta Paleontologica Polonica, 46(2), 235-246.

Ramos, V.A., 1981, Descripción Geológica de la Hoja 33c, Los Chihuidos Norte, Provincia del Neuquén: Buenos Aires, Argentina, Carta geológico-económica de la República de Argentina, escala 1:200000, Servicio Geológico Nacional, 182, 103 p.

Rivera, C., Calvo, J.O., 2016, Nuevos aportes al conocimiento de la icnoespecie Abelichnus astigarrae, Albiano-Cenomaniano (Formación Candeleros, Grupo Neuquén), Provincia de Neuquén, Argentina, en IX Congreso Latinoamericano de Paleontología, Lima, Perú, 1-84. 
Roll, A., 1939, La cuenca de los estratos con dinosaurios al sur del río Neuquén: Buenos Aires, Argentina, Informe Gerencia de Yacimientos Petrolíferos Fiscales, 73 p.

Sánchez, M.L., Heredia, S., Calvo, J.O., 2004, Paleoambientes sedimentarios de la Formación Candeleros (Subgrupo Río Limay), Cretácico Superior, en el Cañadón El Escondido, sudeste del Neuquén, en $\mathrm{X}^{\circ}$ Reunión de Sedimentología-Simposio Límite K/T de Argentina: San Luis, Argentina, Asociación Argentina de Sedimentología, 158.

Seeley, H.G., 1888, The classification of the Dinosauria: Report of the British Association for the Advancement of Science, 1887, 698-699.

Spalletti, L., Gazzera, C.E., 1989, Eventos eólicos en capas rojas cretácicas (Formación Río Limay, Grupo Neuquén), sector sudeste de la Cuenca Neuquina, Argentina, en Spalletti, L. (ed.), Contribuciones de los Simposios sobre Cretácico de América Latina, Parte A, Eventos y Registro Sedimentario: Buenos Aires, Argentina, Actas, 89-100.

Sternberg, C.M., 1932, Dinosaur Tracks from Peace River British Columbia: National Museum of Canada Annual Report, 1930, 59-85.

Uliana, M.A., Dellapé, D.A., 1981, Estratigrafía y evolución paleoambiental de la sucesión maestrichtiano- eoterciaria del engolfamiento neuquino (Patagonia Septentrional), en $\mathrm{VIII}^{\circ}$ Congreso Geológico Argentino: San Luis, Argentina, Asociación Geológica Argentina, 673-711.

Zavala, C., 2005, Tracking sea bed topography in the Jurassic. The Lotena Group in the Sierra de la Vaca Muerta (Neuquén Basin, Argentina): Geológica Acta, 3(2), 107-118. 